Cochrane Database of Systematic Reviews

\title{
Factors that impact on the use of mechanical ventilation weaning protocols in critically ill adults and children: a qualitative evidence- synthesis (Review)
}

Jordan J, Rose L, Dainty KN, Noyes J, Blackwood B

Jordan J, Rose L, Dainty KN, Noyes J, Blackwood B.

Factors that impact on the use of mechanical ventilation weaning protocols in critically ill adults and children: a qualitative evidence-synthesis.

Cochrane Database of Systematic Reviews 2016, Issue 10. Art. No.: CD011812.

DOI: 10.1002/14651858.CD011812.pub2. 
HEADER 1

ABSTRACT

PLAIN LANGUAGE SUMMARY

BACKGROUND

OBJECTIVES

METHODS

RESULTS

Figure 1.

Figure 2.

Figure 3.

Figure 4.

Figure 5.

DISCUSSION

AUTHORS' CONCLUSIONS

ACKNOWLEDGEMENTS

REFERENCES

CHARACTERISTICS OF STUDIES

ADDITIONAL TABLES

APPENDICES

WHAT'S NEW

HISTORY

CONTRIBUTIONS OF AUTHORS

DECLARATIONS OF INTEREST

SOURCES OF SUPPORT

DIFFERENCES BETWEEN PROTOCOL AND REVIEW

NOTES

INDEX TERMS

\section{TABLE OF CONTENTS}


[Qualitative Review]

\section{Factors that impact on the use of mechanical ventilation weaning protocols in critically ill adults and children: a qualitative evidence- synthesis}

Joanne Jordan ${ }^{1}$, Louise Rose ${ }^{2}$, Katie N Dainty ${ }^{3}$, Jane Noyes ${ }^{4}$, Bronagh Blackwood 5

1School of Nursing, Ulster University, Newtownabbey, UK. 2Department of Critical Care Medicine, Sunnybrook Health Sciences Centre and Sunnybrook Research Institute, Toronto, Canada. ${ }^{3}$ Li Ka Shing Knowledge Institute, St. Michael's Hospital, Toronto, Canada. ${ }^{4}$ Centre for Health-Related Research, Fron Heulog, Bangor University, Bangor, UK. ${ }^{5}$ Centre for Experimental Medicine, School of Medicine, Dentistry and Biomedical Sciences, Queen's University Belfast, Belfast, UK

Contact address: Joanne Jordan, School of Nursing, Ulster University, Shore Road, Newtownabbey, Northern Ireland, BT37 OQB, UK. je.jordan@ulster.ac.uk.

Editorial group: Cochrane Emergency and Critical Care Group.

Publication status and date: Edited (no change to conclusions), published in Issue 12, 2018.

Citation: Jordan J, Rose L, Dainty KN, Noyes J, Blackwood B. Factors that impact on the use of mechanical ventilation weaning protocols in critically ill adults and children: a qualitative evidence-synthesis. Cochrane Database of Systematic Reviews 2016 , Issue 10. Art. No.: CD011812. DOI: 10.1002/14651858.CD011812.pub2.

Copyright @ 2018 The Cochrane Collaboration. Published by John Wiley \& Sons, Ltd.

\section{A B S T R A C T}

\section{Background}

Prolonged mechanical ventilation is associated with a longer intensive care unit (ICU) length of stay and higher mortality. Consequently, methods to improve ventilator weaning processes have been sought. Two recent Cochrane systematic reviews in ICU adult and paediatric populations concluded that protocols can be effective in reducing the duration of mechanical ventilation, but there was significant heterogeneity in study findings. Growing awareness of the benefits of understanding the contextual factors impacting on effectiveness has encouraged the integration of qualitative evidence syntheses with effectiveness reviews, which has delivered important insights into the reasons underpinning (differential) effectiveness of healthcare interventions.

\section{Objectives}

1. To locate, appraise and synthesize qualitative evidence concerning the barriers and facilitators of the use of protocols for weaning critically-ill adults and children from mechanical ventilation;

2. To integrate this synthesis with two Cochrane effectiveness reviews of protocolized weaning to help explain observed heterogeneity by identifying contextual factors that impact on the use of protocols for weaning critically-ill adults and children from mechanical ventilation;

3. To use the integrated body of evidence to suggest the circumstances in which weaning protocols are most likely to be used.

\section{Search methods}

We used a range of search terms identified with the help of the SPICE (Setting, Perspective, Intervention, Comparison, Evaluation) mnemonic. Where available, we used appropriate methodological filters for specific databases. We searched the following databases: Ovid MEDLINE, Embase, OVID, PsycINFO, CINAHL Plus, EBSCOHost, Web of Science Core Collection, ASSIA, IBSS, Sociological Abstracts, ProQuest and LILACS on the 26th February 2015. In addition, we searched: the grey literature; the websites of professional associations for relevant publications; and the reference lists of all publications reviewed. We also contacted authors of the trials included in the effectiveness reviews as well as of studies (potentially) included in the qualitative synthesis, conducted citation searches of the publications reporting these studies, and contacted content experts.

We reran the search on 3rd July 2016 and found three studies, which are awaiting classification.

Factors that impact on the use of mechanical ventilation weaning protocols in critically ill adults and children: a qualitative evidence- 


\section{Selection criteria}

We included qualitative studies that described: the circumstances in which protocols are designed, implemented or used, or both, and the views and experiences of healthcare professionals either involved in the design, implementation or use of weaning protocols or involved in the weaning of critically-ill adults and children from mechanical ventilation not using protocols. We included studies that: reflected on any aspect of the use of protocols, explored contextual factors relevant to the development, implementation or use of weaning protocols, and reported contextual phenomena and outcomes identified as relevant to the effectiveness of protocolized weaning from mechanical ventilation.

\section{Data collection and analysis}

At each stage, two review authors undertook designated tasks, with the results shared amongst the wider team for discussion and final development. We independently reviewed all retrieved titles, abstracts and full papers for inclusion, and independently extracted selected data from included studies. We used the findings of the included studies to develop a new set of analytic themes focused on the barriers and facilitators to the use of protocols, and further refined them to produce a set of summary statements. We used the Confidence in the Evidence from Reviews of Qualitative Research (CERQual) framework to arrive at a final assessment of the overall confidence of the evidence used in the synthesis. We included all studies but undertook two sensitivity analyses to determine how the removal of certain bodies of evidence impacted on the content and confidence of the synthesis. We deployed a logic model to integrate the findings of the qualitative evidence synthesis with those of the Cochrane effectiveness reviews.

\section{Main results}

We included 11 studies in our synthesis, involving 267 participants (one study did not report the number of participants). Five more studies are awaiting classification and will be dealt with when we update the review.

The quality of the evidence was mixed; of the 35 summary statements, we assessed 17 as 'low', 13 as 'moderate' and five as 'high' confidence. Our synthesis produced nine analytical themes, which report potential barriers and facilitators to the use of protocols. The themes are: the need for continual staff training and development; clinical experience as this promotes felt and perceived competence and confidence to wean; the vulnerability of weaning to disparate interprofessional working; an understanding of protocols as militating against a necessary proactivity in clinical practice; perceived nursing scope of practice and professional risk; ICU structure and processes of care; the ability of protocols to act as a prompt for shared care and consistency in weaning practice; maximizing the use of protocols through visibility and ease of implementation; and the ability of protocols to act as a framework for communication with parents.

\section{Authors' conclusions}

There is a clear need for weaning protocols to take account of the social and cultural environment in which they are to be implemented. Irrespective of its inherent strengths, a protocol will not be used if it does not accommodate these complexities. In terms of protocol development, comprehensive interprofessional input will help to ensure broad-based understanding and a sense of 'ownership'. In terms of implementation, all relevant ICU staff will benefit from general weaning as well as protocol-specific training; not only will this help secure a relevant clinical knowledge base and operational understanding, but will also demonstrate to others that this knowledge and understanding is in place. In order to maximize relevance and acceptability, protocols should be designed with the patient profile and requirements of the target ICU in mind. Predictably, an under-resourced ICU will impact adversely on protocol implementation, as staff will prioritize management of acutely deteriorating and critically-ill patients.

\section{PLAIN LANGUAGE SUMMARY}

\section{Using qualitative evidence to identify factors influencing ICU health carers' use of guidelines to take adults and children off mechanical ventilation}

\section{Background}

Many critically-ill adults and children being cared for in an intensive care unit (ICU) are unable to breathe by themselves. When this happens they are put on a mechanical ventilator, a machine that helps them to breathe. Staying on a ventilator for too long increases the likelihood of harmful effects, including trauma and infection of the lungs and complications of prolonged immobility such as blood clots in the legs or lungs. Consequently, researchers have tried to find ways to take people off ventilators (that is, to wean them) as soon as is safely possible. One way is by using guidelines, or protocols. Two recent Cochrane reviews combined evidence from different research studies. Some studies showed that protocols were successful in reducing the amount of time spent on a ventilator, while other studies showed that using protocols did not make any difference to the amount of time spent on a ventilator. These contrasting findings could have been caused by a range of factors. Researchers investigating these factors have used qualitative research methods, which usually involve talking to people or observing how people behave, or both.

\section{Review question}

What are the factors influencing how healthcare professionals use protocols to wean adults and children from mechanical ventilation?

\section{Methods}

Factors that impact on the use of mechanical ventilation weaning protocols in critically ill adults and children: a qualitative evidence- 
To identify studies using qualitative methods, we searched relevant electronic databases of journals in February 2015. We also searched the reference lists of articles, contacted the authors of all of the studies included in the two earlier reviews and in our qualitative synthesis, and contacted experts in mechanical ventilation. We combined the findings of the relevant studies to produce a synthesis of the evidence on what influences health professionals to use protocols. We then combined our synthesis with the findings of the two earlier reviews to help explain why some of the studies had shown protocols to be effective and others had not. We were able to do so by producing explanations of how different factors work together to either promote or hinder the use of protocols. We outlined these explanations in a 'logic model'.

\section{Key findings}

Our synthesis included 11 studies, involving around 267 participants; five more studies are awaiting classification. We identified several potential barriers and facilitators to the use of protocols. First, doctors used protocols only in certain circumstances; otherwise they preferred to wean using their own knowledge and skills. Relatively inexperienced nurses often lacked confidence. A protocol could encourage their involvement in weaning because it set out clear instructions and also helped them to feel more secure. Although more experienced nurses also recognized these positive qualities, they criticized protocols as sometimes instructing them to wean contrary to their own clinical judgement. Second, the practical arrangements for care within an ICU could either help or hinder healthcare professionals to work together, and in this way influence how (well) a protocol was used. Third, the use of a protocol reflected how healthcare professionals interact with one another generally. For example, the degree of experience a nurse or doctor possessed could influence the confidence others had that they could wean safely. For this reason, doctors tended to be reluctant to involve nurses they considered to be relatively inexperienced in weaning, even when there was a protocol in place. Furthermore, the fact that doctors occupied a higher professional status or position meant that it was difficult for nurses to be involved in weaning, including by using a protocol, unless the doctors s/he worked with permitted this to happen.

\section{Quality of the evidence}

We developed 35 summary statements. Of these: we assessed 17 statements as 'low' confidence, largely because the evidence used to develop them came from only a small number of studies. We rated 13 statements as 'moderate' confidence, largely because the evidence used to develop them came from very well-conducted studies, and we rated five statements as 'high' confidence, largely because the evidence used to develop them came from a majority of the studies. 


\section{B A C K G R O U N D}

Mechanical ventilation is a common life-supportive therapy for critically-ill adults and children with respiratory failure. Approximately $40 \%$ of adults and $55 \%$ of children admitted to an intensive care unit (ICU) require mechanical ventilation (Farias 2011; Shahin 2014; Wunsch 2013). Most adults and children are successfully weaned off mechanical ventilation at the first attempt (Boles 2007; Farias 2011); for others weaning is difficult and more protracted. ICU mortality for ventilated patients is approximately $30 \%$ in adults (Esteban 2013) and $13 \%$ in children (Farias 2011). Prolonged mechanical ventilation is associated with longer ICU length of stay and higher mortality (Peñeulas 2011), due to complications such as ventilator-associated lung injury and pneumonia (Grap 2009; Jubran 2010; Principi 2010; Shorr 2005). Substantial healthcare costs are associated with mechanical ventilation. In the United States, critical care accounts for an estimated USD 55.5 billion, $13.3 \%$ of hospital costs and $0.6 \%$ of the gross domestic product (Halpern 2010). Direct daily costs of an ICU bed in four European countries (Germany, Italy, the Netherlands, and the United Kingdom) ranged from EUR 1168 to 2025 (Tan 2012).

Potential consequences to patients and the healthcare system resulting from unnecessary delays to extubation have led research to focus on identifying methods that improve ventilator-weaning processes. Two large seminal clinical trials (Brochard 1994; Esteban 1995) indicated that the clinical processes promoting timely recognition of a patient's readiness to wean were more important in reducing the duration of mechanical ventilation than the weaning method itself (Boles 2007). Consequently, over recent years the application of weaning moved from an informal approach, based on clinician education and experience, to a formal approach using guidelines or protocols. Weaning protocols generally provide objective criteria for assessment of weaning and extubation readiness incorporated into a structured algorithm that includes a method of reducing ventilator support based on the patient's response. Protocolized weaning has gained some popularity among the adult and paediatric critical care community because of its purported success in reducing the duration of mechanical ventilation. Surveys of European adult ICUs show that $56 \%$ to $69 \%$ have weaning protocols (Rose 2011a), and in UK paediatric ICUs the prevalence of weaning protocols has increased from 5\% (Manczur 2000) to 18\% (Blackwood 2011).

\section{How the intervention is intended to work}

Protocolized weaning may comprise traditional paper-based protocols or automated closed-loop systems embedded into the ventilator (Rose 2014). Both paper-based and ventilator-based protocols are designed to reduce undesirable variability in weaning practices and avoidable delays arising from clinician preference and availability. Weaning protocols frequently include steps to facilitate recognition of a patient's readiness to wean which may also reduce delays associated with failure to recognize weaning readiness. Another key element of weaning protocols, particularly paper-based versions, is that they enhance responsibilities and autonomy of the interprofessional team, thereby reducing delays created by decisional hierarchies.

\section{Why it is important to do this review}

The Cochrane systematic review and meta-analysis evaluating the efficacy of weaning protocols in 17 trials and 2434 adults found evidence of effect that protocols reduce the duration of mechanical ventilation (Blackwood 2014). The evidence was graded as moderate because of significant variability in effect estimates. This variability is unsurprising, given the international differences in ICU structure, staffing models and critical care education (Rose 2011b), as well as in mechanical ventilation and weaning practices (Blackwood 2011; Burns 2009; Horbar 1999; Rose 2008a; Santschi 2007). The Cochrane systematic review of the efficacy of weaning protocols in children also demonstrated discordant results (Blackwood 2013). One large trial (Foronda 2011) showed a significant reduction in the duration of mechanical ventilation; two trials (Jouvet 2013; Maloney 2007) indicated no effect.

As acknowledged in both these reviews (Blackwood 2013; Blackwood 2014), weaning is a complex clinical intervention influenced by inter-related and interdependent components, all of which are associated with the context in which the weaning intervention is implemented and delivered. 'Context' includes a wide range of potential factors and processes including, for example: ICU organization, resources, staffing and patient casemix; hospital or unit culture (for example, interprofessional working and relationships); and healthcare professional characteristics (for example, skill mix, education and training) (Blackwood 2006; Krishnan 2004; Rose 2008b).

Furthermore, the values, preferences, knowledge and skills of clinicians may influence the uptake and implementation of weaning protocols. Protocols may be perceived to repress critical thinking, clinical innovation and individualized care and therefore may be rejected by clinical staff (Cohen 1991; Ely 2001; Morris 2003). The processes of ventilator weaning in children and adults are similar (Leclerc 2010) and the literature suggests that context, health professionals' characteristics and clinical processes also influence weaning in paediatric ICUs (Marcin 2005; Stockwell 2008).

Accordingly, when considering the potential effectiveness of weaning protocols, it is necessary to consider the ICU and wider context (for example, hospital) within which they are implemented. This is particularly the case when conducting systematic reviews, as the structure and processes of care (for example, healthcare systems, organizational arrangements and interprofessional relationships) vary considerably across countries (Blackwood 2003; Rose 2011b).

It is possible that unobserved patient or clinical factors confounded the trials included in the Blackwood 2013 and Blackwood 2014 reviews. For example, the durations of ventilation, weaning and ICU stay, common outcomes reported in weaning protocol trials, may be modified by different sedation practices such as the type of agent used (Pandharipande 2007), dosing regimens (Carson 2006), protocols (Bucknall 2008) and daily drug interruption (Mehta 2012). Sedative agents such as benzodiazepines have been associated with development of delirium (Kamdar 2015), which also prolongs the duration of ventilation and ICU stay (Lin 2008). Trials included in the Blackwood 2013 and Blackwood 2014 reviews provided little or no information on sedation practices or delirium prevalence.

Cochrane reviews of effectiveness are not intended to account for their findings according to the types of issues outlined above. However, an increasing awareness of the benefits of understanding the factors underpinning effectiveness has focused attention on the value of qualitative research within and outside Cochrane. 
Accordingly, the past 15 years have seen a growing number of qualitative evidence syntheses provide greater clarity and understanding of contextual factors, and the mechanisms of their interaction, that may impact on the outcomes of a wide range of interventions (see, for example: Glenton 2013; Munro 2007; Schumm 2010). As these syntheses have been produced, so too has the supporting methodological literature (Noyes 2011).

Notwithstanding the benefits to be derived from stand-alone syntheses of qualitative evidence, integrating the findings with reviews of effectiveness can provide detailed evidence concerning the barriers and facilitators to the successful implementation of interventions. Relevant qualitative evidence may be derived in the following ways: first, synthesis of evidence from 'sibling' studies, reporting qualitative research conducted alongside or associated with the trials included in the effectiveness review. Second, synthesis of evidence from unrelated but relevant qualitative research to address specific questions arising from the effectiveness review. Finally, synthesis of evidence from both sibling and unrelated studies (Noyes 2011). Matching effectiveness reviews with qualitative syntheses in these ways adds value by exploring questions about the development, delivery, uptake, implementation and experience of interventions, including in relation to observed heterogeneity in outcomes across sites. In so doing, we gain important insights into why interventions do or do not work, for whom, and in what circumstances. Although still rare, several paired Cochrane effectiveness reviews and qualitative evidence syntheses are available (Candy 2011; Glenton 2013; Noyes 2007). These provide detailed, context-specific evidence concerning if, how and why specific interventions have been effective in the settings in which they were delivered and received.

\section{OB JECTIVES}

The aim of this review is to integrate a qualitative evidence synthesis with two Cochrane effectiveness reviews of protocolized weaning (Blackwood 2013; Blackwood 2014) to identify contextual factors that impact on the use of protocols for weaning criticallyill adults and children from mechanical ventilation. Our review expands on the Blackwood 2013 and Blackwood 2014 reviews by synthesizing trial-related qualitative evidence to help explain the observed heterogeneity in included trials. In addition, our review incorporates a synthesis of evidence from relevant qualitative research not related to the included trials to explore broader contextual factors (for example, ICU culture, organization, staffing levels and extent of collaboration) and their interplay, that may impact on the use of weaning protocols in mechanical ventilation. Against a backdrop of inconsistent evidence on the effectiveness of weaning protocols, our review aims to provide clinicians and policy-makers with a rigorous, systematically-derived evidence base concerning the circumstances in which weaning protocols appear to be used in ways most likely to promote timely liberation from mechanical ventilation. This is particularly important to guide policy mandates for adoption of weaning protocols as a qualityimprovement measure to improve efficiency, patient safety and healthcare spending.

The specific research questions guiding the review are:

1. Which contextual factors (facilitators and barriers to implementation) may have contributed to the heterogeneity in effect sizes of the randomized controlled trials included in the
Blackwood 2013 and Blackwood 2014 reviews on protocolized weaning?

2. Which contextual factors (facilitators and barriers to implementation) may have an impact on the use of protocols for weaning critically-ill adults and children from mechanical ventilation?

We capitalized on the demonstrated value of matching Cochrane effectiveness reviews with a qualitative evidence synthesis in order to address our research questions. In so doing we pursued the following objectives:

- To locate, appraise and synthesize qualitative evidence concerning the barriers and facilitators of the use of protocols for weaning critically-ill adults and children from mechanical ventilation;

- To integrate this synthesis with two Cochrane effectiveness reviews of protocolized weaning to help explain observed heterogeneity by identifying contextual factors that impact on the use of protocols for weaning critically-ill adults and children from mechanical ventilation;

- To use the integrated body of evidence to suggest the circumstances in which weaning protocols are most likely to be used.

\section{METHODS}

\section{Criteria for considering studies for this review}

Types of studies for better understanding heterogeneity in included studies in the Blackwood 2013 and Blackwood 2014 reviews

We included studies conducted alongside or associated with the trials included in the Blackwood 2013 and Blackwood 2014 reviews. These included, but were not limited to, studies using participant and non-participant observation and interviews (oneto-one and focus group), underpinned by methodologies such as phenomenology, ethnography, grounded theory, action research, and narrative research.

Types of studies for understanding the broader implementation context in relation to the Blackwood 2013 and Blackwood 2014 reviews

We included qualitative empirical studies (either stand-alone or components of larger, mixed-method studies) that provided evidence concerning the contextual factors (facilitators and barriers) and their interplay, that may impact on the effectiveness of weaning protocols. These included, but were not limited to, studies using participant and non-participant observation and interviews (one-to-one and focus group), underpinned by methodologies such as phenomenology, ethnography, grounded theory, action research, and narrative research.

\section{Types of participants}

Types of participants for better understanding heterogeneity in included studies in the Blackwood 2013 and Blackwood 2014 reviews

We included studies conducted alongside or associated with the Blackwood 2013 and Blackwood 2014 reviews that reported on (a)

Factors that impact on the use of mechanical ventilation weaning protocols in critically ill adults and children: a qualitative evidence- 
contextual factors associated with protocolized weaning; (b) views and experiences of healthcare professionals involved in the design, development, training, uptake, implementation or evaluation of protocolized weaning; (c) and views and experiences of patients undergoing protocolized weaning and their relatives.

Types of participants for understanding the broader implementation context in relation to the Blackwood 2013 and Blackwood 2014 reviews

We included studies not associated with the two reviews that reported contextual factors associated with protocolized weaning, describing the views and experiences of healthcare professionals

- either actively involved in the design, implementation or use of protocols for weaning critically-ill adults or children from mechanical ventilation

- or involved in the weaning of critically-ill adults and children from mechanical ventilation NOT using protocols, and asked, for the purposes of the study, to reflect on any aspect of the use of protocols for weaning critically-ill adults or children from mechanical ventilation

We also included the views and experiences of patients undergoing protocolized weaning, and their relatives.

\section{Types of interventions}

Types of interventions for better understanding heterogeneity in included studies in the Blackwood 2013 and Blackwood 2014 reviews

We included studies specifically conducted to explore factors associated with protocolized and non-protocolized weaning in the trials included in the Blackwood 2013 and Blackwood 2014 reviews.

Types of interventions for understanding the broader implementation context in relation to the Blackwood 2013 and Blackwood 2014 reviews

We included studies that explored contextual factors relevant to the development, implementation or use of written protocols or automated systems to reduce the level of ventilator support to facilitate liberation from mechanical ventilation.

\section{Types of outcome measures}

Phenomena of interest for exploring heterogeneity in included studies in the Blackwood 2013 and Blackwood 2014 reviews

We included studies that reported contextual phenomena and outcomes specifically identified as relevant to the effectiveness of the interventions offered in the trials included in the Blackwood 2013 and Blackwood 2014 reviews.

Phenomena of interest for understanding the broader implementation context in relation to the Blackwood 2013 and Blackwood 2014 reviews

We included studies that reported contextual phenomena and outcomes identified as relevant to the effectiveness of protocolized weaning from mechanical ventilation. These were identified on the basis of:
- perceptions and understandings of healthcare professionals concerning:

* the use of protocols generally (i.e. not in relation to experience of using a specific protocol) for weaning ICU patients from mechanical ventilation, including barriers and facilitators;

* the use of a specific weaning protocol (or protocols) for weaning ICU patients from mechanical ventilation, including barriers and facilitators;

- behaviour of healthcare professionals in relation to the use of a specific protocol for weaning ICU patients from mechanical ventilation (e.g. compliance with the protocol);

- social organization and relationships of professional practice (e.g. interprofessional team working)

- wider organizational constraints and opportunities (e.g. availability of relevant resources)

\section{Search methods for identification of studies}

We used the search terms outlined in the Blackwood 2013 and Blackwood 2014 reviews that included synonyms for ventilator weaning and clinical protocols (reflecting the clinical condition and intervention respectively); we omitted the methods filter used to identify randomized controlled trials and inserted a qualitative search filter. Where available, we used appropriate methodological filters for specific databases (e.g. MeSH term - "Program Evaluation" - in MEDLINE). The qualitative search filters we used were informed by supplementary guidance on searching provided by the Cochrane Qualitative and Implementation Methods Group (CQIMG) (Booth 2011). In line with available guidance, we used a range of search terms (database-specific thesaurus, free-text and broad-based) (Shaw 2004) identified with the help of the SPICE (Setting Perspective Intervention Comparison Evaluation) mnemonic (Booth 2004) to optimize identification of relevant studies.

\section{Electronic searches}

We searched the following electronic databases from 1st January 1950 to 26th February 2015 inclusive. We reran the search on 3rd July 2016 and found three further studies which are awaiting classification

- Ovid MEDLINE - Includes new records, not yet fully indexed, Ovid MEDLINE(R) Daily Update 3rd July 2016, Ovid MEDLINE(R) 1946 to 3rd July 2016.

- Embase, OVID

- PsycINFO, OVID

- CINAHL Plus, EBSCOHost

- Web of Science Core Collection

- Applied Social Science Index and Abstracts (ASSIA), ProQuest

- International Bibliography of the Social Sciences (IBSS), ProQuest

- Sociological Abstracts, ProQuest

- Latin American and Caribbean Health Science Information (LILACS)

We did not exclude studies based on language, because of the premium placed on identifying all relevant studies and the anticipated relatively low rate of return from our searches. 
Our search strategies are presented in Appendix 1, Appendix 2, Appendix 3, Appendix 4, Appendix 5, and Appendix 6.

\section{Other searches}

To identify additional relevant published and unpublished work, we undertook the following activities. A comprehensive grey literature search encompassed the following electronic databases: Biosis; Scirus; Scientific Webplus; Science Watch; US Dept. of Health and Human Services (National Guideline Clearing House, Annotated Bibliographies, Expert Commentaries, Guideline Syntheses); Google; MSN; Medpage; ProQuest (Dissertation and Theses, Nursing and Allied Health Source; Biological Science). Search terms varied according to individual search engines, but were kept as inclusive as possible (for example, wean ${ }^{\star}$, protocol ${ }^{*}$, extub $^{\star}$ ) and used in multiple combinations.

We searched the websites of the following professional associations, and also searched for publications (policy documents, editorials and other statements) by them within BIOSIS and using Google:

- European Society of Intensive Care Medicine;

- European Federation of Critical Care Nursing Associations;

- European Society of Pediatric and Neonatal Intensive Care;

- American Association of Critical Care Nurses;

- American Thoracic Society;

- American Association of Respiratory Care;

- Society of Critical Care Medicine;

- Australian College of Critical Care Nurses;

- Australian and New Zealand Intensive Care Society;

- World Federation of Societies of Intensive and Critical Care

Medicine;

-World Federation of Pediatric Intensive and Critical Care Societies;

-World Federation of Critical Care Nurses.

We initially undertook all searches on 26th February 2015 and reran them on 3rd July 2016. In addition, we handsearched the reference lists of all publications reviewed, contacted authors of the trials included in the effectiveness reviews as well as authors of included studies, conducted citation searches of the publications reporting these studies, and contacted content experts.

\section{Data collection and analysis}

\section{Selection of studies}

Two review authors (JJ, LR) independently screened all retrieved titles and abstracts to assess eligibility, using a specificallydesigned study eligibility form (Appendix 7). We retrieved full-text versions of all papers identified by either or both review authors as potentially eligible. We resolved disagreement by discussion with a third review author (BB). On occasion, we contacted the study authors for further information in order to make a final decision.

\section{Data extraction and management}

Two review authors (JJ, BB) independently extracted study data using a specifically-designed data extraction form (Appendix 8). We extracted data on study setting and population, phenomena of interest, study design, methods, findings and comments. JJ contacted study authors to seek clarification on issues of reporting (typically in relation to study design and methods).
The difficulties inherent in deciding what constitute 'findings' in qualitative research (Glenton 2013; Sandelowski 2002; Thomas 2008) coalesce around the essential difference between (raw) data, the author's analysis or interpretation of these data and other inferences or conclusions made by the author. For the purposes of this review we focused on the authors' analysis, typically presented as analytical themes or categories. We therefore extracted themeor category-level evidence, irrespective of how simple or complex its development. In order to ensure a strict demarcation between 'findings' (that is, the authors' analysis) and the authors' inferences or conclusions based on these findings, we only extracted data included within the 'Findings' section of the included papers. In so doing, we adhered to the same approach as that adopted by Thomas 2008.

\section{Assessment of confidence in extracted evidence}

We used a two-stage process to arrive at a final assessment of our overall confidence in the evidence used in the synthesis. In Stage 1, we assessed the quality of the included studies. Following the guidance provided by CQIMG (Noyes 2011), we adopted a multidimensional concept of quality to assess:

- the quality of reporting (that is, explicitness in reporting all aspects of study aims, design, process and findings)

- the methodological rigour (that is, the validity and reliability of study design and process)

- the overall conceptual integrity (that is, if the stated study aims/rationale were properly reflected in study design, process and findings, AND/OR, if a study was explicitly theoretically informed, if the theory was adequately reflected in study design, process and findings).

Two review authors (JJ, BB) independently critically appraised the included studies using a specifically-designed quality appraisal form (Table 1). We resolved disagreements by discussion and did not require arbitration. The framework consisted of 10 domains, adapted from existing sets of criteria recommended for assessing the quality of qualitative research, and designed to capture the three dimensions of quality in which we were interested. The first set, the Critical Appraisal Skills Programme (CASP) checklist for qualitative research (CASP 2014), is a well-known qualityassessment tool. Although useful, the CASP framework is not designed to consider the more conceptual or theoretical aspects of a study. Consequently, we included two specific domains from the framework developed by Popay 1998, which allowed us to assess these aspects of the included studies.

Using this critical appraisal process, we differentiated between 'high', 'moderate' and 'low' quality studies, as follows:

- High: criteria appropriately applied and described in the paper or ascertained in communication with the primary author of the study.

- Moderate: criteria not reported and impossible to acquire from or clarify with the primary study author.

- Low: criteria inappropriately or not applied.

Essentially, the overall assessment represented a 'weighting' of the respective methodological strengths and weaknesses of each study. We summarized our assessment in an easily accessible table 
format, in which each study was colour-coded according to its assigned quality (high = green; moderate = yellow; low = red).

In Stage 2, we used version 1 of CERQual (Glenton 2013) to assess confidence in the evidence. This relatively recent approach uses principles similar to the GRADE framework (Guyatt 2011), taking into account two dimensions of the evidence. First, the methodological robustness of the included studies (assessed in Stage 1, above). Second, the coherence of the findings generated by the synthesis. Coherence was assessed as either high, moderate or low, according to the extent to which a finding was consistent across multiple contexts or settings. If a finding was applicable to multiple contexts or settings (for example, in terms of ICU organization or routines of care, or both), we designated its coherence as 'high'. Conversely, if a finding was relevant to one context or setting only, we designated its coherence as 'low'.

We combined the two aspects of the evidence (methodological quality and coherence) to create an overall confidence rating for each finding as either 'high', 'moderate' or 'low'. Two review authors $(\mathrm{JJ}, \mathrm{BB})$ independently assigned a rating, resolving disagreements by discussion. We generated all such ratings through a process of expert judgement. Accordingly, we rated a finding drawn from methodologically robust studies and relevant to a wide range of contexts as 'high' confidence. Conversely, we rated a finding drawn from methodologically weak studies and relevant to a limited number of contexts as 'low' confidence. Finally, we rated a finding that was either drawn from studies that evidenced methodological limitations or limited coherence as 'moderate' confidence. Again, the overall assessment of each finding represented a 'weighting' of their respective methodological robustness and coherence.

\section{Synthesis of qualitative evidence}

Data synthesis for understanding heterogeneity in included studies in the Blackwood 2013 and Blackwood 2014 reviews

\section{AND}

Data synthesis for understanding the broader implementation context in relation to the Blackwood 2013 and Blackwood 2014 reviews

In line with CQIMG (Noyes 2011) guidance, our approach to the synthesis of qualitative evidence for both components of the review was the same. Data synthesis was premised on the type of qualitative data available. We were conceptually oriented in that we sought to analyse the original (author-generated) findings to develop new interpretive constructs, set out as analytical themes. This approach reflected the underlying aims and objectives of the review, namely, the identification of contextual barriers and facilitators to the use of protocols for weaning. We used the 'thematic synthesis' approach (Thomas 2008), involving three stages:

Stage 1: The coding of text line-by-line: four review authors (JJ, BB, $L R, K D$ ) read all of the included studies and independently coded a selection. We developed initial codes on a line-by-line basis to reflect directly the meaning and content of the text. This stage of the synthesis constituted a relatively straightforward process of studyspecific 'substantive coding', in that the codes remained close to the substance of the (line or lines of) text to which they had been assigned.
tStage 2: The development of descriptive themes: four review authors ( $\mathrm{LR}, \mathrm{KD}, \mathrm{BB}, \mathrm{JJ}$ ) shared their respective coding frameworks. We used this as a starting point for the development of themes that cross-cut the collective body of findings. We achieved this through completion of two consecutive analytical processes:

- On a study-by-study basis we compared the individual codes with one another, looking for similarities and differences in how they related to the segments of text which they summarized. Through this process we gradually developed a shared coding framework that encompassed all of the findings. During this inductive process, preliminary codes could be lost, amalgamated or new ones created as we worked to ensure that all of the designated codes related to their assigned segments of text in essentially the same way. That is, we worked to ensure that we achieved equivalence in the meaning of the codes across the collective body of findings. Consequently, by the end of this process we were confident that the coding framework was both coherent and consistent. Thomas 2008 describes this process as beginning the translation of concepts from one study to another, and a cornerstone of any developing synthesis;

- Once this coding framework had been agreed, we undertook a process of reviewing all component codes with the aim of identifying any that clustered together according to correspondence in their meaning or focus. We were looking for underpinning themes that could be said to link a number of codes together. We then considered codes identified as such in terms of their potential for categorization under the same 'descriptive theme'. As these were developed, each was given a name that descriptively summarized the (shared) content or focus of the included codes.

Stage 3: Generating analytical themes: in order to develop a series of themes that directly addressed barriers and facilitators to the use of protocols, we undertook the following process:

- One review author $(\mathrm{JJ})$ independently reviewed the entire body of descriptive themes, including the individual codes and associated bodies of text from the original study findings. Simultaneously, another review author (KD) undertook the same process in relation to a selection of descriptive themes. We were confident that a firm basis had been established for the lead author $(\mathrm{JJ})$ to assume primary responsibility for this stage of the analysis, because of the detailed shared development of the descriptive themes previously completed by four review authors (KD, BB, LR, JJ);

- On the basis of a close reading and re-reading of the data, JJ and KD independently developed a series of analytical themes that directly addressed barriers and facilitators to the effective use of protocols for weaning from mechanical ventilation. We undertook this process iteratively, involving an ongoing refinement of the analytical themes as they incorporated growing amounts of 'evidence', in the form of the descriptive themes and associated bodies of texts. Inevitably, a significant degree of interpretation was involved as both review authors moved between the descriptive themes, their constituent codes, relevant individual study findings and the developing analytical themes;

- On completion, JJ and KD shared the two sets of analyses and discussed them with a view to producing a joint analysis. Although this process inevitably enhanced the reliability of the final analytical framework, we were more concerned

Factors that impact on the use of mechanical ventilation weaning protocols in critically ill adults and children: a qualitative evidence- 
with exhausting the full possibilities for analytical insight. Accordingly, the discussion addressed a wide range of issues of interpretation and relevance, premised on the insights both authors had gained in the course of their analyses. They subsequently presented the agreed framework to the other review authors and refined it into its final form based on their reading and feedback.

\section{Summary of qualitative synthesis findings}

In order for the relatively large body of evidence encapsulated within our analytic themes to be used effectively in the synthesis, we condensed it into a series of summary statements. When developing the statements we strategically focused on extracting evidence that directly addressed barriers and facilitators to the use of protocols. Following Glenton 2013, we summarized our analytical themes in the form of a 'Summary of qualitative findings' table. This table is similar to the 'Summary of findings' tables used in Cochrane reviews of effectiveness. Our table summarized the key findings, our confidence in the evidence for each finding, and an explanation of how we arrived at our confidence in the evidence for each finding.

\section{Sensitivity analysis}

We included all studies in our synthesis of qualitative evidence, irrespective of quality assessment. We undertook two subsequent sensitivity analyses. The first ascertained how the removal of studies assessed as 'low' quality impacted on the content and confidence of the synthesis. It involved a two-stage process:

\section{Stage 1}

We reviewed the summary statements, identifying those that had been developed using evidence derived from studies assessed as 'low' quality.

\section{Stage 2}

We extracted the evidence from the low-quality studies in relation to each summary statement. During this process we sought to:

- ascertain the impact of the removal of this evidence on the relevant summary statement;

- assign a new confidence rating;

- provide a rationale for the new confidence ratings assigned.

Our second sensitivity analysis focused on differences in the evidence according to setting, either adult or paediatric ICU. Again, we undertook a two-stage analysis:

\section{Stage 1}

We reviewed the summary statements, extracting those that had been developed using evidence derived from studies set in paediatric ICUs.

\section{Stage 2}

We extracted the evidence from these studies in relation to each summary statement. During this process we sought to:
- ascertain the impact of the removal of this evidence on the relevant summary statement;

- assign a new confidence rating;

- provide a rationale for the new confidence ratings assigned.

\section{Synthesis of the qualitative evidence and the effectiveness reviews}

A key objective of this review was to integrate the findings of the qualitative evidence synthesis with those of the Cochrane effectiveness reviews. Such integration remains relatively innovative, with a number of approaches in use. One such is a logic model methodology (Allmark 2013; Anderson 2011; Baxter 2014). Utilizing this methodology we took the evidence from our qualitative synthesis (in the form of our summary statements) to develop a series of 'chains of reasoning', which linked specific features of the context of weaning to the outcome of interest, namely, the use of protocols.

Two review authors $(\mathrm{BB}, \mathrm{JJ})$ used the summary statements to develop lines of logic that we propose as possible pathways to the use of protocols for weaning from mechanical ventilation. Our lines of logic included:

- A component or feature of the context in which protocols for weaning adults and children from mechanical ventilation may be implemented;

- The barriers and facilitators associated with the component;

- A moderator, that is, a factor that could affect, either positively or negatively, the barriers and facilitators;

- The longer-term outcome, that is, the optimal use of a protocol, which the identified chain could bring about.

The two review authors (JJ, BB) responsible for the development of the lines of logic worked collaboratively. We considered this an appropriate approach as our lines of logic sought to summarize a complex process along multiple dimensions, and as such required deliberation and redrafting in pursuit of clarity and precision. This process was aided considerably by discussion and feedback between the two review authors. We shared a preliminary draft with all review authors, and an iterative process of feedback and refinement saw several versions produced before we agreed a final one across the research team.

In developing the lines of logic we adhered closely to our original findings (that is, summary statements). By so doing, we ensured that the chain of events we developed directly reflected the features and processes of protocol design, implementation and use originally reported in the included studies.

\section{RES U L T S}

\section{Results}

We identified 7770 titles and abstracts, of which we reviewed 77 full-text papers. We included 11 studies that reported qualitative evidence on protocolized weaning of adults and children from mechanical ventilation (Blackwood 2004; Gelsthorpe 2004; Hansen 2007; Hansen 2009a; Hansen 2009b; Keogh 2009; Kydonaki 2011; Lavelle 2011; McLean 2006; Myneni 2012; Vaerland 2011). All of the papers were published since 2004. (Figure 1) 
Figure 1. Study flow diagram.
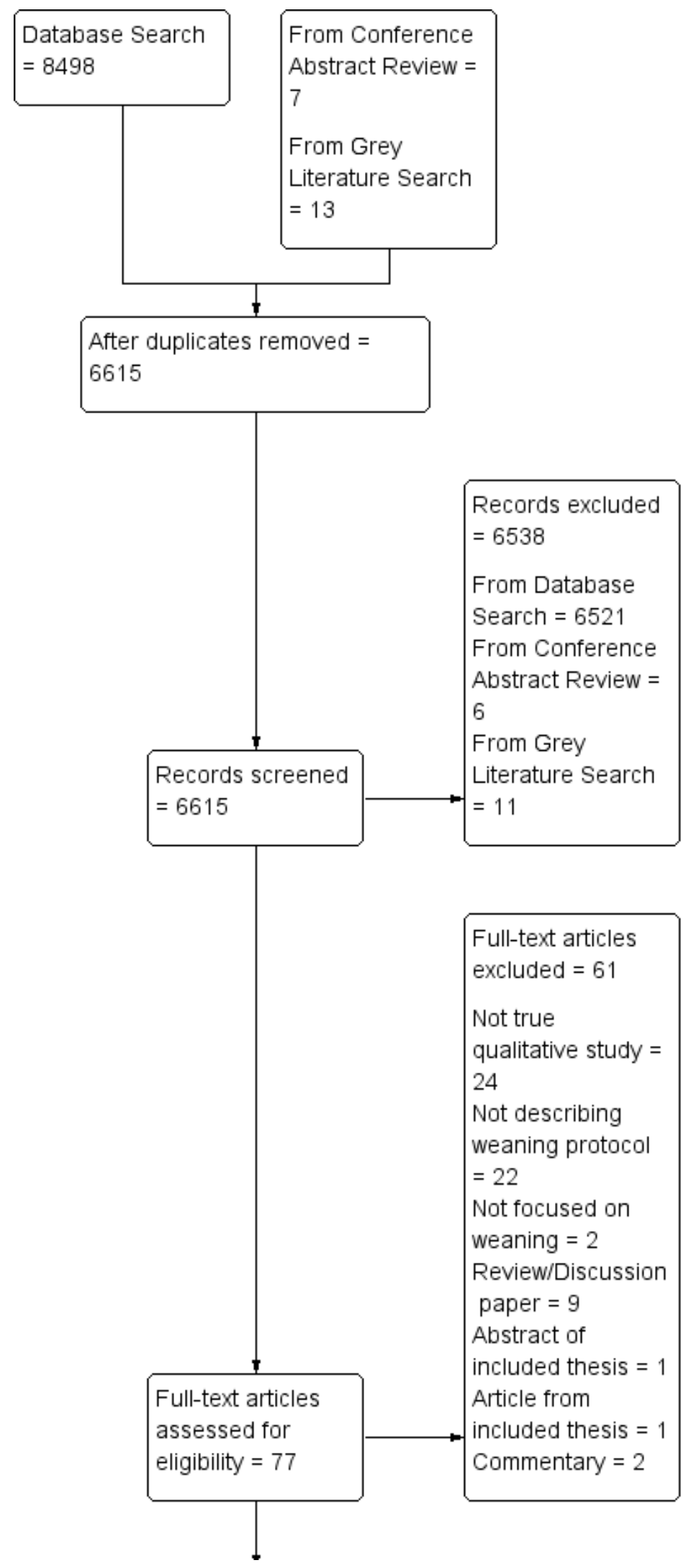

Factors that impact on the use of mechanical ventilation weaning protocols in critically ill adults and children: a qualitative evidence- 
Figure 1. (Continued)

Studies included
in qualitative
synthesis = 11
In addition 5
studies awaiting
classification ( 2
from February
2015 search and
3 from July 2016
search).

We initially ran the searches in February 2015 and reran them in 2016, when we found a further three studies which now await classification. There are now five studies awaiting classification (Pettersson 2012; Solberg 2015; Tingsvik 2014; Tume 2014; Wongrostrai 2016). We will deal with these studies when the review is updated. See the Table Characteristics of studies awaiting classification for more details.

\section{Included studies}

Despite extensive searching, including contacting trial authors, we were unable to locate any trial-related qualitative evidence (socalled 'sibling' studies) for either the Blackwood 2013 (adult) or Blackwood 2014 (paediatric) reviews. Only one of the unrelated included studies (Keogh 2009) was conducted in a paediatric ICU, which arguably is a different context from adult ICUs, as children present with different diagnoses, anatomy and pathophysiology from adults. Consequently, our synthesis uses evidence derived from unrelated qualitative studies, drawn from similar ICU contexts to those in which the trials included in the Blackwood 2014 and effectiveness reviews were conducted, with similar participants and using (where we could tell) broadly similar types of protocols.

We use the trial-unrelated qualitative evidence to address our two review questions. In relation to the first question, concerning the contextual factors (facilitators and barriers) that may have contributed to the heterogeneity in effect sizes of the randomized controlled trials included in the Blackwood 2013 and Blackwood 2014 reviews, our main focus is on the facilitators and barriers to the use of protocols. In so doing, we triangulate the qualitative synthesis findings concerning barriers and facilitators to the use of a protocol generally with the hypotheses put forward by the trial study authors concerning barriers and facilitators to the use of the protocol in their specific trials. As already indicated, the unrelated qualitative studies also provide evidence addressing the second of our review questions, concerning the contextual factors (facilitators and barriers) that may generally have an impact on the use of weaning protocols. As such, we are also able to comment on the broader implementation context in relation to the Blackwood 2013 and Blackwood 2014 reviews. All studies were published in English except one that was translated (from Norwegian into English) (Vaerland 2011).

\section{Study participants}

Participants in the studies included in the qualitative synthesis did not appear to differ markedly from participants in those included in the effectiveness reviews. Most studies $(n=9)$ (Gelsthorpe 2004; Hansen 2007; Hansen 2009b; Keogh 2009; Kydonaki 2011; Lavelle 2011; McLean 2006; Myneni 2012; Vaerland 2011) sought the views and experiences of nurses, either alone or alongside those of other ICU staff, typically physicians and physiotherapists. Two studies, based in Canada (McLean 2006) and the United States (Myneni 2012), also included respiratory therapists. A minority of studies ( $n$ =2) (Blackwood 2004; Hansen 2009a) focused entirely on the views and experiences of physicians.

\section{Setting}

The settings of the studies included in the qualitative synthesis did not appear to be markedly different from those included in the effectiveness reviews. Except for one study (Kydonaki 2011), all were completed in high-income countries, with the majority being undertaken in Europe. Except for one paediatric study (Keogh 2009), all were conducted in an adult ICU. Where reported, ICUs were mixed. Most studies ( $n=9$ ) (Gelsthorpe 2004; Hansen 2007; Hansen 2009a; Hansen 2009b; Keogh 2009; Lavelle 2011; McLean 2006; Myneni 2012; Vaerland 2011) were undertaken in a single ICU. Typically, the studies that addressed a specific protocol (n = 9) (Gelsthorpe 2004; Hansen 2007; Hansen 2009a; Keogh 2009; Kydonaki 2011; Lavelle 2011; McLean 2006; Myneni 2012; Vaerland 2011) were poor at reporting the details of protocol content; only two (Gelsthorpe 2004; Vaerland 2011) included any detailed information concerning its content and procedures for use, which made direct comparisons with included trial intervention protocols challenging. In general the protocols for which there was some description appeared to be broadly similar in purpose to those used in the included trials. A summary of the characteristics of study settings is presented in Table 2 .

\section{Use of protocols in unrelated qualitative studies}

A majority of the studies ( $n=9$ ) (Gelsthorpe 2004; Hansen 2007; Hansen 2009a; Keogh 2009; Kydonaki 2011; Lavelle 2011; McLean 2006; Myneni 2012; Vaerland 2011) sought the views and experiences of participants in relation to a specific weaning protocol. The remaining two studies (Blackwood 2004; Hansen 2009b) sought the views and experiences of participants of weaning patients from mechanical ventilation more generally, including in

Factors that impact on the use of mechanical ventilation weaning protocols in critically ill adults and children: a qualitative evidence- 
relation to the perceived benefits and disadvantages of using a protocol. In most unrelated studies the protocol had already been implemented and in some studies the protocol had been used for some time, although it was difficult to ascertain exactly how long. This contrasts with included trial interventions that focused on the immediate implementation context and for a defined period of follow-up.

\section{Quality of included studies}

The included studies were of variable quality. They tended to adopt a relatively functional approach to the research design and process. Accordingly, attention was paid to issues of transparency and credibility but not to other issues that mark the particular character of qualitative research such as, for example, reflexivity or conceptual elaboration. In addition, the studies tended to provide limited detail concerning all aspects of methodology. In this respect, it is not surprising that the only study (Kydonaki 2011) to have been rated positively across all 10 domains was a $\mathrm{PhD}$ thesis that was able to report in detail on all aspects of research design and process.

The studies relied heavily on interviews and to a lesser extent on focus groups, with only two studies (Kydonaki 2011; Myneni 2012) incorporating observation. In terms of findings, they tended to present technically competent but relatively undeveloped descriptive analyses, showing little evidence of theoretical or conceptual development. However, given the lack of stated theoretical underpinnings, such development would not be expected. Accordingly, only one study (Gelsthorpe 2004) was rated negatively on this domain, having stated an explicit theoretical orientation, but failing to build on this in terms of either research design or analysis of findings. Appendix 9 presents a summary table of our assessment of the quality of included studies.

\section{Thematic synthesis of qualitative evidence}

We developed nine analytical themes, as follows:

- Continual staff training and development: the essentials of knowing how (to use a protocol) to wean

- Clinical experience: the basis of a necessary felt and perceived competence and confidence for (protocolized) weaning

- The vulnerability of weaning protocols to differential (inter) professional working

- Rigidity of protocols militate against a necessary proactivity in clinical practice

- Perceived nursing scope of practice and professional risk

- ICU structure and processes of care

- Protocols as a prompt for shared care, consensus and consistency in weaning

- Maximizing the use of protocols through visibility, relevance and ease of implementation

- Protocols as a framework for communication with parents

Each of the themes includes evidence that directly addresses possible barriers and facilitators to the use of protocols for weaning adults and children from mechanical ventilation as this impacts on their overall effectiveness. Each theme is discussed below.

\section{Continual staff training and development: the essentials of} knowing how (to use a protocol) to wean
The need for ongoing staff development and training was stressed amongst participants, physicians and non-physicians alike (Blackwood 2004; Hansen 2009b; Lavelle 2011). Such training was understood as critical to the maintenance of a comprehensive body of weaning-related pathophysiological knowledge and to achieving competence in the use of protocols (Blackwood 2004; McLean 2006). In one setting observations confirmed the negative outcomes associated with inadequate clinician understanding of the protocol when patients were left on spontaneous breathing trials for prolonged periods of time (Myneni 2012). Some physicians expressed concern over potentially inappropriate use of protocols, being used as a replacement for, rather than as an adjunct to, clinical judgement (Blackwood 2004; Hansen 2009a; Hansen 2009b). Training was considered to minimize the potential for this by helping to equip all those involved with due clinical insight, knowledge and competence (Blackwood 2004). In line with this understanding, those nurses who received regular training in ventilator weaning considered their weaning-related competence and confidence to have improved, including in relation to the use of a protocol (Hansen 2009b; Vaerland 2011). In addition, some nurses were aware of a separate outcome of training, namely, enhancing their credibility to wean amongst colleagues (especially physicians), such that the latter were more inclined to allow them an increased role (Lavelle 2011).

\section{Clinical experience: the basis of a necessary felt and perceived competence and confidence for (protocolized) weaning}

Nurses drew a direct association between experience and clinical expertise and confidence (Gelsthorpe 2004; Hansen 2009b; Keogh 2009; Kydonaki 2011; Lavelle 2011; Vaerland 2011). The greater the experience of a nurse, the more s/he could and should rely on independent clinical insight and skills as the basis of clinical decision-making, including in relation to weaning (Gelsthorpe 2004; Lavelle 2011; Vaerland 2011). Thus, the use of or reliance upon weaning protocols tended to be associated with more junior/ less experienced staff (Kydonaki 2011; Lavelle 2011; Vaerland 2011). Some nurses talked about the weaning protocol as enhancing their feeling of safety when weaning (Hansen 2007). Others talked about not weaning despite the protocol guiding them to do so (Gelsthorpe 2004; Hansen 2007). For junior nursing staff, this caution was explicitly associated with a more generalized caution in weaning practice based on felt inexperience (Gelsthorpe 2004). Some nurses, including but not restricted to relatively junior staff, confirmed that although fully understanding the protocol, they routinely waited for explicit instruction from senior colleagues (typically physicians but sometime senior nurses), based on a felt lack of confidence (Gelsthorpe 2004; Hansen 2007).

Other experienced nurses considered themselves as proactive in weaning. They understood that, over time, their day-to-day work at the patient's bedside had enabled them to develop relevant knowledge, skills and confidence in weaning (Hansen 2007; Hansen 2009b; Lavelle 2011; Vaerland 2011). Such experiential knowledge and the confidence it engendered were regarded as core to their ability to both observe as well as correctly interpret clinical and other indicators. Consequently, some nurses expressed a preference for weaning based on personal insight and expertise, with a protocol acting as a guideline to care, rather than a determinant of it (Gelsthorpe 2004; Kydonaki 2011; Vaerland 2011). Some nurses identified protocols as problematic, in that they

Factors that impact on the use of mechanical ventilation weaning protocols in critically ill adults and children: a qualitative evidence- 
interfered with their ability to effectively wean using personal clinical expertise and insight (Lavelle 2011).

Physicians also acknowledged that the degree of clinical experience and concomitant felt competence and confidence directly impacted on their own as well as colleagues' use of the protocol (Blackwood 2004; Hansen 2009b). Inexperienced or junior physicians described the protocol as providing them with a means of ensuring that decisions made were in line with accepted practice (Hansen 2009b). In this respect, the protocol was understood as a 'safety check', providing reassurance concerning the correctness of weaning management. Similar to experienced nurses, experienced physicians confirmed a preference for weaning decision-making based on personal expertise and insight (Blackwood 2004; Hansen 2009a; Myneni 2012). Moreover, they understood experienced nurses as more likely to 'commit' to weaning, compared to their more inexperienced counterparts (Hansen 2009a). Physicians also expressed a clear preference for engaging in collaborative weaning with experienced nurses (Blackwood 2004; Hansen 2009a). Physicians differed in their understanding of protocolized nurse-led weaning. Whilst some suggested that only experienced nurses could be relied upon to use the protocol appropriately as less experienced nurses would be likely to adhere uncritically to its guidelines (Blackwood 2004; Hansen 2009a), others considered that a combination of training and explicit instructions enshrined in a protocol could underpin enhanced involvement of relatively junior staff (Blackwood 2004).

The fact that the use of protocols increased the involvement of nursing as well as junior medical staff was understood by participants (both nurses and junior physicians) as important to the development of a necessary confidence and competence to wean (Keogh 2009; Kydonaki 2011). Their use afforded nurses and junior medical staff an opportunity to improve as clinicians, including in relation to weaning, and to understand themselves as having improved. This process was two-fold. First, in terms of competence as the protocol encouraged and enabled them to make decisions and take action (Hansen 2007; Keogh 2009). Second, over time, as they practised in this way, confidence in their effectiveness as autonomous practitioners increased (Keogh 2009; McLean 2006). For these reasons, a protocol was talked about as motivating staff in their clinical practice (Hansen 2007).

\section{The vulnerability of weaning protocols to differential (inter) professional working}

Amongst physician participants, weaning was understood in two main ways. First, to involve (patho)physiological indicators that are readily observed, measured and understood (Blackwood 2004). This aspect of weaning was considered to lend itself to the involvement of nursing staff; in such cases, a protocol acted as a tool for nurse decision-making, particularly in the context of straightforward or 'routine' patient weaning (Blackwood 2004). Second, to involve more subtle (patho)physiological and other indicators that could only be observed or understood, or both, on the basis of enhanced clinical insight and expertise (Blackwood 2004). In that these indicators either presented ambiguous information or were only 'visible' to expert/more experienced clinicians, this aspect of weaning was considered by physicians to militate against the involvement of nursing, particularly junior staff (Blackwood 2004; Hansen 2009a).
This understanding of weaning was associated with inconsistency in weaning practice, including in relation to the use of protocols (McLean 2006). Physicians could actively pursue nursing involvement through discussion and joint decision-making. This approach was most likely to be adopted with nurses considered to have sufficient experience and consequent skills to be trusted to undertake clinically appropriate weaning (Blackwood 2004; Hansen 2009a). Here, the protocol was understood to act as a reference point and basis of collaboration (Blackwood 2004; Gelsthorpe 2004). Second, physicians could assume responsibility for weaning, either performing tasks in the absence of any communication with nursing or other clinical staff or simply directing the latter in terms of how to proceed with weaning, sometimes totally ignoring the protocol in the process (Hansen 2007; Hansen 2009a; Kydonaki 2011; Myneni 2012). At times, limited autonomy, in terms of how instructions could be executed, was available to nurses, particularly in relation to patients presenting as clinically unproblematic (Blackwood 2004; Hansen 2009a). However, even in terms of this reduced role, the potential for less experienced nurses to lack sufficient confidence to independently execute instructions, even those set out unambiguously in the form of a protocol, was identified (Blackwood 2004; Hansen 2009a).

Nurse participants were similarly aware of inconsistency in the use of protocols (McLean 2006). In relation to physicians, they variously described a protocol as being implemented "by chance", only through physician choice (so that it could be totally overlooked), or when explicitly prompted by nurses (Hansen 2007; Hansen 2009b; Vaerland 2011). At times, a fundamental lack of interest in weaning was attributed to some physician as well as nursing staff (Hansen 2007). Alternatively nurses acknowledged that, due to the labour-intensive nature of weaning or the stress it placed on patients, or both, they could also choose not to wean, focusing instead on other clinical duties (Hansen 2007). Some physicians were understood to encourage an interprofessional approach to weaning; others denied nurses a role by assuming either sole or main responsibility for relevant decision-making (Hansen 2007; Hansen 2009b). Irrespective, the degree of nurse involvement in weaning was understood to be effectively determined by physicians (Hansen 2007; Kydonaki 2011). At least in part, inconsistency in interprofessional collaboration was understood as stemming from inequalities in professional status. In this context, participants could see themselves as extremely limited in their ability to effectively challenge physician decision-making, such was the disparity in respective professional status (Hansen 2007).

The fact that physicians could deviate from a protocol's instructions or simply ignore its existence was considered by nurses to frustrate effective weaning in that it prevented them from undertaking relevant activity (Hansen 2007). This situation was viewed as particularly unfortunate, as it meant that the detailed patient knowledge possessed by a nurse, a sound basis for appropriate weaning activities, was wasted (Hansen 2007). Nurse participants upheld the value of the particular contribution made by nurses to the weaning process. It was the immediacy (both temporal and physical) with which they could observe and respond to individual patients that was considered to set them apart from other clinical staff (Lavelle 2011).

The lack of consistency in physicians' approach to nurse involvement was perceived to breed uncertainty about how to proceed with weaning, including in relation to the use of a protocol 
(Hansen 2007). Consequently, individual nurses adopted different strategies in an attempt to ensure that their role in weaning adhered to personal preference, as well as felt knowledge and competence, leading to inevitable variation in weaning practice. More experienced and confident nurses could take deliberate steps to involve themselves, particularly in situations where they assessed a patient as ready for weaning, beyond that being pursued by the physician (Hansen 2007). Even here, they could be frustrated as their recommendations could be ignored or overruled. Typically, less confident nurses allowed the physician to dictate the weaning process and their role in it (Hansen 2007).

Physician reluctance to allow nurses a meaningful role in weaning was associated with an individualization of nursing competence (Hansen 2009b). The removal of such individualization was understood to be crucial to enabling nurses to assume an effective role in weaning (Hansen 2007; Hansen 2009b). Such was the perceived importance of meaningful interprofessional collaboration that it could outrank other factors. Thus, for example, although lack of time was understood to significantly militate against weaning, even when such time was available, lack of interprofessional working further impacted negatively on the weaning process (Hansen 2009b). Not only could nurse participants discern the practical value (that is, impact on weaning outcomes) of interprofessional collaboration (Gelsthorpe 2004; Hansen 2007), but were also aware of how such collaboration could contribute to an improvement in personal professional development in terms of improving their ability to convey to others (namely, physicians) their clinical expertise (Hansen 2009b).

\section{Understanding of protocols as militating against a necessary proactivity in clinical practice}

Even when physician participants understood protocols as a valuable means of facilitating the weaning process, they identified an important proviso, namely their limitations in relation to complex patients (Blackwood 2004; Hansen 2009a; Hansen 2009b; Kydonaki 2011). Typically, these patients had significant comorbidity or were otherwise physiologically vulnerable, such that they could be on long-term ventilation. The severity of their condition was understood to necessitate a high degree of physician control of the weaning process (Blackwood 2004; Kydonaki 2011). Other relatively straightforward patients required less physician involvement and so lent themselves to nurse-led weaning using a protocol (Blackwood 2004). Other physicians were more dismissive of the value of protocols. Effective practice was understood by them as premised strictly on clinical judgement and autonomy in decision-making; a protocol could encourage abdication of such responsibility as, once implemented, others could be left to oversee the process (Hansen 2009a).

Relatedly, the protocol could be understood by physician participants as overly generalized and rigid, representing a 'cookbook' approach (Blackwood 2004; Hansen 2009a), and thus unable to deal with an inevitably heterogeneous patient population (McLean 2006). A similar lack of protocol sensitivity was identified in relation to specific phases of weaning, particularly extubation, something exacerbated in clinically complex cases (Myneni 2012). In this regard, protocols were considered redundant in that they could not accommodate decision-making 'at the margins' (Myneni 2012). Moreover, protocols were considered to have the potential to induce clinical apathy, in that clinicians could adhere to their instructions in the absence of a necessary considered decisionmaking process.

Participants, most notably experienced physicians and nurses, prioritized clinical experience as an important arbiter of the appropriate use of a protocol (Blackwood 2004; Gelsthorpe 2004). Experience was thought to equip clinicians with a necessary clinical insight and expertise such that they would be able both to identify the need for, as well as clinically execute, a deviation from a protocol's instructions (Blackwood 2004; Hansen 2009b). Lack of experience and concomitant potential for inappropriate adherence to a protocol, leading to inappropriate or even harmful weaning, was associated particularly with junior nursing and medical staff (Blackwood 2004; Hansen 2009a).

Nurse participants frequently prioritized individualized care as fundamental to effective weaning. This requirement was often seen as militating against the use of protocols, which were understood as overly rigid in the context of a clinically complex process during which different information must to be taken into account (Lavelle 2011; McLean 2006; Vaerland 2011). Some nurse participants contrasted a cautious approach typically adopted by nurses (based on their knowledge of the patient as an individual) with a more aggressive approach of physicians, based at times on their perceived focus on generic (patho)physiological criteria contained in the protocol (Gelsthorpe 2004). Furthermore, protocols could be considered as entirely unnecessary in relation to the weaning of 'straightforward' patients. Not only were these patients 'easy' to wean, but also participants saw themselves as entirely competent to do so on the basis of personal knowledge and expertise (Lavelle 2011).

\section{Perceived nursing scope of practice and professional risk}

Nurse participants described an essentially 'risk averse' approach to clinical activity, including weaning (Gelsthorpe 2004). As such, they routinely sought and closely adhered to explicit instruction. Typically, this instruction was provided by medical, sometimes senior nursing colleagues, with participants considering themselves to be essentially absolved of responsibility so long as a physician had sanctioned the relevant action(s) (Gelsthorpe 2004). To a more limited extent, the same 'cover' could be associated with a weaning protocol, in so far as it too set out explicit instruction to which a nurse was expected to adhere (Hansen 2007; Kydonaki 2011). Differences in the degree to which nurses involved themselves in weaning could be closely related to the degree of risk such involvement was perceived to entail. In one particular setting, nurses understood themselves as totally lacking any legal or professional cover on the grounds that no formal documentation existed, either in the form of a protocol or documented weaning plan. Consequently, they avoided making any independent weaning decisions (Kydonaki 2011). In another setting, nurses operated with explicitly-documented instructions set out in a protocol. Consequently, they felt relatively confident in taking weaning-related decisions using these instructions. That said, when the instructions provided by physicians were perceived to be ambiguous in nature, requiring a significant degree of interpretation, only the more experienced or senior nursing staff took any significant involvement in weaning (Kydonaki 2011).

\section{ICU structure and processes of care}


The use of a protocol for weaning was considered to be closely related to pre-existing ICU organization and routines of care. Physician working hours and arrangements were discussed by both nurse and physician participants as regularly interrupting the weaning process (Hansen 2009a). The fact that lead clinicians worked on a nine-to-five basis, excluding weekends, was regarded as limiting the opportunities for necessary interprofessional communication and decision-making. Physicians could be absent from the ICU even when on duty, yet again frustrating necessary communication and diminishing the continuity and timeliness of weaning (Hansen 2007; Hansen 2009a). Some physician participants drew attention to their increased dependency on nursing staff to undertake weaning during their absence. In such circumstances the use of a protocol was deemed inappropriate; rather, the expertise of particular nurses was relied upon (Hansen 2009a). In one setting, it was the non-participation of respiratory therapists in the morning ward round that was understood to contribute to suboptimal interprofessional communication concerning weaning, including in relation to the use of the protocol (Myneni 2012).

Participants perceived the rotation of nurses amongst patients as restricting the opportunities available for the development of in-depth patient-specific knowledge (Hansen 2007; Hansen 2009b). Such knowledge was typically considered to underpin effective weaning, as it facilitated a comprehensive insight into the ongoing physiological status and associated requirements of patients (Hansen 2009b). More fundamentally, lack of continuity could be understood to impede the development of a sense of responsibility to patients, with a consequent reduction in felt impetus to proactively wean (Hansen 2009b). In those settings in which continuity in nurse-patient allocation was preferred, participants highlighted staff shortages as routinely preventing such a system (Hansen 2009b). Some nurse participants described a lack of urgency to wean amongst physician colleagues, with other more immediate clinical issues thought to take priority (Hansen 2007). For some nurses, their awareness of lack of proactivity on the part of physicians increased felt responsibility to initiate weaning and consequent frustration when physicians continued to thwart their efforts (Hansen 2007). Furthermore, weaning was at times acknowledged by nurses to slip down their own clinical agenda as other issues, typically associated with the care of acutely-ill or deteriorating patients, or both,were prioritized (Hansen 2007).

The fact that weaning was a demanding, time-consuming activity made it vulnerable to being discontinued or even 'avoided', particularly at times of pressure on resources (Hansen 2007; Hansen 2009a; Hansen 2009b; Myneni 2012). Participants could be already overburdened with core clinical duties, all associated with the provision of essential and often time-consuming care (Hansen 2009b). In one setting, observations confirmed the detrimental impact of inadequate resources when delays in the provision of weaning-related information occurred because of ICU 'crowding' and the need to concentrate attention on an acutely-deteriorating patient (Myneni 2012).

Several other organizational routines were discussed as adversely impacting on the weaning process. Some participants talked about a preference for weaning to be undertaken in the mornings, based on a felt 'proactivity' (Gelsthorpe 2004), as well as greater physician presence (and thus opportunities to discuss and plan patient weaning) at this time of the day (Blackwood 2004; Gelsthorpe
2004). Furthermore, open patient visiting, meaning that visitors were present in a unit throughout the working day, was talked about as potentially disruptive to the weaning process (Hansen 2009b).

Participants highlighted a lack of time for important informal (for example, ad hoc 'bedside learning') as well as formal opportunities (for example, ward rounds) for interprofessional discussion as these contributed to weaning-related professional knowledge and skills, as well as multidisciplinary collaboration (Hansen 2009b; Myneni 2012). In this context, they identified one organizational routine as facilitating protocolized weaning, namely, ICU ward rounds. These were seen as providing excellent opportunities for interprofessional discussion and decision-making. This regular or routine interaction was understood to help facilitate a shared or team approach to weaning, including in relation to the use of a protocol (Gelsthorpe 2004).

Finally, some physician participants highlighted how current weaning practice served to make the introduction of a protocol redundant. As staff were already encouraged to titrate respiratory support frequently to individual patient's needs, they considered that a protocol would have little or no effect in making the weaning process more timely (Blackwood 2004).

\section{Protocols as a prompt for shared care, consensus and consistency in weaning}

Both nurse and physician participants associated a number of positive attributes with the use of protocols, all of which were understood to increase the timeliness, consistency and ultimately effectiveness of weaning. Accordingly, protocols were considered to raise the profile of weaning generally (Hansen 2009a; Hansen 2009b; Vaerland 2011). In their absence, weaning was understood as vulnerable to being overlooked, as staff concentrated on other essential aspects of patient care. Furthermore, protocols were understood to facilitate both intra- and interprofessional discussion and collaboration (Hansen 2007; Hansen 2009a; Hansen 2009b; Keogh 2009; Kydonaki 2011; McLean 2006; Vaerland 2011), to provide explicit instruction concerning the weaning process according to known and agreed criteria (Keogh 2009), and to provide a formalized framework for decision-making within which nurses had clear instructions as well as authority to act, including in the absence of physicians (Hansen 2007; Hansen 2009a; Keogh 2009). In addition, some participants understood a protocol to enhance consistency and continuity of care, as all staff were encouraged and facilitated to follow a systematic weaning process (Hansen 2007; Hansen 2009a; Hansen 2009b; Kydonaki 2011). In this context, some physicians identified a need for an extension of nursing weaning responsibility, seeing a protocol as a means of formalizing this process (Hansen 2009b).

\section{Maximizing the use of protocols through visibility, relevance and ease of implementation}

Nurse and physician participants discussed a range of features, either inherent to a protocol itself or to the process by which it was implemented, as likely to enhance its use or effectiveness or both. First, they emphasized the need for it to be easily understood, providing a straightforward framework for decision-making (Keogh 2009; McLean 2006). It was the simplicity of the protocol, enshrining explicit criteria within an equally explicit process of care, that was considered particularly important in promoting its use. In 
one setting, observations confirmed the detrimental impact of a complicated protocol when repeated misinterpretation occurred, leading to significant delays in the weaning process (Myneni 2012). Second, participants highlighted the need for a protocol to be consistently visible and easily accessible, to encourage and facilitate its use; examples of such accessibility included permanent, prominent display at different locations in the ICU (McLean 2006). The detrimental impact of a lack of ongoing protocol 'revalidation' or emphasis was further suggested by nurse participants who talked about an initial enthusiasm for and adherence to the use of a protocol as diminishing over time (McLean 2006).

\section{Protocols as a framework for communication with parents}

Nurse participants could describe protocols as a useful tool for improving communication between themselves and parents. In particular, it provided a framework to which they could refer when explaining or clarifying the weaning process (Keogh 2009).

\section{Synthesis of the qualitative evidence and the effectiveness reviews}

We condensed the findings from the synthesis of qualitative evidence into a series of summary statements, presented in Table 3. So that a direct line may be traced from the thematic synthesis to the summary statements, each is listed under the analytical theme from which it has been derived.

\section{Confidence in the summary of finding statements derived from the synthesis}

We assessed most statements of findings ( $n=17$ ) as 'low' confidence. In such cases, the overriding factor was a lack of coherence. We rated 13 statements as 'moderate' confidence; typically, these were derived from studies assessed as 'moderate' or 'high' quality and conducted across different settings. In relation to the five statements graded as 'high' confidence, the primary factor was the observed high levels of coherence.

\section{Sensitivity analysis}

Our quality appraisal process identified three studies as 'low quality' (Keogh 2009; McLean 2006; Myneni 2012) (Appendix 9). It is important to note that these assessments are comparative (relative to the other studies included in the qualitative synthesis) and specific to the objectives of this review. Appendix 10 presents the results of our two-stage sensitivity analysis, showing the impact on our confidence in the relevant statements when the evidence derived from the three low-quality studies (Keogh 2009; McLean 2006; Myneni 2012) is no longer available for synthesis. Eight summary statements were impacted by the removal of evidence derived from low-quality studies. In the case of five statements, the impact was restricted to a change in designated confidence. Assessed confidence dropped, in all cases from 'moderate' to 'low', because the finding was no longer seen across multiple contexts and thus its coherence decreased. However, despite the drop in assigned confidence, the statements remained valid in terms of evidence that could be used in the development of our lines of logic. In the case of the remaining three statements, namely:

- Protocols should have clarity in their design and instruction, and be straightforward to use
- Protocols should be readily accessible/visible within an ICU at all times

- Nurses understand a protocol to be a useful communication tool, providing a framework through which they can explain and otherwise communicate with parents about the process of weaning their child from ventilation,

the impact was much greater, in that the relevant evidence was derived only from studies designated as of low quality. Consequently, the statements were lost as evidence for use in the development of our lines of logic. Given the uncertainty characterizing the validity of the statements, future research could usefully be undertaken that focuses on their content as a means of strengthening the evidence base.

Only one of the included studies (Keogh 2009) was conducted in a paediatric ICU. Appendix 11 presents the results of our two-stage sensitivity analysis, showing the impact on the relevant summary statements when the evidence derived from the Keogh 2009 study is no longer available for synthesis. Two summary statements were impacted by the removal of evidence derived from the paediatric ICU study (Keogh 2009). In the case of one statement, the impact was restricted to a change in designated confidence. Assessed confidence dropped, from 'moderate' to 'low'. Consequently, the statement remained valid in terms of evidence that could be used in the development of our lines of logic. In the case of the remaining statement, namely:

- Nurses understand a protocol to be a useful communication tool, providing a framework through which they can explain and otherwise communicate with parents about the process of weaning their child from ventilation

the impact was much greater, in that the relevant evidence was derived only from the paediatric study. Consequently, this statement was lost as evidence for use in the development of our lines of logic.

Two of the studies (Blackwood 2004; Hansen 2009b) explored ICU staff views on the use of a protocol in the absence of any direct experience of protocol use. Appendix 12 presents the results of our two-stage sensitivity analysis, showing the impact on the relevant summary statements when the evidence from the Blackwood 2004 and Hansen 2009b studies was no longer available for synthesis. Six summary statements were impacted by the removal of evidence derived from the Blackwood 2004 and Hansen 2009b studies. In the case of two statements, the impact was restricted to a change in designated confidence. Assessed confidence dropped from 'moderate' to 'low'. Consequently, the statement remained valid in terms of evidence that could be used in the development of our lines of logic. In the case of four statements, namely:

- Due to perceived limitations in clinical knowledge and expertise, physicians consider nursing staff as most suitable for a support role in weaning, in which they operate with limited autonomy only

- Physicians are wary of involving any but the most experienced nurses in weaning because it requires advanced clinical insight and judgement

- Nurses associate physician reluctance to involve nurses in weaning decision-making with an individualization of nursing competence 
- Physicians consider that a protocol will have little or no material impact on weaning because the ICU practice already encourages clinicians to wean proactively,

the impact was much greater in that the relevant evidence was derived only from one of these two studies. Consequently, these statements were lost as evidence for use in the development of our lines of logic.

\section{The logic model}

Using the summary statements, we developed our logic model. This process involved:

1. identifying selected components, that is, features of the context of implementation;

2. linking these components with the same designated outcome, namely, use of protocol;

3. developing lines of reasoning that made explicit the nature of the links between the components and the use of a protocol through the identification of barriers and facilitators, moderators and intermediate outcomes.

Integrating the logic model with the findings of the trials included in the effectiveness review to explore heterogeneity of effect

We used the logic model to integrate the findings of the qualitative synthesis with the contextual evidence concerning the effect of the trials included in the effectiveness reviews. In order to do so, we undertook the following process:

1. identified whether a trial intervention was effective or not in terms of the primary and secondary outcomes;

2. extracted the statements made by trial authors (typically included in the Discussion section) that addressed, directly and indirectly, the barriers and facilitators of effectiveness;

3. developed hypotheses on the basis of these statements (see Table 4);

4. mapped these hypotheses onto the logic model by identifying correspondence between them and the barriers and facilitators, moderators and intermediate outcomes associated, directly and indirectly, with the use of a protocol identified by our synthesis of the qualitative evidence.

Through this process, we identified the degree to which the model accommodated the trial hypotheses concerning the use of a protocol; that is, we determined the degree to which the logic model could be considered a useful framework for understanding the outcomes of the trials in terms of protocol use. During this exercise, we were, of course, dependent on the degree to which the authors reported relevant contextual data. The logic model, with the trial-generated hypotheses embedded in relevant summary statements (by label), is presented in Figure 2; Figure 3; Figure 4; Figure 5.

Figure 2. Logic model, with trial authors absent (1)

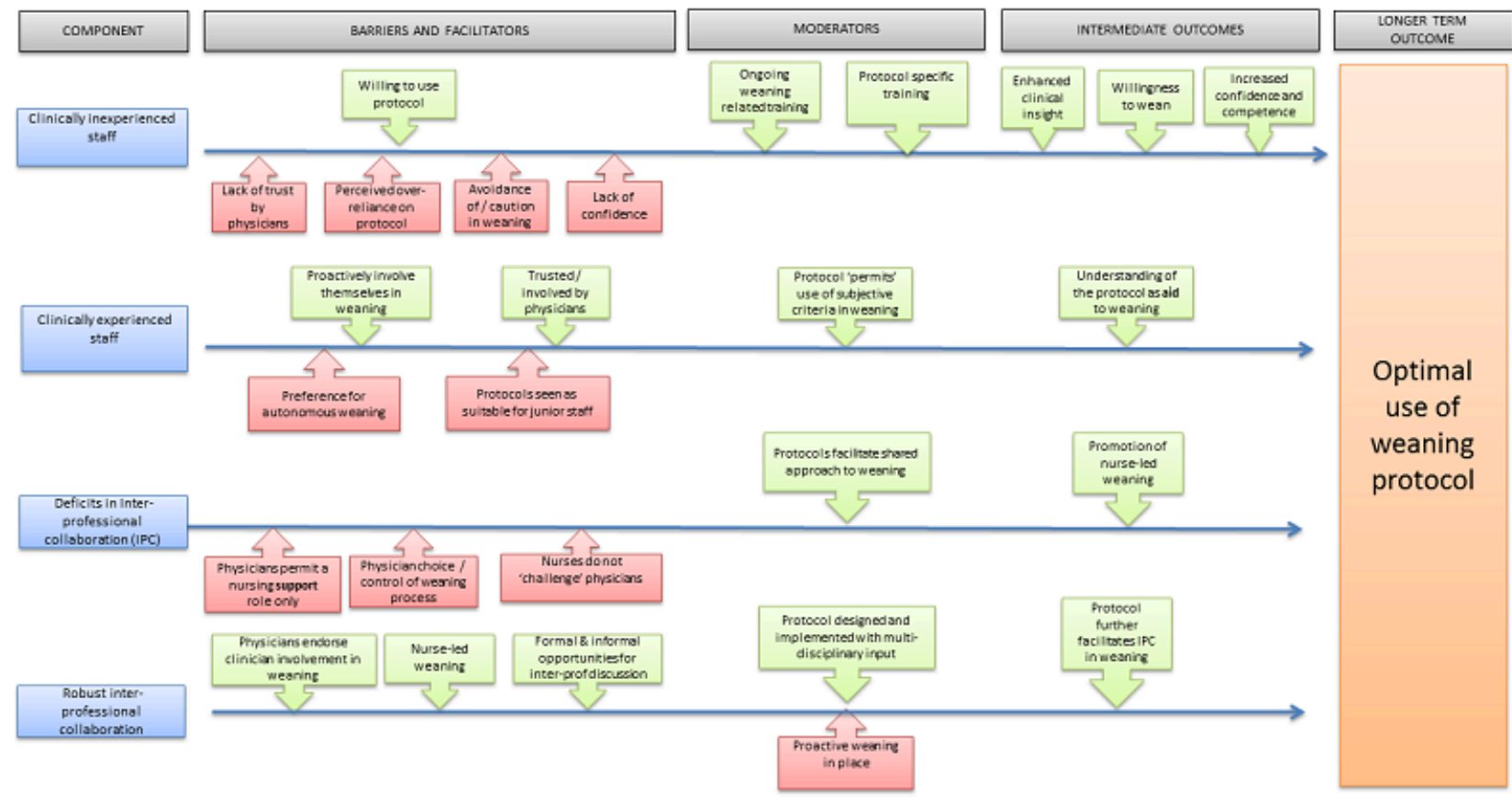

Factors that impact on the use of mechanical ventilation weaning protocols in critically ill adults and children: a qualitative evidence- 
Figure 3. Logic model, with trial authors absent (2)

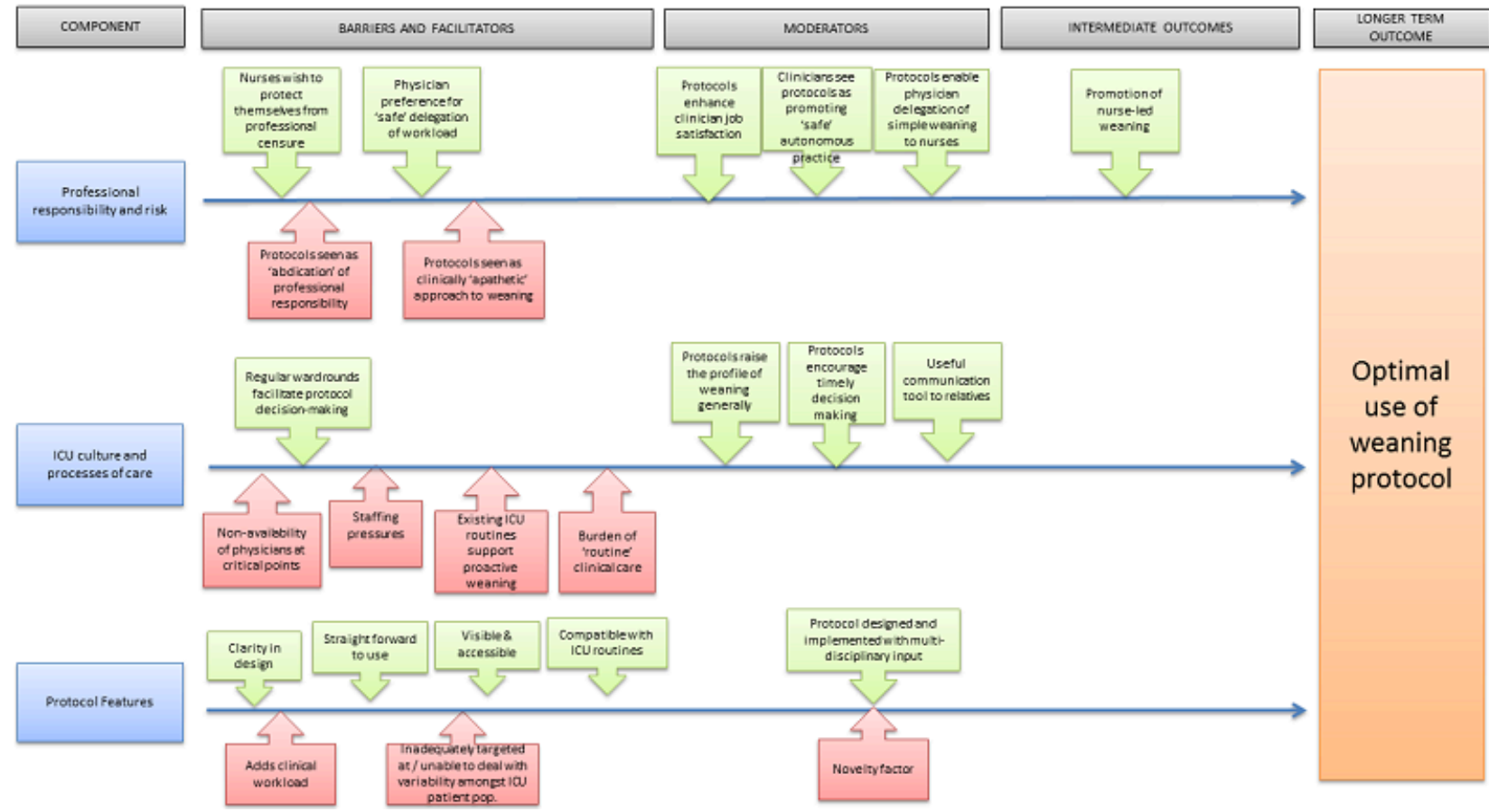

Figure 4. Logic model, with trial authors included (1)

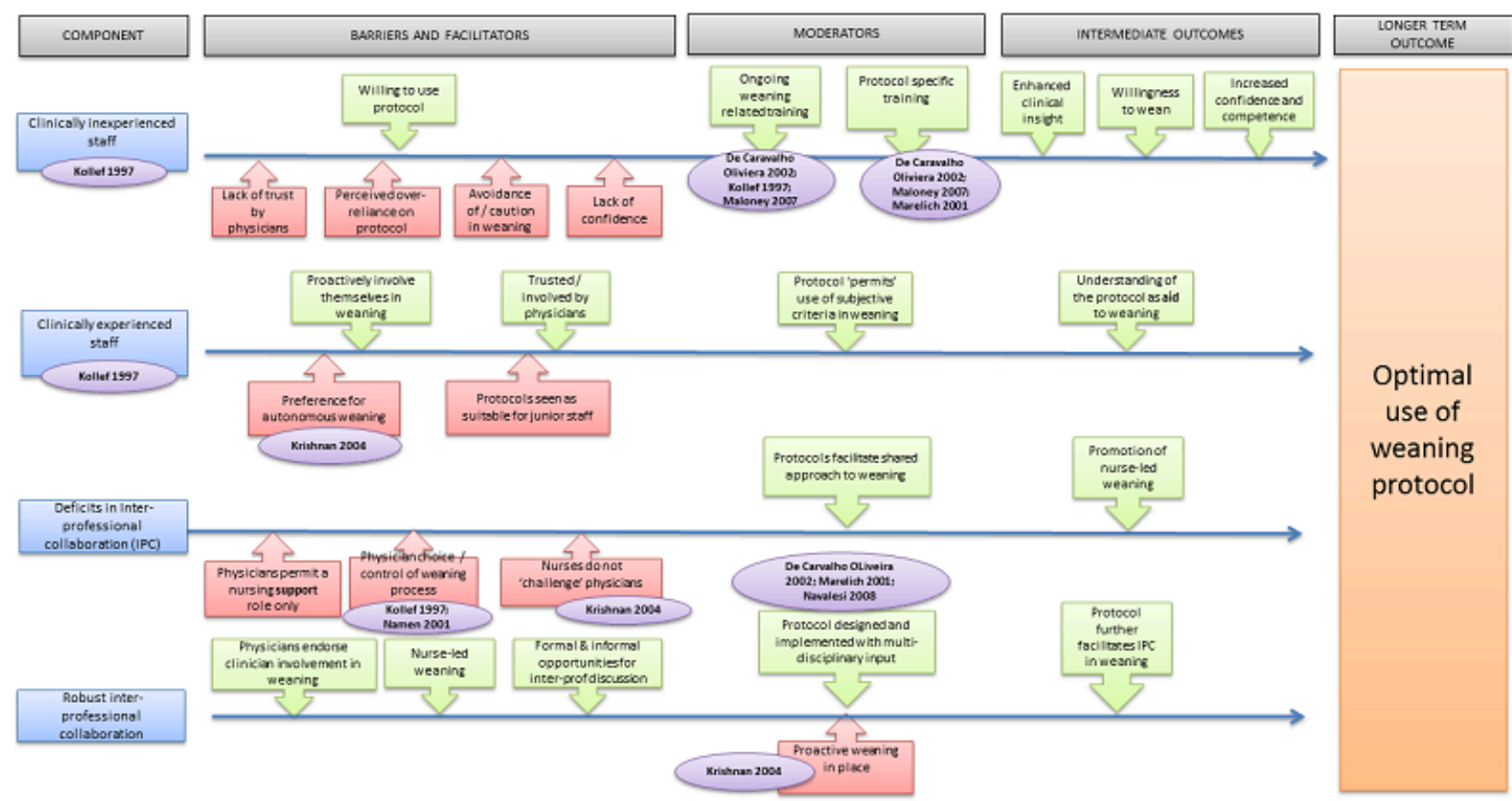


Figure 5. Logic model, with trial authors included (2)

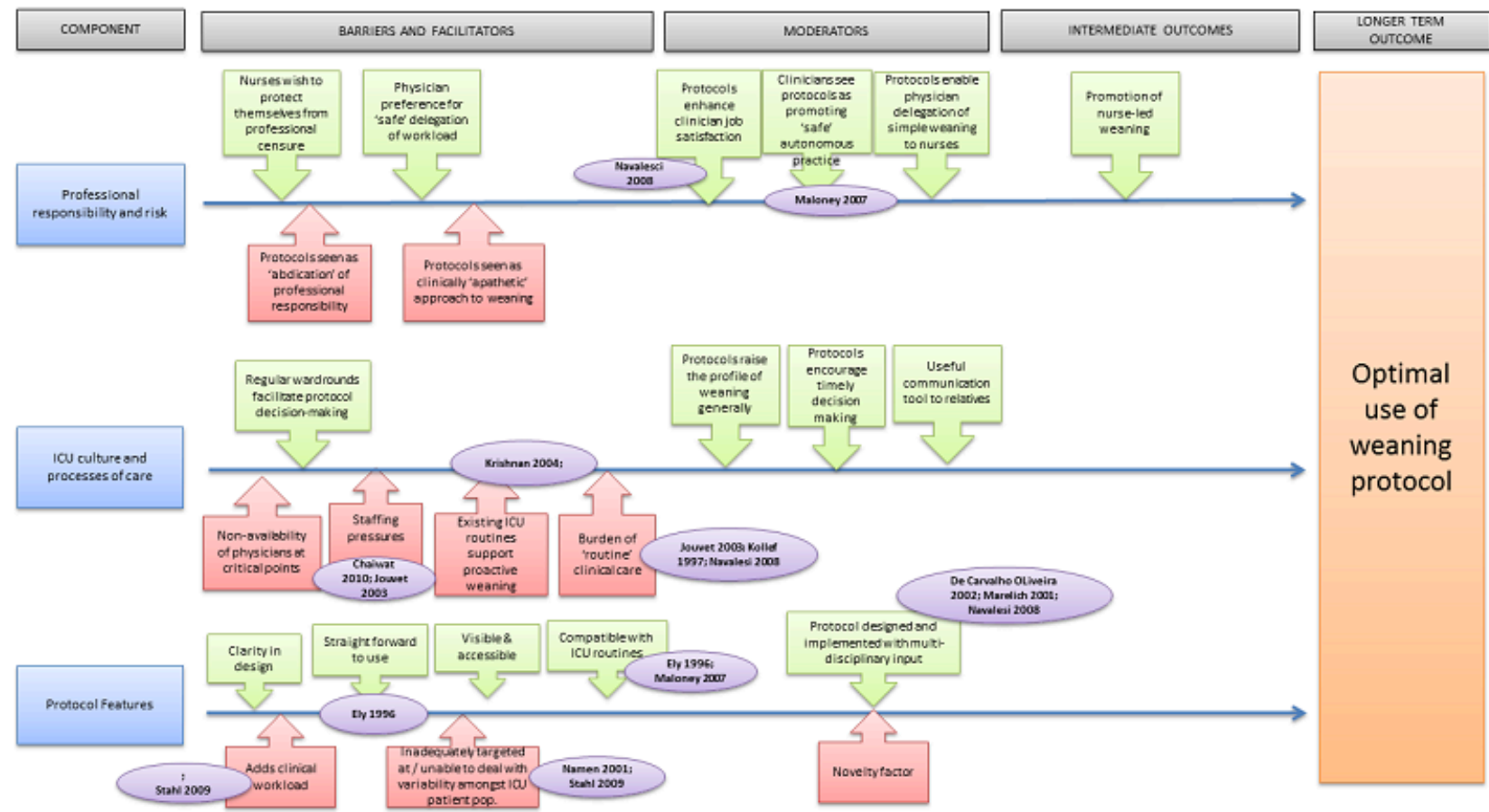

As can be seen from Figures 2 to 5, of the 23 hypotheses that dealt with the use of a protocol proposed by trial authors, 22 were identified in the logic model. Predictably, the trial-author hypotheses were minimally elaborated, and remained specific to the particularities of the circumstances and outcomes of the trials. The added value of the logic model is confirmed by the fact that the trial authors did not report a range of contextual issues that the qualitative evidence synthesis demonstrated to be of central importance to whether and how a protocol is used. Issues related to 'clinical (in)experience' and 'nursing scope of practice' were particularly marked by their absence.

Only one hypothesis was not directly identified within the logic model; it was, however, addressed indirectly. Thus, the hypothesis: 'Pre-existing acknowledgement of the need for standardization of weaning increases acceptance of a protocol' (Maloney 2007), was reflected in the qualitative synthesis evidence that confirmed the importance of the values and preferences of understandings of ICU staff as these impacted on the use of a protocol. Taken overall, the fact that the contextual data available from the trial papers mapped so readily onto the logic model suggests its usefulness as a framework for gaining insight into the factors that impacted, positively and negatively, on protocol use within the trials included in the effectiveness reviews.

Using the logic model to propose core features of the context and content of weaning protocols likely to promote their use

Using the logic model it is possible to complete an original objective of this review, namely, to suggest the contextual factors likely to promote the use of protocols (that is, the facilitators of a protocol). These are as follows:

In terms of context, the factors are:

- All clinical staff receive ongoing weaning-related training
- Routine involvement of all nursing staff in weaning

- Use of a protocol is wholesale, involving all ICU staff

- Nurses' use of a protocol/involvement in weaning is interprofessionally endorsed/mandated

- In so far as is possible, implementation of a protocol is facilitated by (changes to) relevant ICU routine

- Interprofessional collaboration is promoted and facilitated as inherent to ICU clinical practice

- Protocols capitalize on existing proactivity in weaning

In terms of protocol content, the factors are:

- The protocol is designed and implemented with interprofessional input

- All ICU healthcare staff receive protocol-specific training

- Protocols are targeted at the clinical profile and needs of the ICU patient population

- Protocols are flexible and enable some degree of clinical autonomy

- Protocols set out straightforward, unambiguous instruction

- Protocols are highly visible and easily accessed

\section{DISCUSSION}

\section{Summary of main results}

Our synthesis identified a number of potential factors (barriers and facilitators) and the processes through which they might influence the use of protocols. First, factors related to the understandings of healthcare professionals; the decision to use a protocol was influenced by their personal values and priorities, as well as the body of supporting clinical knowledge they possessed. Fundamentally, ICU staff could choose whether and how they used a protocol based on these understandings, something that

Factors that impact on the use of mechanical ventilation weaning protocols in critically ill adults and children: a qualitative evidence- 
inevitably introduced inconsistency in weaning practice. Second, the practical arrangements for care operating within an ICU. To an extent, it was how these arrangements supported or impeded a collaborative approach to weaning that determined whether and how well a protocol was used. Resource constraints were an everpresent backdrop, impacting on staffing levels and concomitant (inter)professional working practice.

Third, the use of a protocol was seen to adhere to certain core properties of (inter)professional working practice. One such was the status inequity that informed working relations between nurses and medical staff. Another was clinical experience, and the perceived competence and confidence this engendered. Accordingly, physicians were inclined to relegate use of a protocol to quite specific circumstances, with a preference for their own practice to be based on autonomous decision-making. Moreover, they tended to espouse reluctance to involve nurses they perceived as relatively inexperienced even with, or sometimes because of, the existence of a protocol. Nurses' use of a protocol was shown to be closely associated with felt confidence. In this context, the role of a protocol in providing professional 'cover' for nursing staff was highlighted. This was especially the case in relation to junior nurses. Amongst more experienced nurses, the situation was more nuanced. On the one hand, they too were aware of the protection offered by protocols; on the other hand they were equally aware of the (potentially) restrictive nature of the protocol on clinical decision-making.

\section{Overall completeness and applicability of evidence}

We were unable to locate any trial-related qualitative evidence (sibling studies) for either the Blackwood 2013 or Blackwood 2014 reviews. Such evidence would have added to an understanding of the contextual factors specific to particular trial interventions, thereby helping to further explain observed heterogeneity in the effectiveness of weaning protocols on ventilation outcomes. Although we did not have access to trial-related qualitative evidence in the context of addressing the second of our study objectives (to explain heterogeneity in the findings of the studies included in the effectiveness reviews), we were able to draw on the evidence from the unrelated qualitative studies conducted in broadly similar and mostly adult ICU contexts. This evidence is therefore of relevance when considering the factors likely to have impacted on the observed differential effectiveness. For example, protocols must be used if they are to produce an effect. Of the 46 statements made by trial authors concerning contextual factors they considered likely to have impacted on the outcomes of their trials, exactly half ( $n=23$ ) (Table 4) were concerned, directly or indirectly, with factors impacting on the use of protocols. Moreover, as has already been confirmed, all of these factors were identified by our qualitative synthesis (one indirectly).

Effectiveness of protocolized weaning is also premised on a wide range of other contextual factors. Several of these were suggested by the qualitative synthesis and by authors of the trial papers included in the effectiveness reviews. Thus, the qualitative evidence showed that when a protocol is implemented in a unit in which weaning is already proactively pursued (for example, nurse-led weaning is in place), its effectiveness is likely to be limited by the fact that key functions of the protocol (for example, to enable nurses to pursue autonomous weaning) are already being fulfilled. The same issue was highlighted by three of the trial authors. Thus, Kollef 1997 explicitly associated pre-existing physician delegation of weaning function to nursing staff with diminished protocol effectiveness. Krishnan 2004 speculated that sustained physician presence in the unit may have allowed them to assess patient's readiness to breathe unassisted on a regular basis, thereby making the protocol redundant. Additionally, the authors discussed the permanent display of a 'rounding' template as likely to have prompted staff to address ventilator issues on a regular basis, again effectively marginalizing the (added) value of the protocol. Finally, Rose 2008b suggested that the proactive, nurse-led weaning regimen already in place within the participating trial unit contributed to the lack of a significant effect of the weaning protocol.

A second such contextual factor impacting on effectiveness that was suggested by the qualitative synthesis and by authors of the trial papers concerns autonomy of clinical practice. The qualitative evidence confirmed a strong preference for autonomous practice amongst experienced nursing and medical staff alike. Effective clinical practice was understood by them as premised on independent judgement and decision-making. An outcome of this impetus towards autonomy in practice was highlighted by several of the trial authors. Krishnan 2004 highlighted enhanced physician proactivity in the weaning of patients over whom they maintained clinical authority. Consequently, the weaning of these 'non-protocolized' patients was more timely (and thus effective) than those patients whose weaning was being directed by a protocol. Namen 2001 suggested that physician adherence to a weaning protocol was dependent on their appreciation of its suitability to the clinical profile and needs of the ICU patient population. As such, adherence can be seen to be premised on autonomous practice, whereby physicians decide on a case-bycase basis whether or not to follow the protocol's instructions.

The above examples demonstrate that established clinical practice (in this case, proactive weaning) and clinician preference (in this case, for autonomous decision-making) can impact significantly on protocol effectiveness. They illuminate the contextual factors that can contribute to a situation in which a protocol is used but its effectiveness is curtailed. The situation is further complicated by the fact that the same weaning proactivity and preference for clinical autonomy can discourage actual use of a protocol on the basis of its (perceived) irrelevance to ICU practice. In the first case, as understood by ICU staff, there is no need for a protocol, as weaning practice is already optimally proactive. In the second case, as understood by experienced ICU staff, use of a protocol adversely interferes with a necessary autonomy of clinical practice. However, a further layer of complication is added when we take into account the findings of the qualitative synthesis that amongst relatively inexperienced staff there is a preference for use of a weaning protocol, as this is understood to facilitate a degree of clinical autonomy within safe 'limits'.

The qualitative evidence we were able to include clearly pertained to different settings from those in which the trial studies were conducted. That said, the limited integration that was possible between the contextual data included in the trial studies and the qualitative synthesis suggests the latter to be pertinent to understanding the trial outcomes in terms of protocol use. We used the qualitative evidence, extracted from our logic model, to suggest certain core factors to be taken into consideration in the planning, design, implementation and use of any protocol. In line with our original research question, we took a pragmatic decision to frame 
these factors positively, that is, in ways likely to promote the use of a protocol.

The majority of the included studies $(n=10)$ (Blackwood 2004; Gelsthorpe 2004; Hansen 2007; Hansen 2009a; Hansen 2009b; Kydonaki 2011; Lavelle 2011; McLean 2006; Myneni 2012; Vaerland 2011) were undertaken in an adult ICU setting. Only one study (Keogh 2009) investigated the use of a weaning protocol in a paediatric ICU setting. All of the studies focused on the views and experiences of ICU staff, with those of other key stakeholders, for example, hospital educators and managers, being entirely absent. We were therefore unable to explore contextual factors impacting on the use of the protocol from their perspectives. This is a significant gap, as these stakeholders are likely to be involved in a range of relevant organizational systems, not least how resources are identified and allocated.

Two of the studies (Blackwood 2004; Hansen 2009b) explored ICU staff views of the use of a protocol 'in theory', as distinct from being based on actual use. Although these findings remain pertinent (they still report relevant views and experiences of ICU staff), they are limited by not being based on specific clinical practice. Studies evidenced a heavy European bias $(n=8)$ (Blackwood 2004; Gelsthorpe 2004; Hansen 2007; Hansen 2009a; Hansen 2009b; Kydonaki 2011; Lavelle 2011; Vaerland 2011), with half undertaken in Scandinavia (Hansen 2007; Hansen 2009a; Hansen 2009b; Vaerland 2011). All studies were undertaken in highincome countries. Consequently, despite our efforts to include geographically disparate studies (for example, our inclusion criteria of studies published in non-English languages), this did not happen. Notwithstanding, the evidence base of this qualitative synthesis is inclusive of a range of geographical settings.

Only one unrelated low-quality study was included from a paediatric setting (Keogh 2009) and therefore evidence relating to this specific context is incomplete and inadequate. It is, however, likely that there are some common issues between adult and paediatric contexts and we have made the judgement that it is appropriate to include adult and paediatric contextual evidence as a single data set until more qualitative evidence derived from the paediatric setting is available. When further paediatric qualitative studies are published, a high-quality comparative analysis can be undertaken in a future update of this review, and paediatric-specific implementation factors explicated.

\section{Quality of the evidence and certainty of the findings}

The majority of studies involved the use of one-to-one or group interviews. Only two studies included observation (Kydonaki 2011; Myneni 2012), which was used in combination with other methods (e.g. interviews) as part of an overall ethnographic research design. The relative lack of 'naturally occurring' data is a limitation, given the insight afforded by direct observation of social processes occurring in real time (Silverman 2015). In this case, an enhanced body of evidence based on observation would have delivered important knowledge concerning the day-to-day challenges and opportunities underpinning the use of a protocol. Instead, our evidence base relied heavily on what ICU staff said, rather than what they actually did. The two are not necessarily the same. Nowhere is this made clearer than in the contrast drawn by one of the included study authors (Kydonaki 2011) between statements made by physicians upholding the benefits of a protocol in providing consistency in weaning and subsequent observation of marked differences in relevant clinical practice. In attempting to explain the contradictory evidence (by directly quizzing ICU staff), the author identified two factors, namely perceived limitations of the protocol and physician preference for autonomous practice, both of which have been identified in our review as important factors impacting on the use of a protocol.

Findings across study settings were essentially consistent. Differences tended to be a matter of degree, rather than of kind. The same contextual factors emerged, but could be more pronounced in some settings than others. This included, for example, the degree of 'control' over weaning enjoyed by physicians or the degree of clinical circumspection evidenced by nurses. Substantive difference in findings emerged in two respects. First, between studies conducted in an adult ICU setting and that undertaken in a paediatric setting. Thus, the idea of a protocol as enhancing communication between ICU staff and patient carers emerged only in the context of communication with parents of children. Given the need for parents to be kept informed of the nature of and rationale for the care of their child, and the fact that a protocol enshrined both, it is unsurprising that it provided a ready framework for communication. Second, two findings were restricted to studies assessed as of 'low quality'. Both addressed the inherent properties of a protocol, either in terms of its content or its exposure within an ICU. Both were endorsed by the hypotheses generated from trial authors' suggestions.

As far as we were able to establish, the vast majority of contexts in which the qualitative studies were undertaken (that is, adult ICUs) operated with similar structures and processes of care. Consequently, it was appropriate for us to assess the coherence of our summary statements as, by and large, high or moderate, with a low assessment being reserved for findings derived from a small number or even single studies only. We assessed the quality of a study on a 'stand-alone' basis, without any predetermined hierarchy of study design. Certainly, Kydonaki 2011, using an ethnographic approach, was assessed as 'high quality'. However, Myneni 2012, which was also ethnographic, was assessed as 'low quality', primarily because of a sustained lack of reporting of methodological details.

\section{Agreements and disagreements with other studies and reviews}

This review followed on from earlier effectiveness reviews (Blackwood 2013; Blackwood 2014). A related scoping review (Rose 2014) sought to determine the available qualitative evidence concerning weaning from mechanical ventilation, but did not involve any systematic synthesis of this evidence.

We found no other systematic review of qualitative evidence concerning the use of protocols for weaning from mechanical ventilation. This is not surprising, given the absence of any qualitative evidence pertaining to the trials included in either of the effectiveness reviews. What is surprising is that we found no other systematic reviews of qualitative evidence concerning the use of protocols in any area of clinical practice. Moreover, we found none concerning any aspect of care delivered in an ICU setting. Hence, this review is the first to provide robust qualitative evidence concerning the implementation and use of protocols, and the first to provide such evidence concerning any aspect of care provided in the ICU.

Factors that impact on the use of mechanical ventilation weaning protocols in critically ill adults and children: a qualitative evidence- 
The benefits to be derived from qualitative research, whether as part of primary research (e.g. a process evaluation accompanying an effectiveness trial) or in terms of a systematic review, are now well established (Moore 2015; Noyes 2011; Oakley 2006). It remains to be seen if the factors that we have identified as pertinent to the use of ICU weaning protocols have more generic resonance concerning the implementation and use of other types of protocols, including in other types of settings.

\section{The use of novel methodological approaches in the synthesis}

Our review utilized both well-established as well as more innovative methods. The thematic content analysis we conducted of the qualitative data following Thomas 2008 is now routinely used. We found it to be methodologically straightforward, delivering an explicitly robust analysis. The approach we used to assess confidence in the assembled evidence (CERQual) (Glenton 2013) is more innovative and continues to evolve. We are aware that since we conducted our assessment, a new version of CERQual has been developed and is currently being used in at least one other systematic review (Whitaker 2014). Again, our experience of using CERQual is overwhelmingly positive; we found it to be an effective way of assessing confidence in the assembled evidence (as distinct from the individual studies from which this evidence is derived). Although we included all available evidence, irrespective of assessed confidence, the exercise enabled us to determine, through the sensitivity analysis, the impact of the removal of 'low-confidence' evidence on the analysis. As reported above, the impact was minimal, with only three out of 35 summary statements being lost (one of these was the single statement derived only from the paediatric study (Keogh 2009).

Our use of a logic model supported a step-by-step analytical process and also acted as a heuristic device, making explicit our conceptual thinking. The danger here is that it encouraged a reductionist approach, whereby complex phenomena became overly simplified, stripped of the very contextual nuances that we hoped to illuminate. We sought to avoid this by presenting our thematic content analysis in some detail. Only after this was set out did we 'condense' the analysis into the summary statements and then use these to develop the logic model. Throughout this process, we sought to ensure that the summary statements did not conflate different issues in ways that glossed over the inherent complexities.

A potential weakness of our model is that the unrelated qualitative evidence mainly related to a postimplementation context and retrospective recall of implementation, as well as current views and experiences of using protocols as routine practice, with two studies where protocols had not yet been implemented. The included trials Blackwood 2013 all focused on immediate implementation, with a relatively short follow-up. The model would therefore be further strengthened by the inclusion of evidence from well-conducted prospective process evaluations conducted alongside future RCTs to determine the immediate implementation factors that optimize effect and sustainability of use.

The lines of reasoning did not take into account the views and experiences of stakeholders beyond the immediate ICU context. As these stakeholders play a central role in determining the policy and practice environment (for example, in decision-making concerning the allocation of resources), the robustness of the model in accommodating a broader range of relevant contextual factors would have been improved by their inclusion.
In addition, our model sets out discrete and linear processes through which different components are linked to the same outcome. Of course, in reality, not only do these processes work together but can feed back on themselves. If process evaluations had been conducted alongside the trials included in the effectiveness reviews, it would have been possible to consider using a causal loop analysis, thereby enabling consideration of how positive and negative factors interact with each other in clinical environments. Notwithstanding these potential limitations, the very simplicity of logic models can be a strength, so long as they strive to distil and not eliminate the complexity of the processes involved (Glenton 2013). If assembled in this way, logic models can be an effective means of presenting information that can be used to think through how best to develop and implement a specific intervention or wider programme of work.

We were able to achieve a partial integration of the trial-related findings and those of the qualitative evidence synthesis. After synthesizing the qualitative evidence we 'tested' the logic model using the trial-related contextual findings. Inevitably, the value of this exercise was compromised by the partiality with which authors reported relevant information. Moreover, the entire exercise runs the risk of being seen as one of collective 'member checking' (Guba 1998). We would argue that it is more than this, as it provides an effective means of bringing together disparate evidence in the development of an overarching explanatory framework.

\section{AUTHORS' CONCLUSIONS}

\section{Implications for practice}

There is a clear need for weaning protocols to take account of the social and cultural environment in which they are to be implemented. Irrespective of its inherent strengths, a protocol will not be used if it does not accommodate the complexities of clinical practice found in the ICU environment. Our logic model presents these complexities in a way that can be used to inform protocol development and implementation with an emphasis on the adult context. In terms of development, comprehensive interprofessional input will help to ensure broad-based understanding and a sense of ownership. In terms of general implementation, all relevant ICU staff will benefit from both general weaning as well as protocol-specific training; not only will this help secure a relevant clinical knowledge base and operational understanding of the protocol, but also demonstrate to others that this knowledge and understanding is in place.

In this regard, our review suggests an under-utilization of nursing expertise. Ironically, the marginalization of junior staff from weaning (by themselves and by physicians) militated against them gaining the very experience both they and their senior colleagues prioritized. The professional and clinical reassurance provided by a protocol suggests its importance in facilitating the involvement of junior staff in weaning. Amongst more experienced nurses, the situation is more nuanced. On the one hand, they too were aware of the protection offered by protocols; on the other hand they were equally aware of the (potentially) restrictive nature of the protocol on clinical practice. This finding, alongside that of the prioritization of clinical autonomy amongst physicians, suggests protocols should be designed with the patient profile and requirements of the target ICU in mind. It also further underscores the need for protocols to be planned, designed, implemented and used with meaningful (not token) interprofessional input. 
Predictably, an under-resourced ICU will impact adversely on protocol implementation, as staff will prioritize management of acutely deteriorating and critically-ill patients. Of particular importance is nursing workload; as protocolized weaning is nurseled, nurses must have access to adequate time and clinical 'space' in which to undertake weaning-related tasks. In this context, hospital management plays a paramount role in ensuring appropriate organizational arrangements, particularly staffing levels.

\section{Implications for research}

As a complex intervention, the implementation of protocolized weaning should be accompanied by qualitative research, preferably as part of a wider process evaluation, to help explain the outcomes achieved. A vital component of this explanation will address the views and experiences of the ICU staff who are responsible for delivery. As the intervention is so heavily dependent on their actions, it is imperative that we seek to understand the consequences of delivery on them.

Future research should include the perspectives and experiences of stakeholders concerning initial implementation and occupying spaces beyond the immediate context of the ICU. This should include, for example, hospital management (clinical leads as well as managers) as well as relevant policy-makers. Collectively, they are responsible for setting important organizational parameters (e.g. staffing levels, relevant policies) within which the ICU operates, including in relation to weaning. In the absence of their perspectives, we are likely to miss important 'upstream' factors impacting on outcomes. The paediatric and neonatal contexts require particular attention, as the context and population are arguably different from adults and present different challenges.

As already highlighted, observational research will enable insight into the actions of staff - most obviously whether and how they use the protocol in their day-to-day 'real life' environment of practice. This will help counter a current over-reliance on self-report data.

In terms of this review, we can envisage three primary uses. First, the evidence can inform the future design, development and implementation of weaning protocols. Second, the evidence may be used as a 'checklist' against which ongoing implementation of weaning protocols can be reviewed. In relation to both suggestions, we are not claiming that the factors identified in our synthesis will be pertinent to all cases or even that they are exhaustive. But they do provide a useful set of criteria with which to consider the possibilities for action. Third, one way of effectively testing the validity of our findings is by trialing an intervention that specifically addresses the factors our evidence suggests as likely to impact on the use of a protocol.

\section{ACKNOWLEDGEMENTS}

We would like to thank Harald Herkner (content and statistical editor), Thordis Thomsen, Janet Harris, Sue Huckson, Marjolein de Wit (peer reviewers), Denny John (consumer referee) for their help and editorial advice during the preparation of this systematic review.

We would like to thank Harald Herkner (content and statistical editor), Karin Hannes, Thordis Thomsen, Janet Harris, Ingrid Egerod, John Kress, Marjolein de Wit (peer reviewers), and Janet Wale (consumer) for their help and editorial advice during the preparation of the protocol (Jordan 2012), for the systematic review. We would also like to thank Elizabeth Uleryk, Director Hospital Library and Archives, The Hospital for Sick Children, Toronto, for her considerable help in devising and implementing the search strategies.This review was part-funded by a Canadian Institutes of Health Research Knowledge Synthesis grant. 


\section{R E F E R E N C E S}

\section{References to studies included in this review}

Blackwood 2004 \{published data only\}

Blackwood B, Wilson-Barnett J, Trinder J. Protocolized weaning from mechanical ventilation: ICU physicians' views. Journal of Advanced Nursing 2004;48(1):26-34. [PUBMED: 15347047]

\section{Gelsthorpe 2004 \{published data only\}}

Gelsthorpe T, Crocker C. A study exploring factors which influence the decision to commence nurse-led weaning. Nursing in Critical Care 2004;9(5):213-21. [PUBMED: 15462119]

\section{Hansen 2007 \{published data only\}}

Hansen BS, Severinsson E. Intensive care nurses' perceptions of protocol-directed weaning: a qualitative study. Intensive and Critical Care Nursing 2007;23(4):196-205. [PUBMED: 17446075]

\section{Hansen 2009a \{published data only\}}

Hansen BS, Severinsson E. Physicians' perceptions of protocoldirected weaning in an intensive care unit in Norway. Nursing and Health Sciences 2009;11(1):71-6. [PUBMED: 19298312]

\section{Hansen 2009b \{published data only\}}

Hansen BS, Severinsson E. Dissemination of research-based knowledge in an intensive care unit - a qualitative study. Intensive and Critical Care Nursing 2009;25(3):147-54. [PUBMED: 19362841]

\section{Keogh 2009 \{published data only\}}

Keogh S. Staff Perceptions of Guidelines for Weaning Children from Mechanical Ventilation: A Qualitative Study [Masters Thesis]. Brisbane, Australia: Queensland University of Technology, 2009.

\section{Kydonaki 2011 \{published data only\}}

Kydonaki K. Decision Making Processes of Weaning from Mechanical Ventilation: A Comparative Ethnographic Insight into the Dynamics of the Decision Making Environment [PhD Thesis],. Edinburgh, UK: University of Edinburgh, 2011.

Lavelle 2011 \{published data only\}

Lavelle C, Dowling M. The factors which influence nurses when weaning patients from mechanical ventilation: findings from a qualitative study. Intensive and Critical Care Nursing 2011;27(5):244-52. [PUBMED: 21784639]

\section{McLean 2006 \{published data only\}}

McLean SE, Jensen LA, Schroeder DG, Gibney NRT, Skjodt NM. Improving adherence to a mechanical ventilation weaning protocol for critically ill adults: outcomes after an implementation program. American Journal of Critical Care 2006;15(3):299-309. [PUBMED: 16632772]

\section{Myneni 2012 \{published data only\}}

Myneni S, McGinnis D, Cohen T, Almoosa K, Patel B, Patel V. Effective use of clinical decision support in critical care: using risk assessment framework for evaluation of a computerized weaning protocol. Special Issue of Annals of Information Systems on Healthcare Informatics. 2012.
Vaerland 2011 \{published data only\}

Voerland IE, Kristoffersen K. Weaning from mechanical ventilation: protocol and evidence. Nordisk Sygeplejeforskning 2011;1(4):285-96.

\section{References to studies excluded from this review}

Crocker 2009a \{published data only\}

Crocker C, Scholes J. The importance of knowing the patient in weaning from mechanical ventilation. Nursing in Critical Care 2009;14(6):289-96.

Crocker 2009b \{published data only\}

Crocker C, Timmons S. The role of technology in critical care nursing. Journal of Advanced Nursing 2009;65(1):52-61.

Hancock 2006 \{published data only\}

Hancock HC, Easen PR. The decision-making processes of nurses when extubating patients following cardiac surgery: an ethnographic study. International Journal of Nursing Studies 2006;43(6):693-705.

Kydonaki 2010 \{published data only\} Kydonaki K. Observing the approaches to weaning of long term ventilated patients. Nursing in Critical Care 2010;15(2):49-56.

Kydonaki 2014 \{published data only\}

Kydonaki K, Huby G, Tocher J. Difficult to wean patients: Cultural factors and their impact on weaning decision-making. Journal of Clinical Nursing 2014;23(5-6):683-93.

Powers 2006 \{published data only\}

Powers YP. Qualitative Study on Ventilator Management [MSC dissertation]. USA: Nursing, Mountain State University, 2006.

\section{References to studies awaiting assessment}

Pettersson 2012 \{published data only\}

Pettersson S, Melaniuk-Bose M, Edell-Gustafsson U. Anaesthetists' perceptions of facilitative weaning strategies from mechanical ventilator in the intensive care unit (ICU): A qualitative interview study. Intensive and Critical Care Nursing 2012;28(3):168-75.

\section{Solberg 2015 \{published data only\}}

Solberg MT, Hansen TWR, Bjork IT. The need for predictablity in coordination of ventilator treatment of newborn infants - A qualitative study. Intensive and Critical Care Nursing 2015;31(4):205-12.

\section{Tingsvik 2014 \{published data only\}}

Tingsvik $\mathrm{C}$, Johannson $\mathrm{K}$, Martensson J. Weaning from mechanical ventilation: factors that influence intensive care nurses' decision-making.. Nursing in Critical Care 2014;20(1):16-24.

Factors that impact on the use of mechanical ventilation weaning protocols in critically ill adults and children: a qualitative evidence- 
Tume 2014 \{published data only\}

Lakin B, Scally A, Tume I. Nurse led weaning and extubation on PICU: A survey of perspective of medical staff.. Intensive Care Medicine. 2013; Vol. 39:s140-1.

Tume LN, Scally A, Carter B. Paediatric intensive care nurses' and doctors' perceptions of nurse-led protocol-directed ventilator weaning and extubation. Nursing in Critical Care 2014;19(6):292-303.

\section{Wongrostrai 2016 \{published data only\}}

Wongrostrai Y, Fongkaew W, Pinyokham N, Hanneman SK. A qualitative study of factors affecting sustainable implementation of a mechanical ventilation weaning protocols. Pacific Rim International Journal of Nursing Research 2016;20(2):132-47.

\section{Additional references}

\section{Allmark 2013}

Allmark P, Baxter S, Goyder E, Guillaume L, Crofton-Martin G. Assessing the health benefits of advice services: using research evidence and logic model methods to explore complex pathways. Health and Social Care in the Community 2013;21(1):59-68.

\section{Anderson 2011}

Anderson LM, Petticrew M, Rehfuess E, Armstrong R, Ueffing E, Baker P, et al. Using logic models to capture complexity in systematic reviews. Research Synthesis Methods 2011;21(1):33-42.

\section{Baxter 2014}

Baxter SK, Blank L, Buckley Woods H, Payne N, Rimmer M, Goyder E. Using logic model methods in systematic review synthesis: describing complex pathways in referral management interventions. BMC Medical Research Methodology 2014;14:62.

\section{Blackwood 2003}

Blackwood B. Can protocolised weaning developed in the United States transfer to the United Kingdom context: a discussion. Intensive and Critical Care Nursing Journal 2003;19(4):215-25.

\section{Blackwood 2006}

Blackwood B, Wilson-Barnett J, Patterson C, Lavery GG. An evaluation of protocolised weaning on the duration of mechanical ventilation. Anaesthesia 2006;61(11):1079-86.

\section{Blackwood 2011}

Blackwood B, Junk C, Lyons J, McAuley DF, Rose L. United Kingdom survey of mechanical ventilation and weaning role responsibilities in paediatric intensive care units. 6th World Congress, Pediatric Critical Care. 2011.

\section{Blackwood 2013}

Blackwood B, Murray M, Chisakuta A, Cardwell CR, O'Halloran P. Protocolized versus non-protocolized weaning for reducing the duration of invasive mechanical ventilation in critically ill paediatric patients. Cochrane Database of Systematic Reviews 2013, Issue 7. [DOI: 10.1002/14651858.CD009082.pub2]

\section{Blackwood 2014}

Blackwood B, Burns KEA, Cardwell CR, O'Halloran P. Protocolized versus non-protocolized weaning for reducing the duration of mechanical ventilation in critically ill adult patients. Cochrane Database of Systematic Reviews 2014, Issue 11. [DOI: 10.1002/14651858.CD006904.pub3]

\section{Boles 2007}

Boles JM, Bion J, Connors A, Herridge M, Marsh B, Merlot C, et al. Weaning from mechanical ventilation. European Respiratory Journal 2007;29(5):1033-56.

\section{Booth 2004}

Booth A. Formulating answerable questions. In: A. Booth, A. Brice editor(s). Evidence Based Practice for Information Professionals: A Handbook. London: Facet Publishing, 2004:51-70.

\section{Booth 2011}

Booth A. Searching for studies (Chapter 3). In: Noyes J, Booth A, Hannes K, Harden A, Harris J, Lewin S, Lockwood C editor(s). Supplementary Guidance for Inclusion of Qualitative Research in Cochrane Systematic Reviews of Interventions. Version 1. Cochrane Collaboration Qualitative Methods Group, 2011. [cqrmg.cochrane.org/supplemental-handbook-guidance]

\section{Brochard 1994}

Brochard L, Rauss A, Benito S, Conti G, Mancebo J, Rekik N, et al. Comparison of three methods of gradual withdrawal from ventilatory support during weaning from mechanical ventilation. American Journal of Respiratory and Critical Care Medicine 1994;150(4):896-903.

\section{Bucknall 2008}

Bucknall TK, Manias E, Presneill JJ. A randomised trial of protocol-directed sedation management for mechanical ventilation in an Australian intensive care unit. Critical Care Medicine 2008;36(5):1444-50.

\section{Burnard 1991}

Burnard PA. A method of analysing interview transcripts in qualitative research. Nurse Education Today 1991;11(6):461-6.

\section{Burns 2009}

Burns KE, Lellouche F, Loisel F, Slutsky AS, Meret A, Smith O, et al. Weaning critically ill adults from invasive mechanical ventilation: a national survey. Canadian Journal of Anaesthesia 2009;56(8):567-76.

\section{Candy 2011}

Candy B, King M, Jones L, Oliver S. Using qualitative synthesis to explore heterogeneity of complex interventions. BMC Medical Research Methodology 2011;11:124.

\section{Carson 2006}

Carson SS, Kress JP, Rodgers JE, Vinayak A, Campbell-Bright S, Levitt J, et al. A randomised trial of intermittent lorazepam 
versus propofol with daily interruption in mechanically ventilated patients. Critical Care Medicine 2006;34:1326-32.

\section{CASP 2014}

Critical Appraisal Skills Programme (CASP). CASP Qualitative Checklist. www.casp-uk.net 2014 (accessed 2nd October 2015).

\section{Chaiwat 2010}

Chaiwat O, Sarima N, Niyompanitpattana K, Komoltri C, Udomphorn Y, Kongsayreepong S. Protocol-directed vs physician-directed weaning from ventilator in intraabdominal surgical patients. Journal of Medical Association of Thailand 2010;93(8):930-6.

\section{Cohen 1991}

Cohen IL, Bari N, Strosberg MA, Weinberg PF, Wacksman RM, Millstein $\mathrm{BH}$, et al. Reduction of duration and cost of mechanical ventilation in an intensive care unit by use of a ventilatory management team. Critical Care Medicine 1991;19(10):1278-84.

\section{Dahlgren 1991}

Dahlgren L, Fallsberg O. Phenomenography as a qualitative approach in social pharmacy research. Journal of Social Administration and Pharmacy 1991;8:150-156.

\section{De Carvalho 2002}

De Carvalho Oliveira LR, Jose A, Dias EC, Dos Santos VLA, Chiavone $\mathrm{Pa}$. Weaning protocol for mechanical ventilation: effects of its use in an intensive care unit. A controlled, prospective and randomised trial. Revista Brasileira Terapia Intensiva 2002;14(1):22-32.

\section{Ely 1996}

Ely EW, Baker AM, Dunagan DP, Burke HL, Smith AC, Kelly PT, et al. Effect on the duration of mechanical ventilation of identifying patients capable of breathing spontaneously. New England Journal of Medicine 1996;335(25):1864-9.

\section{Ely 2001}

Ely EW, Meade MO, Haponik EF, Kollef MH, Cook DJ, Guyatt GH, et al. Mechanical ventilator weaning protocols driven by nonphysician health-care professionals: evidence-based clinical practice guidelines. Chest 2001;120 Suppl 6:454-63.

\section{Esteban 1995}

Esteban A, Frutos F, Tobin MJ, Alia I, Solsona JF, Valverdu I, et al. Spanish Lung Failure Collaborative Group. A comparison of four methods of weaning from mechanical ventilation. New England Journal of Medicine 1995;332(6):345-50.

\section{Esteban 2013}

Esteban A, Frutos-Vivar F, Muriel A, Ferguson ND, Peñuelas O, Abraira $\mathrm{V}$, et al. Evolution of mortality over time in patients receiving mechanical ventilation. American Journal of Respiratory and Critical Care Medicine 2013;188(2):220-30.

\section{Farias 2011}

Farias JA, Fernández A, Monteverde E, Flores JC, Baltodano A, Menchaca $A$, et al. Mechanical ventilation in pediatric intensive care units during the season for acute lower respiratory infection. A multicenter study. Pediatric Critical Care Medicine 2012;13(2):158-64

\section{Foronda 2011}

Foronda FA, Troster EJ, Farias JA, Barbas CS, Ferraro AA, Faria $L S$, et al. The impact of daily evaluation and spontaneous breathing test on the duration of pediatric mechanical ventilation: a randomized controlled trial. Critical Care Medicine 2011;11:2526-33.

\section{Glenton 2013}

Glenton C, Colvin CJ, Carslen B, Swartz A, Lewin S, Noyes J, et al. Barriers and facilitators to the implementation of lay health worker programmes to improve access to maternal and child health: qualitative evidence synthesis. Cochrane Database of Systematic Reviews 2013, Issue 10. [DOI: 10.1002/14651858.CD010414.pub2]

\section{Grap 2009}

Grap M. Not-so-trivial pursuit: mechanical ventilation risk reduction. American Journal of Critical Care 2009;18(4):299-309.

\section{Guba 1998}

Guba EG, Lincoln YS. The Landscape of Qualitative Research. Thousand Oaks, California: Sage, 1998.

\section{Guyatt 2011}

Guyatt GH, Oxman AD, Schünemann HJ, Tugwell P, Knottnerus A. GRADE guidelines: a new series of articles in the Journal of Clinical Epidemiology. Journal of Clinical Epidemiology 2011;64(4):380-2.

\section{Halpern 2010}

Halpern NA, Pastores SM. Critical care medicine in the United States 2000-2005: an analysis of bed numbers, occupancy rates, payer mix, and costs. Critical Care Medicine 2010;38(1):65-71.

\section{Horbar 1999}

Horbar JD. The Vermont Oxford Network: evidence based quality improvement for neonatology. Pediatrics 1999;103 Suppl E(1):350-9.

\section{Jouvet 2013}

Jouvet PA, Payen V, Gauvin F, Emeriaud G, Lacroix J. Weaning children from mechanical ventilation with a computer-driven protocol: a pilot trial. Intensive Care Medicine 2013;39(5):919-25.

\section{Jubran 2010}

Jubran A, Lawm G, Kelly J, Duffner LA, Gungor G, Collins EG, et al. Depressive disorders during weaning from prolonged mechanical ventilation. Intensive Care Medicine 2010;36(5):828-35.

\section{Kamdar 2015}

Kamdar BB, Niessen T, Colantuoni E, King LM, Neufeld KJ, Bienvenu OJ, et al. Delirium transitions in the medical ICU: exploring the role of sleep quality and other factors. Critical Care Medicine 2015;43(1):135-41. 


\section{Kollef 1997}

Kollef MH, Shapiro SD, Silver P, St John RE, Prentice D, Sauer S, et al. A randomized, controlled trial of protocol-directed versus physician-directed weaning from mechanical ventilation. Critical Care Medicine 1997;25(4):567-74.

\section{Krishnan 2004}

Krishnan JA, Moore D, Robeson C, Rand CS, Fessler HE. A prospective controlled trial of a protocol-based strategy to discontinue mechanical ventilation. Intensive Care Medicine 2004;169(6):673-8.

\section{Leclerc 2010}

Leclerc F, Noizet O, Botte A, Binoche A, Chaari W, Sadik A, et al. Weaning from invasive mechanical ventilation in pediatric patients (excluding premature neonates). Archives of Pediatrics 2010;17(4):399-406

\section{Lin 2008}

Lin SM, Huang CD, Liu CY, Lin HC, Wang CH, Huang PY, et al. Risk factors for the development of early-onset delirium and the subsequent clinical outcome in mechanically ventilated patients. Journal of Critical Care 2008;23(3):372-9.

\section{Lincoln 1985}

Lincoln YS, Guba EG. Naturalistic Inquiry. Newbury Park, CA: Sage Publications, 1985.

\section{Maloney 2007}

Maloney CG. Computerized Weaning of Childhood Respiratory Failure [PhD thesis] content.lib.utah.edu/cdm4/document.php? CISOROOT=/undthes\&CISOPTR=4650. University of Utah, 2007 (accessed 13th September 2016).

\section{Manczur 2000}

Manczur T, Greenough A, Rafferty GF. Weaning from mechanical ventilation in paediatric intensive care. British Journal of Intensive Care 2000;10:114-20.

\section{Marcin 2005}

Marcin JP, Rutan E, Rapetti PM, Brown JP, Rahnamayi R, Pretzlaff RK. Nurse staffing and unplanned extubation in the PICU. Pediatric Critical Care Medicine 2005;6(3):254-7.

\section{Marelich 2000}

Marelich GP, Murin S, Battistella F, Inciardi J, Vierra T, Roby M. Protocolised weaning of mechanical ventilation in medical and surgical patients by respiratory care practitioners and nurses: effect on weaning time and incidence of ventilator-associated pneumonia. Chest 2000;118(2):459-67.

\section{Mehta 2012}

Mehta S, Burry L, Cooke D, Fergusson D, Steinberg M, Granton J, et al. Daily sedation interruption in mechanically ventilated critically ill patients cared for with a sedation protocol: a randomized controlled trial. JAMA 2012;308(19):1985-92.

\section{Moore 2015}

Moore GF, Audrey S, Barker M, Bond L, Bonell C, Hardeman W, et al. Process Evaluation of Complex Interventions: UK Medical Research Council (MRC) Guidance. www.mrc.ac.uk/documents/ pdf/mrc-phsrn-process-evaluation-guidance-final/ (accessed 13th September 2016) 2015.

\section{Morris 2003}

Morris A. Treatment algorithms and protocolized care. Current Opinion in Critical Care 2003;9(3):236-40.

\section{Munro 2007}

Munro SA, Lewin SA, Smith, HJ, Engel ME, Fretheim A, Volmink J. Patient adherence to tuberculosis treatment: A systematic review of qualitative research. PLOS Medicine 2007;7(4):e238.

\section{Namen 2001}

Namen AM, Ely EW, Tatter SB, Case LD, Lucia MA, Smith A, et al. Predictors of successful extubation in neurosurgical patients. American Journal of Respiratory and Critical Care Medicine 2001;163(3; Part 1):658-64.

\section{Navalesi 2008}

Navalesi P, Frigerio P, Moretti MP, Sommariva M, Vesconi S, Baiardi $P$, et al. Rate of reintubation in mechanically ventilated neurosurgical and neurologic patients: evaluation of a systematic approach to weaning and extubation. Critical Care Medicine 2008;36(11):2986-92.

\section{Noyes 2007}

Noyes J, Popay J. Directly observed therapy and tuberculosis: how can a systematic review of qualitative research contribute to improving services? A qualitative meta-synthesis. Journal of Advanced Nursing 2007;57(3):227-43.

\section{Noyes 2011}

Noyes J, Popay J, Pearson A, Hannes K, Booth A. Qualitative research and Cochrane reviews. In: Higgins JPT, Green S, editor(s). Cochrane Handbook for Systematic Reviews of Interventions Version 5.1.0 (updated March 2011). The Cochrane Collaboration, 2011. Available at handbook.cochrane.org.

\section{Oakley 2006}

Oakley A, Strange V, Bonell C, Allen E, Stephenson J. Process evaluation in randomised controlled trials of complex interventions. BMJ 2006;332(7538):413-6.

\section{Pandharipande 2007}

Pandharipande PP, Pun BT, Herr DL, Maze M, Girard TD, Miller RR, et al. Effect of sedation with dexmedetomidine vs lorazepam on acute brain dysfunction in mechanically ventilated patients: the MENDS randomized controlled trial. JAMA 2007;12(298):2644-53.

\section{Peñeulas 2011}

Peñuelas O, Frutos-Vivar F, Fernández C, Anzueto A, Epstein SK, Apezteguía C, et al. Ventila Group. Characteristics and outcomes of ventilated patients according to time to liberation from mechanical ventilation. American Journal of Respiratory and Critical Care Medicine 2011;184(4):430-7.

\section{Popay 1998}

Popay J, Rogers A, Williams G. Rationale and standards for the systematic review of qualitative literature in health care. Qualitative Health Research 1998;8(3):341-51.

Factors that impact on the use of mechanical ventilation weaning protocols in critically ill adults and children: a qualitative evidence- 


\section{Principi 2010}

Principi T, Fraser DD, Morrison GC, Farsi SA, Carrelas JF, Maurice EA, et al. Complications of mechanical ventilation in the pediatric population. Pediatric Pulmonology 2010;46(5):452-7.

\section{RevMan 2014 [Computer program]}

The Nordic Cochrane Centre, The Cochrane Collaboration. Review Manager. Version 5.3. Copenhagen: The Nordic Cochrane Centre, The Cochrane Collaboration, 2014.

\section{Rose 2008a}

Rose L, Nelson S, Johnston L, Presneill JJ. Workforce profile, organisation, structure and role responsibility for ventilation and weaning practices in Australia and New Zealand intensive care units. Journal of Clinical Nursing 2008;17(8):1035-43.

\section{Rose 2008b}

Rose L, Presneill JJ, Johnston L, Cade JF. A randomized controlled trial of conventional weaning versus an automated system (SmartCare/PS) in mechanically ventilated critically ill patients. Intensive Care Medicine 2008;34(10):1788-95.

\section{Rose 2011a}

Rose L, Blackwood B, Egerod I, Haugdahl H, Hofhuis J, Isfort M, et al. Decisional responsibility for mechanical ventilation and weaning: an International Survey. Critical Care 2011;15(6):R295.

\section{Rose 2011b}

Rose L, Blackwood B, Burns SM, Frazier SK, Egerod I. The influence of structure and process on weaning from mechanical ventilation: international perspectives. American Journal of Critical Care Nursing 2011;20(1):e10-8.

\section{Rose 2014}

Rose L, Schultz MJ, Cardwell CR, Jouvet P, McAuley DF, Blackwood B. Automated versus non-automated weaning for reducing the duration of mechanical ventilation for critically ill adults and children. Cochrane Database of Systematic Reviews 2014, Issue 6. [DOI: 10.1002/14651858.CD009235.pub2]

\section{Sandelowski 2002}

Sandelowski M, Barroso J. Finding the findings in qualitative studies. Journal of Nursing Scholarship 2002;34(3):213-9.

\section{Santschi 2007}

Santschi M, Gauvin F, Hatzakis G, Lacroix J, Jouvet P. Acceptable respiratory limits for children during the weaning phase of mechanical ventilation. Intensive Care Medicine 2007;33(2):319-25

\section{Schumm 2010}

Schumm K, Skea Z, McKee L, Dow N. "They're doing surgery on two people": a meta-ethnography of the influences on couples' treatment decision making for prostate cancer. Health Expectations 2010;13:335-49.

\section{Shahin 2014}

Shahin J, Harrison D, Rowan KM. Is the volume of mechanically ventilated admissions to UK critical care units associated with improved outcomes?. Intensive Care Medicine 2014;40:353-60.

\section{Shaw 2004}

Shaw RL, Booth A, Sutton AJ, Miller T, Smith JA, Young B, et al. Finding qualitative research: an evaluation of search strategies. BMC Medical Research Methodology 2004;4:5.

\section{Shorr 2005}

Shorr A, Kollef M. Ventilator-associated pneumonia: insights from recent clinical trials. Chest 2005;128 Suppl 2(5):583-91.

\section{Silverman 2015}

Silverman D. Doing Qualitative Research. A Practical Handbook. 4th Edition. London: Sage, 2015.

\section{Stahl 2009}

Stahl C, Dahmen G, Ziegler A, Muhl E. Comparison of automated protocol-based versus non-protocol-based physician-directed weaning from mechanical ventilation. Intensivmedizin und Notfallmedizin 2009;46(6):441-6.

\section{Stockwell 2008}

Stockwell DC, Slonim AD. Patient safety in the PICU. In: Wheeler DS, Wang HR, Shanly TP editor(s). Science and Practice of Pediatric Critical Care Medicine. Springer, 2008.

\section{Tan 2012}

Tan SS, Bakker J, Hoogendoorn ME, Kapila A, Martiin J, Pezzi A, et al. Direct cost analysis of intensive care unit stay in four European countries: applying a standardised costing methodology. Value Health 2012;15(1):81-6.

\section{Thomas 2008}

Thomas J, Harden A. Methods for the thematic synthesis of qualitative research in systematic reviews. BMC Medical Research Methodology 2008;8:45.

\section{Whitaker 2014}

Whitaker Rh, Hendry M, Booth A, Carter B, Chrales J, Craine N, et al. Intervention Now To Eliminate Repeat Unintended Pregnancy in Teenagers (INTERUPT): a systematic review of intervention effectiveness and cost-effectiveness, qualitative and realist synthesis of implementation factors and user engagement. BMJ Open 2014;4(4):e004733.

\section{Wunsch 2013}

Wunsch H, Wagner J, Herlim M, Chong DH, Kramer AA Halpern SD. ICU occupancy and mechanical ventilator use in the United States. Critical Care Medicine 2013;41(12):2712-9.

\section{References to other published versions of this review Jordan 2012}

Jordan J, Rose L, Dainty KN, Noyes J, Clarke S, Blackwood B. Factors that impact on the use of mechanical ventilation weaning protocols in critically ill adults and children: a qualitative evidence-synthesis. Cochrane Database of Systematic Reviews 2012, Issue 5. [DOI: 10.1002/14651858.CD009851]

Factors that impact on the use of mechanical ventilation weaning protocols in critically ill adults and children: a qualitative evidence- 


\section{CHARACTERISTICS OF STUDIES}

\section{Characteristics of included studies [ordered by study ID]}

\section{Blackwood 2004}

\begin{tabular}{ll}
\hline Study type & $\begin{array}{l}\text { Qualitative research exploring the understandings and experiences of ICU physicians concerning wean- } \\
\text { ing from mechanical ventilation, with a particular focus on key issues impacting on the use of protocols } \\
\text { and involvement of nurses in the weaning process }\end{array}$ \\
\hline $\begin{array}{l}\text { Theoretical/Conceptual } \\
\text { framework }\end{array}$ & None stated \\
\hline Methods & Method of data collection: individual semi-structured interviews \\
& Method of data recording: audio-recorded \\
& Method of data analysis: thematic content \\
& Reliability: interview guide; transcribing; cross-checking \\
& Validity: respondent validation
\end{tabular}

Notes

\section{Risk of bias}

\begin{tabular}{lll}
\hline Bias & Authors' judgement & Support for judgement \\
\hline $\begin{array}{l}\text { Is there a logical fit be- } \\
\text { tween stated research }\end{array}$ & Low risk & Yes, logical fit \\
$\begin{array}{l}\text { aim(s) and method(s) } \\
\text { used? }\end{array}$ & \\
\end{tabular}

Was the recruitment strat- Low risk $\quad$ Yes, all ICU consultants invited and agreed to participate (p. 27)
egy appropriate to the

aims of the research?

Is there detailed evidence Unclear risk $\quad$ Yes, minimal detail

of steps taken in data col-

lection?

\begin{tabular}{lll}
\hline $\begin{array}{l}\text { Is there a clear and de- } \\
\text { tailed statement of find- } \\
\text { ings? }\end{array}$ & Low risk \\
\hline $\begin{array}{l}\text { Were the data au- } \\
\text { dio-recorded and tran- } \\
\text { scribed? }\end{array}$ & Low risk & Yes \\
\hline $\begin{array}{l}\text { Is there evidence of de- } \\
\text { tailed steps taken in data } \\
\text { analysis? }\end{array}$ & Low risk & Yes, minimal detail \\
\hline $\begin{array}{l}\text { Did data analysis involve } \\
\text { inter-rater discussion? }\end{array}$ & Low risk & \\
\hline $\begin{array}{l}\text { Was there consideration of } \\
\text { disconfirming findings? }\end{array}$ & Low risk & $\begin{array}{l}\text { Yes, in that emerging categories were cross-checked by BB and another author } \\
\text { (p. 28) }\end{array}$ \\
\hline
\end{tabular}

Factors that impact on the use of mechanical ventilation weaning protocols in critically ill adults and children: a qualitative evidence- 


\section{Blackwood 2004 (Continued)}

Is there evidence of a reflexive concern with the conduct of the study? (i.e. does the author reflect on his or her own role in the research, including as this might introduce bias?)
High risk No reflexive concern apparent

Is there evidence of analy- Low risk No, not relevant
sis and interpretation of
the findings at a conceptu-
al and theoretical level?

\section{Gelsthorpe 2004}

\begin{tabular}{ll} 
Study type & $\begin{array}{l}\text { Qualitative research, exploring the decision-making of nurses regarding the commencing of weaning of } \\
\text { patients from mechanical ventilation using a protocol }\end{array}$ \\
\hline $\begin{array}{l}\text { Theoretical/Conceptual } \\
\text { framework }\end{array}$ & Phenomenology \\
\hline Methods & Method of data collection: individual structured interviews, involving use of a vignette \\
& Method of data recording: tape-recorded \\
& Method of data analysis: thematic analysis \\
& Reliability: transcribing; inter-rater reliability \\
& Validity: inter-rater validation
\end{tabular}

\section{Notes}

\section{Risk of bias}

\begin{tabular}{|c|c|c|}
\hline Bias & Authors' judgement & Support for judgement \\
\hline $\begin{array}{l}\text { Is there a logical fit be- } \\
\text { tween stated research } \\
\text { aim(s) and method(s) } \\
\text { used? }\end{array}$ & High risk & $\begin{array}{l}\text { No, because the authors claim phenomenology as the theoretical framework } \\
\text { within which the study is located but this framework is not subsequently re- } \\
\text { flected in any aspect of the methodology. In addition, although a vignette is } \\
\text { employed with the stated aim of enabling participants to reflect on/make ex- } \\
\text { plicit their decision-making concerning weaning, there is no linking of the vi- } \\
\text { gnette to (the production) of findings. These findings appear to be derived } \\
\text { mainly from structured questions also asked and not the vignette itself }\end{array}$ \\
\hline $\begin{array}{l}\text { Was the recruitment strat- } \\
\text { egy appropriate to the } \\
\text { aims of the research? }\end{array}$ & Low risk & $\begin{array}{l}\text { Yes, in that the stated approach is purposive sampling. But, the authors do } \\
\text { not make sufficiently explicit the rational underpinning the selection of par- } \\
\text { ticipants. They state that the latter were selected according to their exposure } \\
\text { to nurse-led weaning and experience of ICU nursing and that } 7 \text { nurses out of } \\
\text { a total of } 55 \text { potential participants were selected, but they provide no detail } \\
\text { on how/why these } 7 \text { participants were deemed appropriate. Reporting is fur- } \\
\text { ther confused by the fact that the authors state in the section on methods, and } \\
\text { nowhere else, that this is a pilot study }\end{array}$ \\
\hline $\begin{array}{l}\text { Is there detailed evidence } \\
\text { of steps taken in data col- } \\
\text { lection? }\end{array}$ & Unclear risk & Yes, minimal detail \\
\hline
\end{tabular}

Factors that impact on the use of mechanical ventilation weaning protocols in critically ill adults and children: a qualitative evidence- 
Gelsthorpe 2004 (Continued)

Is there a clear and de- High risk No, the Findings are not presented as a discrete body of evidence. Rather, they tailed statement of findare presented in a cursory manner, largely embedded within a discussion that ings? incorporates evidence from other research literature

\begin{tabular}{lll}
\hline $\begin{array}{l}\text { Were the data au- } \\
\text { dio-recorded and tran- } \\
\text { scribed? }\end{array}$ & Low risk & Yes \\
\hline $\begin{array}{l}\text { Is there evidence of de- } \\
\text { tailed steps taken in data } \\
\text { analysis? }\end{array}$ & Low risk & $\begin{array}{l}\text { Yes, minimal detail. Aside from telling the reader that thematic content analy- } \\
\text { sis was used (p. 216), the way in which this procedure was applied and how it } \\
\text { led to the production of findings is not made explicit }\end{array}$
\end{tabular}

Did data analysis involve Low risk $\quad$ Yes, 3 researchers independently analysed data (p. 216)
inter-rater discussion?

\begin{tabular}{|c|c|c|}
\hline $\begin{array}{l}\text { Was there consideration of } \\
\text { disconfirming findings? }\end{array}$ & Low risk & $\begin{array}{l}\text { Yes, (p. 219), in relation to disparate perceptions, between more and less expe- } \\
\text { rienced nurses, of the need for support regarding the clinical decision to wean }\end{array}$ \\
\hline $\begin{array}{l}\text { Is there evidence of a re- } \\
\text { flexive concern with the } \\
\text { conduct of the study? (i.e. } \\
\text { does the author reflect on } \\
\text { his or her own role in the } \\
\text { research, including as this } \\
\text { might introduce bias?) }\end{array}$ & Low risk & $\begin{array}{l}\text { Yes (p. 217), there is an acknowledgement of a potential ethical problem } \\
\text { caused by the principal researcher also being a staff nurse in the unit under } \\
\text { study }\end{array}$ \\
\hline $\begin{array}{l}\text { Is there evidence of analy- } \\
\text { sis and interpretation of } \\
\text { the findings at a conceptu- } \\
\text { al and theoretical level? }\end{array}$ & High risk & $\begin{array}{l}\text { No, yet relevant. Lived experience, as promoted by the stated theoretical } \\
\text { framework of phenomenology, is not explicitly reflected in the findings }\end{array}$ \\
\hline
\end{tabular}

Hansen 2007

Qualitative research exploring participants' experiences of a weaning protocol, the implementation
process and interdisciplinary collaboration. The key question was the nurses' perceptions (attitudes
and beliefs) of the weaning protocol. Participants were asked to describe their initial thoughts on hear-
ing the term 'weaning protocol' and allowed to talk freely about it

Theoretical/Conceptual None stated
framework

Methods Method of data collection: 3 focus-group interviews

Method of data recording: audio-taped

Method of data analysis: content analysed

Reliability: inter-rater discussion

Validity: not reported

\section{Notes}

\section{Risk of bias}

Bias Authors' judgement Support for judgement

Factors that impact on the use of mechanical ventilation weaning protocols in critically ill adults and children: a qualitative evidence- 
Hansen 2007 (Continued)

Is there a logical fit between stated research $\operatorname{aim}(\mathrm{s})$ and method(s) used?
Low risk Yes
Was the recruitment strat- High risk egy appropriate to the aims of the research?
No, authors claim that participants were randomly selected, but state that the ward manager decided how many and who should participate in the interviews in order to ensure that the ward was adequately staffed at all times. They subsequently state that the participants were representative of nurse working in ICU. However, no information on the total population is provided and limited information on sample characteristics is provided - need all such information in order to assess if recruitment strategy is appropriate. Not only does the fact that the ward manager selected participants introduce bias, but why did they opt for (supposed) 'random' sampling within a qualitative study and when it was clear that they needed a range of experience etc?

\begin{tabular}{lll}
$\begin{array}{l}\text { Is there detailed evidence } \\
\text { of steps taken in data col- } \\
\text { lection? }\end{array}$ & Low risk & Yes, full detail \\
\hline $\begin{array}{l}\text { Is there a clear and de- } \\
\text { tailed statement of find- } \\
\text { ings? }\end{array}$ & Low risk & Yes \\
\hline $\begin{array}{l}\text { Were the data au- } \\
\text { dio-recorded and tran- } \\
\text { scribed? }\end{array}$ & Low risk & Yes (p. 198) \\
\hline $\begin{array}{l}\text { Is there evidence of de- } \\
\text { tailed steps taken in data } \\
\text { analysis? }\end{array}$ & Low risk & \\
\end{tabular}

\begin{tabular}{ll}
\hline $\begin{array}{l}\text { Did data analysis involve } \\
\text { inter-rater discussion? }\end{array}$ & $\begin{array}{l}\text { Not reported. There is reference (p. 200) to discussion between the focus } \\
\text { group 'moderator' and 'observer' of the significance of the data after comple- } \\
\text { tion of interviews but the purpose/outcome of this discussion also not made } \\
\text { clear }\end{array}$
\end{tabular}

Was there consideration of High risk No, Findings tend to represent all nurses as holding the same views concerndisconfirming findings? ing issues associated with protocol-directed weaning

\begin{abstract}
Is there evidence of a reflexive concern with the conduct of the study? (i.e. does the author reflect on his or her own role in the research, including as this might introduce bias?)
\end{abstract}

High risk No

Is there evidence of analy- Low risk No, not relevant
sis and interpretation of
the findings at a conceptu-
al and theoretical level?


Hansen 2009a

Study type
Qualitative research exploring the perceptions of ICU physicians concerning protocol-directed weaning from mechanical ventilation

\section{Theoretical/Conceptual None stated \\ framework}

\begin{tabular}{|c|c|}
\hline \multirow[t]{5}{*}{ Methods } & Method of data collection: 1 focus group \\
\hline & Method of data recording: audio-taped \\
\hline & Method of data analysis: content analysed \\
\hline & Reliability: inter-rater discussion \\
\hline & Validity: not reported \\
\hline
\end{tabular}

\section{Notes}

\section{Risk of bias}

\begin{tabular}{|c|c|c|}
\hline Bias & Authors' judgement & Support for judgement \\
\hline $\begin{array}{l}\text { Is there a logical fit be- } \\
\text { tween stated research } \\
\text { aim(s) and method(s) } \\
\text { used? }\end{array}$ & Low risk & Yes \\
\hline $\begin{array}{l}\text { Was the recruitment strat- } \\
\text { egy appropriate to the } \\
\text { aims of the research? }\end{array}$ & High risk & $\begin{array}{l}\text { No, participants selected by their manager on pragmatic grounds that this en- } \\
\text { sured the ward was adequately staffed so potential bias introduced. Authors } \\
\text { state that manager was aware of need for mix of experience. However, no in- } \\
\text { formation on the total population is provided and limited information on sam- } \\
\text { ple characteristics is provided; we need all such information in order to assess } \\
\text { if recruitment strategy is appropriate }\end{array}$ \\
\hline
\end{tabular}

Is there detailed evidence
of steps taken in data col- $\quad$ Yos, minimal detail
of steps taken in data collection?

\begin{tabular}{l}
\hline Is there a clear and de- $\quad$ Low risk \\
tailed statement of find- \\
ings?
\end{tabular}

\begin{tabular}{lll}
\hline $\begin{array}{l}\text { Were the data au- } \\
\text { dio-recorded and tran- }\end{array}$ & Low risk & Yes (p. 72) \\
scribed? & \\
\hline $\begin{array}{l}\text { Is there evidence of de- } \\
\text { tailed steps taken in data } \\
\text { analysis? }\end{array}$ & Low risk & Yes, minimal detail \\
\end{tabular}

\begin{tabular}{lll}
\hline $\begin{array}{l}\text { Did data analysis involve } \\
\text { inter-rater discussion? }\end{array}$ & High risk & No \\
\hline $\begin{array}{l}\text { Was there consideration of } \\
\text { disconfirming findings? }\end{array}$ & Low risk & $\begin{array}{l}\text { Yes, Findings acknowledge disparate attitudes amongst physicians concerning } \\
\text { the usefulness of protocol-directed weaning (e.g. last paragraph of p. } 72 \text { sum- } \\
\text { marizes this disparity) }\end{array}$ \\
\hline $\begin{array}{l}\text { Is there evidence of a re- } \\
\text { flexive concern with the }\end{array}$ & High risk & No \\
\hline
\end{tabular}


Hansen 2009a (Continued) conduct of the study? (i.e. does the author reflect on his or her own role in the research, including as this might introduce bias?)

Is there evidence of analy- Low risk

No, not relevant sis and interpretation of the findings at a conceptual and theoretical level?

Hansen 2009b

Study type Qualitative research exploring the understandings of ICU physicians and nurses of the findings of research that focused on protocol-directed weaning

Theoretical/Conceptual None stated

framework

Methods

Method of data collection: multistage focus groups (2 sessions)

Method of data recording: audio-recorded

Method of data analysis: content analysed

Reliability: inter-rater discussion

Validity: not reported

\section{Notes}

\section{Risk of bias}

\begin{tabular}{lll}
\hline Bias & Authors' judgement & Support for judgement \\
\hline $\begin{array}{ll}\text { Is there a logical fit be- } \\
\text { tween stated research }\end{array}$ & Low risk & Yes \\
aim(s) and method(s) & & \\
used? &
\end{tabular}

Was the recruitment strat- High risk egy appropriate to the aims of the research?
No, participants selected by their managers on pragmatic grounds that this ensured the ward was adequately staffed so potential bias introduced. Authors state that managers were aware of need for mix of experience. However, no information on the total population is provided and limited information on sample characteristics is provided; we need all such information in order to assess if recruitment strategy is appropriate

\begin{tabular}{lll}
$\begin{array}{l}\text { Is there detailed evidence } \\
\text { of steps taken in data col- }\end{array}$ & Low risk \\
lection? & \\
\hline $\begin{array}{l}\text { Is there a clear and de- } \\
\text { tailed statement of find- } \\
\text { ings? }\end{array}$ & Low risk & Yes \\
\hline
\end{tabular}


Hansen 2009b (Continued)

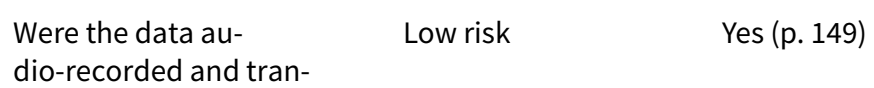

scribed?

Is there evidence of de- Low risk $\quad$ Yes, full detail
tailed steps taken in data
analysis?

Did data analysis involve Unclear risk

inter-rater discussion?

Not reported; there is reference (p. 149) to an 'observer' with whom the author discussed the significance of the data after completion of interviews but the purpose/outcome of this discussion is not made clear. Also reference (p. 149) to the fact that the 2 authors discussed alternatives in order to reach consensus but again the precise nature etc of these discussions remains unclear

Was there consideration of High risk No; although the Findings draw distinctions between the understandings of
disconfirming findings? physicians and nurses, intra-group understandings are presented as uniform

\begin{abstract}
Is there evidence of a reflexive concern with the conduct of the study? (i.e. does the author reflect on his or her own role in the research, including as this might introduce bias?)
\end{abstract} High risk No

Is there evidence of analy-

sis and interpretation of the findings at a conceptual and theoretical level?

\title{
Keogh 2009
}

Qualitative research exploring the attitudes, perceptions and understandings of nurses and doctors
concerning the use of collaborative weaning guidelines

\begin{tabular}{ll}
\hline $\begin{array}{l}\text { Theoretical/Conceptual } \\
\text { framework }\end{array}$ & None stated \\
\hline Methods & Method of data collection: focus group interviews using a semi-structured guideline \\
& Method of data recording: audio-taped \\
& Method of data analysis: thematic content analysis \\
& Reliability: inter-rater discussion, participant verification, decision trail \\
& Validity: independent generation of categories by 3 researchers, return of results to unit staff to check \\
truth value
\end{tabular}

\footnotetext{
Notes
}

\section{Risk of bias}

\begin{tabular}{lll}
\hline Bias & Authors' judgement & Support for judgement \\
\hline $\begin{array}{l}\text { Is there a logical fit be- } \\
\text { tween stated research }\end{array}$ & Low risk & Yes \\
\hline
\end{tabular}

Factors that impact on the use of mechanical ventilation weaning protocols in critically ill adults and children: a qualitative evidence- 
Keogh 2009 (Continued) $\operatorname{aim}(\mathrm{s})$ and method(s) used?

\begin{tabular}{ll}
\hline $\begin{array}{l}\text { Was the recruitment strat- } \\
\text { egy appropriate to the }\end{array}$ & High risk \\
$\begin{array}{l}\text { No, author claims the use of a purposive sample but confuses the situation by } \\
\text { also stating that participants 'volunteered' (p. 6). There is no information on } \\
\text { how/according to what criteria the sample was purposive }\end{array}$
\end{tabular}

Is there detailed evidence Low risk Yes, minimal detail
of steps taken in data collection?

\begin{tabular}{lll}
\hline $\begin{array}{l}\text { Is there a clear and de- } \\
\text { tailed statement of find- } \\
\text { ings? }\end{array}$ & High risk & $\begin{array}{l}\text { No, presentation of Findings is superficial with little data to support the identi- } \\
\text { fied themes. Moreover, Findings are copresented along with Discussion }\end{array}$ \\
\hline $\begin{array}{l}\text { Were the data au- } \\
\text { dio-recorded and tran- }\end{array}$ & Low risk & Yes (p. 6) \\
scribed?
\end{tabular}

Is there evidence of de- $\quad$ Low risk $\quad$ Yes, minimal detail (p. 7)
tailed steps taken in data
analysis?

\begin{tabular}{|c|c|c|}
\hline $\begin{array}{l}\text { Did data analysis involve } \\
\text { inter-rater discussion? }\end{array}$ & Low risk & $\begin{array}{l}\text { Yes, author states (p. } 7 \text { ) that } 2 \text { colleagues also independently generated list of } \\
\text { categories and } 3 \text { lists subsequently compared. No information is provided on } \\
\text { how the } 2 \text { independent lists were developed or how the } 3 \text { were compared }\end{array}$ \\
\hline $\begin{array}{l}\text { Was there consideration of } \\
\text { disconfirming findings? }\end{array}$ & High risk & No \\
\hline $\begin{array}{l}\text { Is there evidence of a re- } \\
\text { flexive concern with the } \\
\text { conduct of the study? (i.e. } \\
\text { does the author reflect on } \\
\text { his or her own role in the } \\
\text { research, including as this } \\
\text { might introduce bias?) }\end{array}$ & High risk & No \\
\hline $\begin{array}{l}\text { Is there evidence of analy- } \\
\text { sis and interpretation of } \\
\text { the findings at a conceptu- } \\
\text { al and theoretical level? }\end{array}$ & Low risk & No, not relevant \\
\hline
\end{tabular}

\section{Kydonaki 2011}

\begin{tabular}{ll}
\hline Study type & $\begin{array}{l}\text { Qualitative research exploring the decision-making processes and behaviour of nurses in relation to } \\
\text { weaning patients from mechanical ventilation as these occur in the socio-cultural context of ICU }\end{array}$ \\
\hline $\begin{array}{l}\text { Theoretical/Conceptual } \\
\text { framework }\end{array}$ & Interpretivism (conceptual framework); ethnography (methodology) \\
\hline Methods & $\begin{array}{l}\text { Method of data collection: participant observation, think-aloud interviews followed by explanatory and } \\
\text { semi-structured interviews } \\
\text { Method of data recording: audio-recording and written report of observations at the end of each day } \\
\text { Method of data analysis: thematic analysis }\end{array}$
\end{tabular}


Kydonaki 2011 (Continued)

Reliability: independent coding, inter-rater discussion

Validity: participant validation

\section{Notes}

\section{Risk of bias}

\begin{tabular}{|c|c|c|}
\hline Bias & Authors' judgement & Support for judgement \\
\hline $\begin{array}{l}\text { Is there a logical fit be- } \\
\text { tween stated research } \\
\text { aim(s) and method(s) } \\
\text { used? }\end{array}$ & Low risk & Yes \\
\hline $\begin{array}{l}\text { Was the recruitment strat- } \\
\text { egy appropriate to the } \\
\text { aims of the research? }\end{array}$ & Low risk & $\begin{array}{l}\text { Yes. But there is an ambiguity around selection of participants. The sampling } \\
\text { strategy is never formally labelled but author states that participants were 'in- } \\
\text { vited' and participation was 'voluntary' ( } p \text {. 128). Provides inclusion criteria for } \\
\text { nurse participants ( } p .128 \text { ) but none for medical staff and physiotherapists. } \\
\text { On p. 198, a table setting out the demographic characteristics of nurse partici- } \\
\text { pants is included. Explicitly states the need to select nurse participants as well } \\
\text { as medical staff participants with a range of experience. No such need ascribed } \\
\text { to selection of physiotherapists (simply that they specialized in critical care). } \\
\text { Appendix } 4.6 \text { sets out demographic characteristics of medical staff but no such } \\
\text { information provided for physiotherapists }\end{array}$ \\
\hline
\end{tabular}

Is there detailed evidence Low risk $\quad$ Yes, full detail
of steps taken in data col-

of steps taken in data col-

lection?

Is there a clear and de-
tailed statement of find-
ings?

\begin{tabular}{ll}
\hline $\begin{array}{l}\text { Were the data au- } \\
\text { dio-recorded and tran- }\end{array}$ & Low risk
\end{tabular}

scribed?

Is there evidence of de- $\quad$ Low risk $\quad$ Yes, full detail
tailed steps taken in data
analysis?

\begin{tabular}{|c|c|c|}
\hline $\begin{array}{l}\text { Did data analysis involve } \\
\text { inter-rater discussion? }\end{array}$ & Low risk & Yes (pp. $155-157$ ) \\
\hline $\begin{array}{l}\text { Was there consideration of } \\
\text { disconfirming findings? }\end{array}$ & Low risk & $\begin{array}{l}\text { Yes (e.g. pp. } 282-285 \text {, in which intra-group nurse and doctor disparity is pre- } \\
\text { sented/explained re the use of weaning protocols and documentation of } \\
\text { weaning plans }\end{array}$ \\
\hline $\begin{array}{l}\text { Is there evidence of a re- } \\
\text { flexive concern with the } \\
\text { conduct of the study? (i.e. } \\
\text { does the author reflect on } \\
\text { his or her own role in the } \\
\text { research, including as this } \\
\text { might introduce bias?) }\end{array}$ & Low risk & Yes, e.g. pp. 135 - 137 \& pp. 184 - 192 \\
\hline $\begin{array}{l}\text { Is there evidence of analy- } \\
\text { sis and interpretation of }\end{array}$ & Low risk & Yes, relevant \\
\hline
\end{tabular}


Kydonaki 2011 (Continued)

the findings at a conceptu-

al and theoretical level?

Lavelle 2011

Study type Qualitative research exploring nurses' involvement in weaning in the Irish context

Theoretical/Conceptual None stated

framework

Methods

Method of data collection: semi-structured interviews guided by a vignette

Method of data recording: audio-recording

Method of data analysis: thematic content analysis (Burnard 1991)

Reliability: development of vignette based on literature review and patient case histories; reviewed by expert panel and pretested on 2 ICU nurses; independent confirmation of categories and themes by subject expert

Validity: participant validation

\section{Notes}

\section{Risk of bias}

\begin{tabular}{|c|c|c|}
\hline Bias & Authors' judgement & Support for judgement \\
\hline $\begin{array}{l}\text { Is there a logical fit be- } \\
\text { tween stated research } \\
\text { aim(s) and method(s) } \\
\text { used? }\end{array}$ & Low risk & $\begin{array}{l}\text { Yes, but although a vignette is employed with the stated aim of enabling par- } \\
\text { ticipants to reflect on/make explicit their decision-making concerning wean- } \\
\text { ing, some of the themes identified in the Findings section are derived from } \\
\text { non-vignette-related questions, and the reader is told nothing about how/why } \\
\text { these questions were asked }\end{array}$ \\
\hline
\end{tabular}

\begin{tabular}{|c|c|c|}
\hline $\begin{array}{l}\text { Was the recruitment strat- } \\
\text { egy appropriate to the }\end{array}$ & Low risk & $\begin{array}{l}\text { Yes (p. 247), but nurses were stratified by level of experience into } 3 \text { groups anc } \\
\text { then randomly selected; why not simply adopt purposive? }\end{array}$ \\
\hline
\end{tabular}
aims of the research?

Is there detailed evidence Low risk $\quad$ Yes, minimal detail
of steps taken in data col-
lection?

\begin{tabular}{lll}
\hline $\begin{array}{l}\text { Is there a clear and de- } \\
\text { tailed statement of find- } \\
\text { ings? }\end{array}$ & Low risk & \\
\hline $\begin{array}{l}\text { Were the data au- } \\
\text { dio-recorded and tran- } \\
\text { scribed? }\end{array}$ & Low risk & Yes (p. 247) \\
\hline $\begin{array}{l}\text { Is there evidence of de- } \\
\text { tailed steps taken in data } \\
\text { analysis? }\end{array}$ & Low risk & Yes, minimal detail \\
\hline $\begin{array}{l}\text { Did data analysis involve } \\
\text { inter-rater discussion? }\end{array}$ & Low risk & \\
& & $\begin{array}{l}\text { Yes (p. 247); 3 nurse participants reviewed transcribed interview and identi- } \\
\text { fied main points emerging. No detail provided concerning how these identified } \\
\text { points were built into the final analysis }\end{array}$ \\
\hline
\end{tabular}

Factors that impact on the use of mechanical ventilation weaning protocols in critically ill adults and children: a qualitative evidence38 synthesis (Review)

Copyright $\odot 2018$ The Cochrane Collaboration. Published by John Wiley \& Sons, Ltd. 
Lavelle 2011 (Continued)

Was there consideration of High risk No disconfirming findings?

Is there evidence of a re- Low risk

Yes, briefly on p. 251 - see 'Study Limitations'

flexive concern with the

conduct of the study? (i.e.

does the author reflect on

his or her own role in the

research, including as this

might introduce bias?)

Is there evidence of analy- Low risk No, not relevant
sis and interpretation of
the findings at a conceptu-
al and theoretical level?

\section{McLean 2006}

Study type Qualitative research exploring the perceptions of ICU staff of a ventilator-weaning protocol and the practice safety climate as these impact on the effectiveness of the Model for Accelerating Improvement to improve weaning adherence and clinical outcomes

\begin{tabular}{ll}
\hline $\begin{array}{l}\text { Theoretical/Conceptual } \\
\text { framework }\end{array}$ & None stated \\
\hline Methods & Method of data collection: focus groups \\
& Method of data recording: not reported \\
& Method of data analysis: content analysis \\
& Reliability: not reported \\
& Validity: not reported \\
\hline
\end{tabular}

Notes

\section{Risk of bias}

\begin{tabular}{lll}
\hline Bias & Authors' judgement & Support for judgement \\
\hline $\begin{array}{l}\text { Is there a logical fit be- } \\
\text { tween stated research }\end{array}$ & Low risk & Yes \\
$\begin{array}{l}\text { aim(s) and method(s) } \\
\text { used? }\end{array}$ & &
\end{tabular}

\begin{tabular}{l} 
Was the recruitment strat- Unclear risk \\
egy appropriate to the \\
aims of the research? \\
\hline $\begin{array}{l}\text { Is there detailed evidence High risk } \\
\text { of steps taken in data col- } \\
\text { lection? }\end{array}$
\end{tabular}




\section{McLean 2006 (Continued)}

Is there a clear and detailed statement of findings?
High risk No in relation to the focus group data (data that are relevant to the synthesis) Presented in summary form only (Table 1, p. 303)

\begin{tabular}{lll}
$\begin{array}{l}\text { Were the data au- } \\
\text { dio-recorded and tran- } \\
\text { scribed? }\end{array}$ & Unclear risk & Not reported \\
\hline $\begin{array}{l}\text { Is there evidence of de- } \\
\text { tailed steps taken in data } \\
\text { analysis? }\end{array}$ & High risk & No, no detail \\
\hline $\begin{array}{l}\text { Did data analysis involve } \\
\text { inter-rater discussion? }\end{array}$ & Unclear risk & Not reported \\
\hline $\begin{array}{l}\text { Was there consideration of } \\
\text { disconfirming findings? }\end{array}$ & High risk & $\begin{array}{l}\text { No, although there is evidence within the Findings that participants expressed } \\
\text { a range of views, the data are so superficially presented/reduced that it is } \\
\text { impossible to know the precise nature of this 'range'. As it stands, the Find- } \\
\text { ings read as very generic, e.g. although it is clear that participants differed in } \\
\text { their assessments of the value of a protocol, the precise nature of these differ- } \\
\text { ences/how they were expressed is not made clear }\end{array}$
\end{tabular}

\begin{abstract}
Is there evidence of a re-
\end{abstract}
High risk

No

flexive concern with the

conduct of the study? (i.e.

does the author reflect on

his or her own role in the

research, including as this

might introduce bias?)

Is there evidence of analy- Low risk No, not relevant
sis and interpretation of
the findings at a conceptu-
al and theoretical level?

\title{
Myneni 2012
}

\begin{tabular}{ll} 
Study type & $\begin{array}{l}\text { Qualitative research focusing on the implementation and use of a risk assessment met } \\
\text { Resonance Accident Method (FRAM)), originally proposed for adverse event analysis in } \\
\text { dustry, to evaluate the effectiveness of a computerized weaning protocol (CWP) in a }\end{array}$ \\
\hline $\begin{array}{l}\text { Theoretical/Conceptual } \\
\text { framework }\end{array}$ & None stated \\
\hline Methods & Method of data collection: non-participant observation, semi-structured interviews \\
& Method of data recording: not reported \\
& Method of data analysis: not reported \\
& Reliability: not reported \\
& Validity: not reported
\end{tabular}

\section{Notes}

\section{Risk of bias}

Factors that impact on the use of mechanical ventilation weaning protocols in critically ill adults and children: a qualitative evidence- 
Myneni 2012 (Continued)

\begin{tabular}{|c|c|c|}
\hline Bias & Authors' judgement & Support for judgement \\
\hline $\begin{array}{l}\text { Is there a logical fit be- } \\
\text { tween stated research } \\
\text { aim(s) and method(s) } \\
\text { used? }\end{array}$ & Low risk & Yes \\
\hline
\end{tabular}

Was the recruitment strat- Unclear risk Not reported
egy appropriate to the
aims of the research?

\begin{tabular}{lll}
\hline $\begin{array}{l}\text { Is there detailed evidence } \\
\text { of steps taken in data col- }\end{array}$ & High risk & \\
lection? & & \\
\hline $\begin{array}{l}\text { Is there a clear and de- } \\
\text { tailed statement of find- }\end{array}$ & Low risk & Yes \\
ings? & & \\
\hline
\end{tabular}

\begin{tabular}{lll}
\hline $\begin{array}{l}\text { Were the data au- } \\
\text { dio-recorded and tran- }\end{array}$ & Unclear risk & \\
scribed? & & \\
\hline $\begin{array}{l}\text { Is there evidence of de- } \\
\text { tailed steps taken in data }\end{array}$ & High risk & No, no detail \\
analysis? & &
\end{tabular}

\begin{tabular}{|c|c|c|}
\hline $\begin{array}{l}\text { Did data analysis involve } \\
\text { inter-rater discussion? }\end{array}$ & Unclear risk & Not reported \\
\hline $\begin{array}{l}\text { Was there consideration of } \\
\text { disconfirming findings? }\end{array}$ & Unclear risk & Not reported \\
\hline $\begin{array}{l}\text { Is there evidence of a re- } \\
\text { flexive concern with the } \\
\text { conduct of the study? (i.e. } \\
\text { does the author reflect on } \\
\text { his or her own role in the } \\
\text { research, including as this } \\
\text { might introduce bias?) }\end{array}$ & High risk & No \\
\hline $\begin{array}{l}\text { Is there evidence of analy- } \\
\text { sis and interpretation of } \\
\text { the findings at a conceptu- } \\
\text { al and theoretical level? }\end{array}$ & Low risk & $\begin{array}{l}\text { No, not relevant* } \\
\text { *There is no evidence of such analysis in relation to methodology but the en- } \\
\text { tire research process and Findings are framed using the FRAM model }\end{array}$ \\
\hline
\end{tabular}

\section{Vaerland 2011}

\begin{tabular}{ll}
\hline Study type & $\begin{array}{l}\text { Qualitative research exploring the views and experiences of nurses of weaning patients from mechani- } \\
\text { cal ventilation, with a specific focus on the role of medical evidence }\end{array}$ \\
\hline $\begin{array}{l}\text { Theoretical/Conceptual } \\
\text { framework }\end{array}$ & Phenomenology \\
\hline Methods & Method of data collection: semi-structured interviews
\end{tabular}

Factors that impact on the use of mechanical ventilation weaning protocols in critically ill adults and children: a qualitative evidence- 
Vaerland 2011 (Continued)
Method of data recording: audio-recording
Method of data analysis: content analysis
Reliability: not reported
Validity: not reported

\section{Notes}

\section{Risk of bias}

\begin{tabular}{lll}
\hline Bias & Authors' judgement & Support for judgement \\
\hline $\begin{array}{ll}\text { Is there a logical fit be- } \\
\text { tween stated research }\end{array}$ & Low risk & Yes \\
aim(s) and method(s) & & \\
used? & & \\
\hline
\end{tabular}

Was the recruitment strat- High risk No, in that the Nursing Director selected participants (p. 290)
egy appropriate to the

Low risk Yes, minimal detail

Is there detailed evidence $\quad$ Low risk $\quad$ Yes, minimal detail
of steps taken in data col-

of steps taken in data col-

lection?

Is there a clear and de- Low risk $\quad$ Yes
tailed statement of find-
ings?

\begin{tabular}{lll}
\hline $\begin{array}{l}\text { Were the data au- } \\
\text { dio-recorded and tran- }\end{array}$ & Low risk & \\
scribed? & \\
\hline $\begin{array}{l}\text { Is there evidence of de- } \\
\text { tailed steps taken in data } \\
\text { analysis? }\end{array}$ & Low risk & Yes, minimal detail \\
\end{tabular}

\begin{tabular}{|c|c|c|}
\hline $\begin{array}{l}\text { Did data analysis involve } \\
\text { inter-rater discussion? }\end{array}$ & Unclear risk & Not reported \\
\hline $\begin{array}{l}\text { Was there consideration of } \\
\text { disconfirming findings? }\end{array}$ & High risk & No, Findings are presented as uniform/consistent across all 8 participants \\
\hline $\begin{array}{l}\text { Is there evidence of a re- } \\
\text { flexive concern with the } \\
\text { conduct of the study? (i.e. } \\
\text { does the author reflect on } \\
\text { his or her own role in the } \\
\text { research, including as this } \\
\text { might introduce bias?) }\end{array}$ & High risk & No \\
\hline $\begin{array}{l}\text { Is there evidence of analy- } \\
\text { sis and interpretation of } \\
\text { the findings at a conceptu- } \\
\text { al and theoretical level? }\end{array}$ & Low risk & Yes, relevant \\
\hline
\end{tabular}

CWP: Computerised Weaning Protocol

Factors that impact on the use of mechanical ventilation weaning protocols in critically ill adults and children: a qualitative evidence- 
FRAM: Functional Resonance Accident Method

HDU: high dependency unit

ICU: Intensive Care Unit

PICU: Paediatric Intensive Care Unit

Characteristics of excluded studies [ordered by study ID]

\begin{tabular}{ll}
\hline Study & Reason for exclusion \\
\hline Crocker 2009a & Did not address the issue of protocolized weaning \\
\hline Crocker 2009b & Did not address the issue of protocolized weaning \\
\hline Hancock 2006 & Did not address the issue of protocolized weaning \\
\hline Kydonaki 2010 & Conference abstract of findings from author's PhD thesis \\
\hline Kydonaki 2014 & $\begin{array}{l}\text { Article included partial findings from author's PhD thesis. We included the PhD thesis as the detail } \\
\text { in relation to e.g. study setting, data collection and analysis and findings was more complete }\end{array}$ \\
\hline Powers 2006 & $\begin{array}{l}\text { Presents the views and opinions of } 3 \text { staff members, none of whom had experience of protocolized } \\
\text { weaning }\end{array}$ \\
\hline
\end{tabular}

PhD: Doctor of Philosophy

Characteristics of studies awaiting assessment [ordered by study ID]

Pettersson 2012

Study type Method of data collection: explorative qualitative interviews

Method of data recording: taped recording

Method of data analysis: Dahlgren \& Fallsberg's seven steps (Dahlgren 1991)

Reliability: not reported

Validity: not reported

Theoretical/Conceptual frame- Phenomenology

work

Methods Method of selection: purposive sample

Inclusion/exclusion criteria: At least 1 year of clinical experience in an ICU and of ventilator weaning

Notes

Solberg 2015

Study type Method of data collection: focus group

Method of data recording: audiotaped

Method of data analysis: concept-driven concept analysis

Reliability/Validity: Only 1 focus group convened and the participants were from a single NICU

Factors that impact on the use of mechanical ventilation weaning protocols in critically ill adults and children: a qualitative evidence- 
Solberg 2015 (Continued)

Theoretical/Conceptual frame- Theory of Relational Co-ordination work

Methods

Method of selection: purposive sample

Inclusion/exclusion criteria: none reported

Notes

\section{Tingsvik 2014}

\section{Study type}

Method of data collection: semi-structured interviews

Method of data recording: audio-taped

Method of data analysis: qualitative content analysis

Reliability/Validity: Authors adhered to Lincoln 1985 qualitative research criteria in order to strengthen credibility. The pre-understanding of 2 of the authors comprised several years experience as ICU nurses. This may have been positive, as the authors were familiar with the subject and context but it also involved a risk that they might construct their own interpretations. To counteract this, the authors adopted a critical attitude and discussed their pre-understanding throughout the data analysis process. A prerequisite for transferability is a careful description of the selection process, context and results. Four ICUs were included, and the fact that these were similar in character can be regarded as a limitation. A greater variation of experiences among ICU nurses could have been seen if university hospitals as well as county regional hospitals were included in the study. Due to practical reasons the unit manager arranged contact with ICU nurses interested in participating in the study. This resulted in less control of the selection process. The authors had no relationship with the included units or participants, which strengthened credibility

Theoretical/Conceptual frame- None reported

work

Methods $\begin{aligned} & \text { Method of selection: strategic } \\ & \text { Inclusion/exclusion criteria: Inclusion criteria = registered ICU nurses, and those with experience of } \\ & \text { nursing patients during ventilator weaning, and with a minimum of } 2 \text { years clinical practice in this } \\ & \text { area }\end{aligned}$

Notes

Method of data analysis: for data derived from the open-ended questions - not reported

Reliability: for data derived from the open-ended questions - not reported

Validity: for data derived from the open-ended questions - not reported

\section{Theoretical/Conceptual frame- None stated} work 
Tume 2014 (Continued)

Methods

Method of selection: not reported

Inclusion/exclusion criteria: not reported

\section{Notes}

\section{Wongrostrai 2016}

Study type

Method of data collection: descriptive, with observation of practice, focus-group discussion, and in-depth interviews

Method of data recording: audio-recording

Method of data analysis: thematic analysis (of interview and focus-group data)

Reliability/Validity: To enhance trustworthiness of the data analysis (defined as credibility, accuracy, transferability, and dependability of the study findings): multiple methods of data collection used (methodological triangulation); data sources compared in order to ensure accurate findings; member-checking; peer debriefing; findings shared with co-authors for verification of accuracy of interpretation; detailed descriptions were developed to help reader understand study context and participants in order to evaluate transferability of the findings to other contexts. An audit trail of the data collection process, complete record of raw data, audiotapes and transcripts, and decisions made was created for evaluation of dependability; advisory committee members served as auditors of the research process and end product

\section{Theoretical/Conceptual frame- None reported}

work

Methods

\section{Method of selection: purposive and snowball sampling}

Inclusion/exclusion criteria:

For the focus groups: nurses had to have at least 1 year's work experience at the bedside with mechanical ventilation weaning protocols;

For the in-depth interviews:

Head nurses: have responsibility for staff continuing education, resources, and supervision;

Nurse supervisors: have responsibility for facilitating communication and collaboration among staff and with other units, monitoring MVWP use, and staff continuing education on MVWP use;

For the physicians: have work experience with mechanical ventilation weaning protocol implementation for at least 1 year in 1 of the 4 study hospitals

ANPs: Advanced Nurse Practitioners

ICU: Intensive Care Unit

MVWP: mechanical ventilation weaning protocol

NICU: Neonatal Intensive Care Unit

NLVW: Nurse-led ventilator weaning

PICU: Paediatric Intensive Care Unit

WTE: whole-time equivalent

\section{ADDITIONAL TABLES}

Factors that impact on the use of mechanical ventilation weaning protocols in critically ill adults and children: a qualitative evidence- 
Table 1. Framework for quality assessment

\begin{tabular}{|c|c|}
\hline Question / Criteria & Assessment \\
\hline Is there a logical fit between stated research aim(s) and method(s) used? & 'Yes', 'No' or 'Not reported' \\
\hline Is the recruitment strategy appropriate to the aims of the research? & 'Yes', 'No' or 'Not reported' \\
\hline $\begin{array}{l}\text { Is there detailed evidence of steps taken in data collection (e.g. interview guide, means } \\
\text { of recording, how focus group composed) and why? }\end{array}$ & $\begin{array}{l}\text { 'Yes (full/minimal detail)', 'No' or 'Not re- } \\
\text { ported' }\end{array}$ \\
\hline Were the data audio-recorded and transcribed? & 'Yes', 'No' or 'Not reported' \\
\hline Is there a detailed statement of steps taken in data analysis? & $\begin{array}{l}\text { 'Yes (full/minimal detail)', 'No' or 'Not re- } \\
\text { ported' }\end{array}$ \\
\hline Did data analysis involve inter-rater discussion? & 'Yes', 'No' or 'Not reported' \\
\hline Was there consideration of disconfirming findings? & 'Yes', 'No' or 'Not reported' \\
\hline Is there a clear and detailed statement of findings? & 'Yes', 'No' or 'Not reported' \\
\hline Is there evidence of a reflexive concern with the conduct of the study? & 'Yes', 'No' or 'Not reported' \\
\hline $\begin{array}{l}\text { Is there evidence of analysis and interpretation of the findings at a conceptual and theo- } \\
\text { retical level? }\end{array}$ & 'Yes', 'No' or 'Not reported' \\
\hline Summary quality assessment & 'High', 'Moderate' or 'Low' \\
\hline
\end{tabular}




\begin{tabular}{|c|c|c|c|c|c|c|c|c|}
\hline Study & Methodology & Country & $\begin{array}{l}\text { Number } \\
\text { of partici- } \\
\text { pants }\end{array}$ & $\begin{array}{l}\text { Number } \\
\text { of Hospi- } \\
\text { tals }\end{array}$ & $\begin{array}{l}\text { ICU num- } \\
\text { ber \& type }\end{array}$ & Population & $\begin{array}{l}\text { ICU clinical popula- } \\
\text { tion }\end{array}$ & $\begin{array}{l}\text { Protocol - presence \& level of de- } \\
\text { scription }\end{array}$ \\
\hline $\begin{array}{l}\text { Black- } \\
\text { wood } \\
2004\end{array}$ & $\begin{array}{l}\text { Semi-struc- } \\
\text { tured inter- } \\
\text { views; thematic } \\
\text { content analy- } \\
\text { sis }\end{array}$ & $\begin{array}{l}\text { Northern } \\
\text { Ireland }\end{array}$ & 10 & 2 & $\begin{array}{l}2 \\
\text { Closed }\end{array}$ & Physicians & Not reported & No protocol \\
\hline $\begin{array}{l}\text { Gelsthor- } \\
\text { pe } 2004\end{array}$ & $\begin{array}{l}\text { Unstructured } \\
\text { interviews; the- } \\
\text { matic analysis }\end{array}$ & UK & 7 & 1 & $\begin{array}{l}1 \\
\text { Closed }\end{array}$ & Nurses & $\begin{array}{l}\text { Adult mixed-medical } \\
\& \text { surgical }\end{array}$ & $\begin{array}{l}\text { Written protocol in use } \\
\text { Detailed description }\end{array}$ \\
\hline $\begin{array}{l}\text { Hansen } \\
2007\end{array}$ & $\begin{array}{l}\text { Focus groups; } \\
\text { content analy- } \\
\text { sis }\end{array}$ & Norway & 24 & 1 & $\begin{array}{l}1 \\
\text { Closed }\end{array}$ & Nurses & $\begin{array}{l}\text { Adult mixed - medical, } \\
\text { surgical and trauma }\end{array}$ & $\begin{array}{l}\text { Written protocol in use } \\
\text { Vey limited description }\end{array}$ \\
\hline $\begin{array}{l}\text { Hansen } \\
\text { 2009a }\end{array}$ & $\begin{array}{l}\text { Focus groups; } \\
\text { content analy- } \\
\text { sis }\end{array}$ & Norway & 6 & 1 & $\begin{array}{l}1 \\
\text { Not re- } \\
\text { ported }\end{array}$ & Physicians & Not reported & $\begin{array}{l}\text { Written protocol in use } \\
\text { No details reported }\end{array}$ \\
\hline $\begin{array}{l}\text { Hansen } \\
2009 b\end{array}$ & $\begin{array}{l}\text { Focus groups; } \\
\text { content analy- } \\
\text { sis }\end{array}$ & Norway & 10 & 1 & $\begin{array}{l}1 \\
\text { Not re- } \\
\text { ported }\end{array}$ & $\begin{array}{l}\text { Nurses \& physi- } \\
\text { cians }\end{array}$ & $\begin{array}{l}\text { Adult mixed - medical, } \\
\text { surgical and trauma }\end{array}$ & No protocol \\
\hline $\begin{array}{l}\text { Keogh } \\
2009\end{array}$ & $\begin{array}{l}\text { Focus groups; } \\
\text { thematic con- } \\
\text { tent analysis }\end{array}$ & Australia & 22 & 1 & $\begin{array}{l}1 \\
\text { Not re- } \\
\text { ported }\end{array}$ & $\begin{array}{l}\text { Nurses \& physi- } \\
\text { cians }\end{array}$ & Paediatric & $\begin{array}{l}\text { Protocol in use } \\
\text { No details reported }\end{array}$ \\
\hline $\begin{array}{l}\text { Kydonaki } \\
2011\end{array}$ & $\begin{array}{l}\text { Observation; } \\
\text { think-aloud \& } \\
\text { follow-up ex- } \\
\text { planatory in- } \\
\text { terviews; se- } \\
\text { mi-structured } \\
\text { interviews; } \\
\text { framework } \\
\text { analysis }\end{array}$ & $\begin{array}{l}\text { Scotland \& } \\
\text { Greece }\end{array}$ & 44 & $\begin{array}{l}1 \text { hospital } \\
\text { per site }\end{array}$ & $\begin{array}{l}1 \text { ICU per } \\
\text { hospital } \\
\text { Not re- } \\
\text { ported }\end{array}$ & $\begin{array}{l}\text { Nurses, physi- } \\
\text { cians \& physio- } \\
\text { therapists }\end{array}$ & $\begin{array}{l}\text { Adult mixed - medical, } \\
\text { surgical and trauma }\end{array}$ & $\begin{array}{l}\text { Written protocol in use } \\
\text { No details reported }\end{array}$ \\
\hline $\begin{array}{l}\text { Lavelle } \\
2011\end{array}$ & $\begin{array}{l}\text { Semi-struc- } \\
\text { tured inter- }\end{array}$ & Ireland & 24 & 1 & 1 & Nurses & Not reported & Protocol in use \\
\hline
\end{tabular}




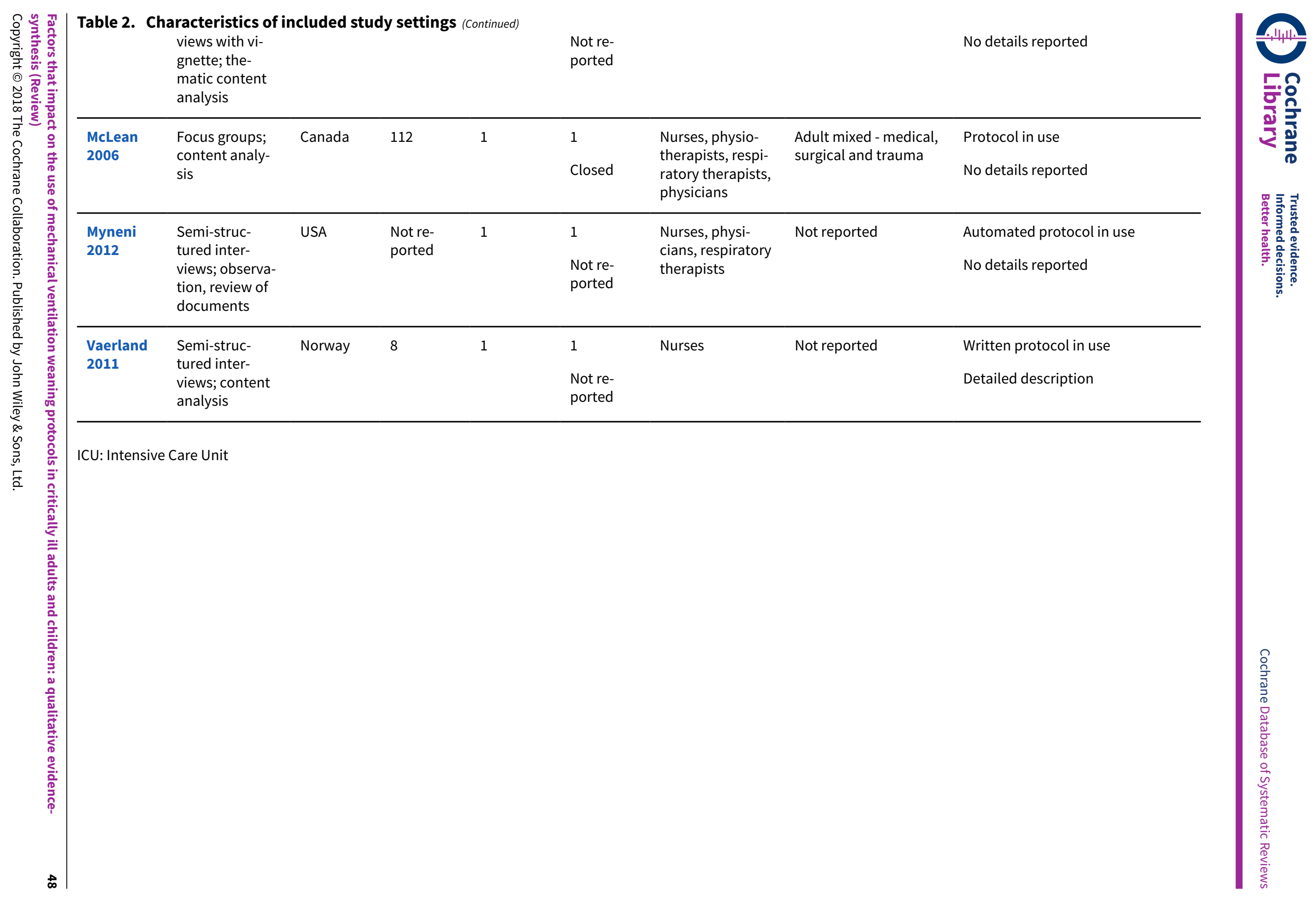


Table 3. Summary statements derived from synthesis of qualitative evidence

Summary statement $\quad \begin{aligned} & \text { Confidence in the Explanation of assessed confidence } \\ & \text { evidence }\end{aligned}$

\section{Analytic theme: Continual staff training and development: the essentials of knowing how (to use a protocol) to wean}

Physicians and nurses should possess a comprehen- Moderate Confi- $\quad$ The studies were of at least moderate quality and the sive (patho) physiological knowledge base dence finding was seen in 3 settings

Blackwood 2004 (UK, Northern Ireland)

Hansen 2007 (Norway)

Vaerland 2011 (Norway)

Physicians and nurses delivering protocolized weaning should

receive ongoing discipline-relevant clinical training to increase clinical competence and confidence
Moderate Confidence
The majority of studies were of high quality and the finding was seen in 3 settings

Blackwood 2004 (UK, Northern Ireland)

Hansen 2009b (Norway)

Lavelle 2011 (Ireland)

Physicians and nurses should receive training on the practicalities of using a protocol being introduced into the intensive care setting to

ensure proper understanding and implementation
Moderate Confidence
The studies were of mixed quality and the finding was seen in 5 settings

Blackwood 2004 (UK, Northern Ireland)

Hansen 2009b (Norway)

Lavelle 2011 (Ireland)

McLean 2006 (Canada)

Myneni 2012 (USA)

\section{Analytic theme: Clinical experience: the basis of a necessary felt and perceived competence and confidence for (protocolized)} weaning

The cautious approach to (protocolized) weaning by High Confidence inexperienced

nurses is mediated by felt lack of clinical competence and confidence
The studies were of at least moderate quality and the finding was seen in 7 settings

Blackwood 2004 (UK, Northern Ireland)

Gelsthorpe 2004 (UK, England)

Hansen 2007 and Hansen 2009b (Norway)

Kydonaki 2011 (Scotland)

Kydonaki 2011 (Greece)

Lavelle 2011 (Ireland)

Vaerland 2011 (Norway)

Lack of clinical competence and confidence is understood by

High Confidence

The studies were of at least moderate quality and the finding was seen in 7 settings

Blackwood 2004 (UK, Northern Ireland)

Gelsthorpe 2004 (UK, England)

physicians to limit some nurses' ability to contribute effectively to

Factors that impact on the use of mechanical ventilation weaning protocols in critically ill adults and children: a qualitative evidence- 
Table 3. Summary statements derived from synthesis of qualitative evidence (Continued) weaning

Hansen 2007 and Hansen 2009b (Norway)

Kydonaki 2011 (Scotland)

Kydonaki 2011 (Greece)

Lavelle 2011 (Ireland)

Vaerland 2011 (Norway)

\begin{tabular}{|c|c|c|}
\hline $\begin{array}{l}\text { Nurses understand personal weaning competence } \\
\text { and confidence }\end{array}$ & $\begin{array}{l}\text { Moderate Confi- } \\
\text { dence }\end{array}$ & $\begin{array}{l}\text { The studies were of at least moderate qua } \\
\text { finding was seen in } 4 \text { settings }\end{array}$ \\
\hline to be based on the day-to-day routine of work, and & & Gelsthorpe 2004 (UK, England) \\
\hline (n) expentice & & Hansen 2007 and Hansen 2009b (Norway) \\
\hline consequently gained & & Lavelle 2011 (Ireland) \\
\hline & & Vaerland 2011 (Norway) \\
\hline
\end{tabular}

More experienced nurses prefer to base weaning deci- High Confidence sion-making

on their clinical insight and expertise. Protocols are considered to

interfere with this process
The studies were of at least moderate quality and the finding was seen in 6 settings

Gelsthorpe 2004 (UK, England)

Hansen 2007 (Norway)

Kydonaki 2011 (Scotland)

Kydonaki 2011 (Greece)

Lavelle 2011 (Ireland)

Vaerland 2011 (Norway)
Moderate Confidence
The majority of studies were of high quality and the finding was seen in 4 settings

Hansen 2009b (Norway)

Kydonaki 2011 (Scotland)

Kydonaki 2011 (Greece)

Lavelle 2011 (Ireland)
The use of a protocol increases felt confidence and competence

amongst nurses and junior physicians as it 'supports' autonomous

practice
Moderate Confidence
The studies were of mixed quality and the finding was seen in 4 settings

Hansen 2009b (Norway)

Keogh 2009 (Australia)

Kydonaki 2011 (Scotland)

Kydonaki 2011 (Greece)
Effective weaning requires nurses to be able to 'read' both readily

observable and more subtle clinical indicators. An ability to do so is
The studies were of at least moderate quality and the finding was seen in 6 settings.

Gelsthorpe 2004 (UK, England)

Hansen 2007 and Hansen 2009b (Norway)

premised on extended clinical experience

High Confidence

Factors that impact on the use of mechanical ventilation weaning protocols in critically ill adults and children: a qualitative evidencesynthesis (Review)

Copyright @ 2018 The Cochrane Collaboration. Published by John Wiley \& Sons, Ltd. 
Table 3. Summary statements derived from synthesis of qualitative evidence (Continued)

$$
\begin{aligned}
& \text { Kydonaki } 2011 \text { (Sotland) } \\
& \text { Kydonaki } 2011 \text { (Greece)) } \\
& \text { Lavelle } 2011 \text { (Ireland) } \\
& \text { Vaerland } 2011 \text { (Norway) }
\end{aligned}
$$

\section{Analytic theme: The vulnerability of weaning protocols to differential (inter) professional working}

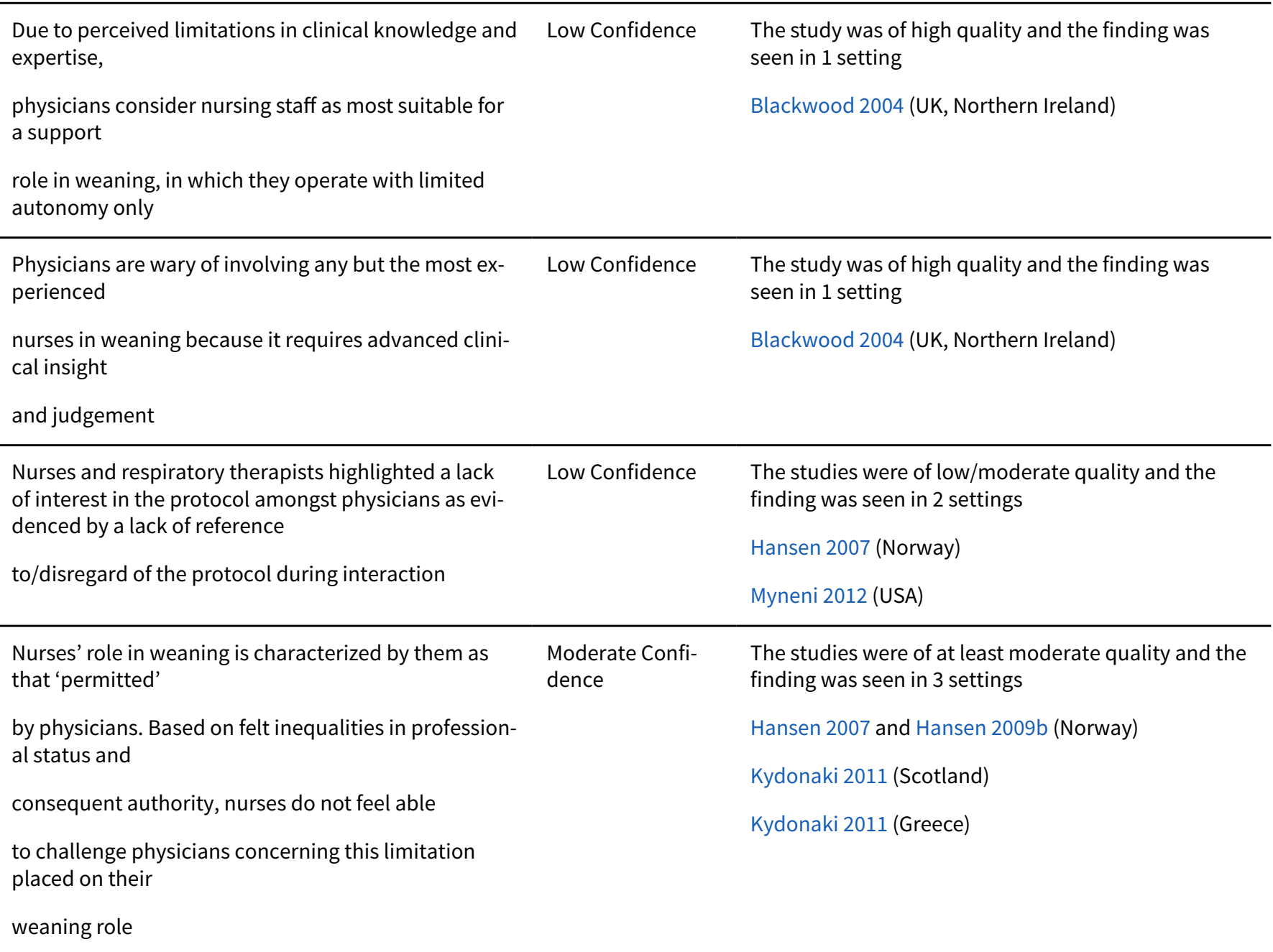

Experienced nurses counter physician 'control' of weaning by involving

Low confidence

themselves in weaning decision-making. Less experienced/confident

nurses allow physicians to control the weaning process

\section{The study was of moderate quality and the finding was seen in 1 setting}

Hansen 2007 (Norway)
The availability of routine (formal and informal) opportunities for

interprofessional discussion and learning is considered by nurses
Low confidence

The studies were of moderate quality and the finding was seen in 2 settings

Gelsthorpe 2004 (UK, England)

Hansen 2009b (Norway)

Factors that impact on the use of mechanical ventilation weaning protocols in critically ill adults and children: a qualitative evidence- 
Table 3. Summary statements derived from synthesis of qualitative evidence (Continued)

to be a crucial bedrock of collaborative and effective weaning.

Lack of time is one factor militating against such opportunities

\begin{tabular}{|c|c|c|}
\hline $\begin{array}{l}\text { Nurses associate physician reluctance to involve nurs- } \\
\text { es in }\end{array}$ & Low confidence & $\begin{array}{l}\text { The study was of moderate quality and the finding } \\
\text { was seen in } 1 \text { setting }\end{array}$ \\
\hline $\begin{array}{l}\text { weaning decision-making with an individualization of } \\
\text { nursing }\end{array}$ & & Hansen 2009b (Norway) \\
\hline \multicolumn{3}{|l|}{ competence } \\
\hline $\begin{array}{l}\text { Nurses consider physicians as able to choose whether } \\
\text { or not to }\end{array}$ & Low confidence & $\begin{array}{l}\text { The studies were of moderate quality and the finding } \\
\text { was seen in } 1 \text { setting }\end{array}$ \\
\hline use the protocol & & Hansen 2007 and Hansen 2009b (Norway) \\
\hline
\end{tabular}

\section{Analytic theme: Understanding of protocols as militating against a necessary proactivity in clinical practice}

The use of a protocol is associated with abdication of professional

responsibility and/or a clinically 'apathetic' approach to weaning
Moderate confi- The studies were of mixed quality and the finding was dence seen in 6 settings

Blackwood 2004 (UK, Northern Ireland)

Gelsthorpe 2004 (UK, England)

Hansen 2009a (Norway)

Keogh 2009 (Australia)

McLean 2006 (Canada)

Myneni 2012 (USA)

No one protocol is able to address the diversity of ICU High confidence patient

The majority of studies were of at least moderate quality and the finding was seen in 8 settings

Blackwood 2004 (UK, Northern Ireland)

Hansen 2009a and Hansen 2009b (Norway)

Kydonaki 2011 (Scotland)

Kydonaki 2011 (Greece)

Lavelle 2011 (Ireland)

McLean 2006 (Canada)

Myneni 2012 (USA)

Vaerland 2011 (Norway)

\section{Analytic theme: Perceived nursing scope of practice and professional risk}

Based on a felt need to protect themselves from pro-

fessional risk/

censure, nurses prefer to undertake weaning-related activity based
Moderate confidence

\author{
The studies were of at least moderate quality and the \\ finding was seen in 3 settings \\ Gelsthorpe 2004 (UK, England) \\ Kydonaki 2011 (Scotland)
}


Table 3. Summary statements derived from synthesis of qualitative evidence (Continued) on explicit instruction, either in the form of instrucKydonaki 2011 (Greece) tions from senior

colleagues or in the form of a protocol

Nurses understand a protocol as advancing professional autonomy.

As such it is considered to motivate clinical practice
Moderate confidence
The studies were of mixed quality and the finding was seen in 5 settings

Hansen 2007 (Norway)

Kydonaki 2011 (Scotland)

Kydonaki 2011 (Greece)

McLean 2006 (Canada)

Vaerland 2011 (Norway)
Physicians consider a protocol to alleviate their work- Low confidence load as nurses

can be left to wean 'straightforward' patients while they concentrate

on other clinical tasks
The study was of moderate quality and the finding was seen in 1 setting

Hansen 2009a (Norway)

\section{Analytic theme: ICU structure and processes of care}

ICU routines impact adversely on weaning. Examples included: the

limited availability of physicians outside of set times (such as morning

clinical rounds); a more 'proactive' approach to weaning at the

beginning of a working day; and the interruption to weaning caused

by patient visiting (hours)
Moderate confi- The majority of studies were of at least moderate dence quality and the finding was seen in 4 settings

Blackwood 2004 (UK, Northern Ireland)

Gelsthorpe 2004 (UK, England)

Hansen 2007, Hansen 2009a and Hansen 2009b (Norway)

Myneni 2012 (USA)
Nurses prioritize continuity of care as necessary for patient-specific clinical insight and effective weaning. Staffing pressures can encourage the rotating of nurses between patients, which militates against this continuity
Low confidence

The studies were of moderate quality and the finding was seen in 1 setting

Hansen 2007 and Hansen 2009b (Norway)
Weaning is frequently subordinated to immediate clinical priorities,

particularly in the context of caring for acutely ill/deteriorating patients
Low confidence

The studies were of moderate/low quality and the finding was seen in 2 settings

Hansen 2007, Hansen 2009a and Hansen 2009b (Norway)

Myneni 2012 (USA) seen in 1 setting

Physicians consider that a protocol will have little or no material impact

Low confidence

on weaning because the ICU practice already encourBlackwood 2004 (UK, Northern Ireland) 


\section{Table 3. Summary statements derived from synthesis of qualitative evidence (Continued)}
Ward rounds provide a timely opportunity to discuss Low confidence patient weaning,
The study was of moderate quality and the finding was seen in 1 setting
including in terms of the use of the protocol
Gelsthorpe 2004 (UK, England)

\section{Analytic theme: Protocols as a prompt for shared care, consensus and consistency in weaning}

Use of a protocol facilitates a shared understanding of the weaning process, thereby enhancing inter-professional collaboration and, through this process, greater effectiveness in weaning

Moderate confi- The studies were of mixed quality and the finding was dence seen in 6 settings

Hansen 2007, Hansen 2009a \& Hansen 2009b (Norway)

Keogh 2009 (Australia)

Kydonaki 2011 (Scotland)

Kydonaki 2011 (Greece)

McLean 2006 (Canada)

Vaerland 2011 (Norway)

A protocol contributes positively to weaning as it helps raise the profile of weaning generally, prompting clinicians to think about weaning when they might otherwise focus on other clinical priorities
Moderate confidence

The studies were of mixed quality and the finding was seen in 5 settings

Blackwood 2004 (UK, Northern Ireland)

Hansen 2009a and Hansen 2009b (Norway)

Keogh 2009 (Australia)

McLean 2006 (Canada)

Vaerland 2011 (Norway)

Physicians consider a protocol as a positive contribution to their working practice as it allows them to Low confidence

The study was of moderate quality and the finding was seen in 1 setting

Hansen 2009a (Norway) nurses, while they concentrate on other clinical tasks

\section{Analytic theme: Maximizing the use of protocols through visibility, relevance and ease of implementation}

\begin{tabular}{|c|c|c|}
\hline \multirow[t]{4}{*}{$\begin{array}{l}\text { Protocols should have clarity in their design and in- } \\
\text { struction, and be straightforward to use }\end{array}$} & Low confidence & $\begin{array}{l}\text { All of the studies were of low quality and the finding } \\
\text { was seen in } 3 \text { settings }\end{array}$ \\
\hline & & Keogh 2009 (Australia) \\
\hline & & McLean 2006 (Canada) \\
\hline & & Myneni 2012 (USA) \\
\hline \multirow[t]{2}{*}{$\begin{array}{l}\text { Protocols should be readily accessible/visible within } \\
\text { an ICU unit at all times }\end{array}$} & Low confidence & $\begin{array}{l}\text { The study was of low quality and the finding was seen } \\
\text { in } 1 \text { setting }\end{array}$ \\
\hline & & McLean 2006 (Canada) \\
\hline \multirow[t]{2}{*}{$\begin{array}{l}\text { Protocols require constant 'revalidation' to encour- } \\
\text { age ongoing adherence }\end{array}$} & Low confidence & $\begin{array}{l}\text { The study was of moderate quality and the finding } \\
\text { was seen in } 1 \text { setting }\end{array}$ \\
\hline & & Hansen 2007 (Norway) \\
\hline
\end{tabular}

Factors that impact on the use of mechanical ventilation weaning protocols in critically ill adults and children: a qualitative evidence- 
Table 3. Summary statements derived from synthesis of qualitative evidence (Continued)

\section{Analytic theme: Protocols as a framework for communication with parents of children}

\begin{tabular}{|c|c|c|}
\hline $\begin{array}{l}\text { Nurses understand the protocol to be a useful com- } \\
\text { munication tool, providing a framework through } \\
\text { which they can explain and otherwise communicate } \\
\text { about the process of weaning their child from ventila- } \\
\text { tion }\end{array}$ & Low confidence & $\begin{array}{l}\text { The study was of low quality and the finding was seen } \\
\text { in } 1 \text { setting } \\
\text { Keogh } 2009 \text { (Australia) }\end{array}$ \\
\hline
\end{tabular}

ICU: Intensive Care Unit

Table 4. Hypotheses generated from trial author statements concerning the use of protocols

$\begin{array}{lll}\begin{array}{l}\text { Trial study with sum- } \\ \text { mary outcome }\end{array} & \begin{array}{l}\text { Hypotheses generated through trial author statement(s) con- } \\ \text { cerning factors likely to impact positively on the use of a protocol }\end{array} & \begin{array}{l}\text { Hypotheses generated through } \\ \text { trial author statement(s) con- } \\ \text { cerning factors likely to impact } \\ \text { negatively on the use of a proto- } \\ \text { col }\end{array} \\ \end{array}$

Chaiwat 2010

(Significant effect on duration of mechanical ventilation)

Increased nurse:patient ratios (staff shortages) reduces the time available to adhere to a weaning protocol

\begin{tabular}{lll}
\hline De Carvalho 2002 & $\begin{array}{l}\text { Shared multidisciplinary team design and development of a weaning } \\
\text { protocol promotes successful implementation }\end{array}$ & $\begin{array}{l}\text { Resistance to change within the } \\
\text { interdisciplinary team should be } \\
\text { managed through training and ed- } \\
\text { ucation }\end{array}$
\end{tabular}

\begin{tabular}{|c|c|}
\hline Ely 1996 & $\begin{array}{l}\text { Compatibility between a weaning protocol and professional routines } \\
\text { of care promotes its adoption }\end{array}$ \\
\hline $\begin{array}{l}\text { duration of mechani- } \\
\text { cal ventilation and on } \\
\text { duration of weaning) }\end{array}$ & $\begin{array}{l}\text { Weaning protocols that are technically straightforward to under- } \\
\text { stand and use require minimal additional workload }\end{array}$ \\
\hline
\end{tabular}

\section{Jouvet 2013- Paedi- atric ICU}

(Significant effect on duration of weaning)
Weaning can be delayed due to ICU workload and resource pressures

\section{Kollef 1997 \\ (Significant effect on \\ Physician and non-physician weaning-related training and experi- ence impacts on use of weaning protocols} duration of mechanical ventilation)
Physician and non-physician weaning-related training and experience impacts on use of weaning protocols

Changing clinical priorities and workload pressures impacts on use of weaning protocols

Physicians can choose whether or not to adhere to a protocol

Nurses' reluctance to interrupt physicians in their work prevents them from securing explicit au-

(No effect) 
Table 4. Hypotheses generated from trial author statements concerning the use of protocols (Continued)

thority to execute a weaning pro-

tocol

Maloney 2007-Paedi- Enhanced perceived autonomy encourages acceptance of a protocol atric ICU amongst clinicians

(Significant effect on Computerized paediatric weaning protocols are minimally intrusive duration of weaning) to workflow

Pre-existing acknowledgement of the need for standardization of weaning increases acceptance of a protocol

Strong leadership, commitment and support from ICU clinical support teams are key to successful implementation of a weaning protocol

Ongoing feedback concerning the impact of weaning-related research and development initiatives encourages their acceptance/implementation

\section{Marelich 2000}

(Significant effect on duration of mechanical ventilation and on duration of weaning)
Multidisciplinary team protocol development promotes its implementation by the wider ICU team

Education and leadership provided by medical and clinical leads to their respective colleagues promotes the use of a weaning protocol

$\begin{array}{ll}\text { Namen } 2001 & \text { Physician adherence to a weaning protocol is dependent on their ap- } \\ \text { (No effect) } & \text { preciation of its suitability to the clinical profile and needs of the ICU } \\ \text { patient population }\end{array}$

Navalesi 2008

(No effect)
Shared multidisciplinary team design and development of a weaning protocol encourages high protocol adherence

Implementation of a weaning protocol improves nursing and allied health professional staff felt professional status and concomitant job satisfaction
Implementation of a weaning protocol is perceived to increase ICU workload
Stahl 2009

(No effect)
A weaning protocol will be poorly accepted if it increases staff workload

ICU: Intensive Care Unit

\section{APPEN DICES}

\section{Appendix 1. MEDLINE search strategy}

1. ventilator weaning/ or ventilators, mechanical/ or ventilators, negative-pressure/ or respiration, artificial/ or exp positive-pressure respiration/ or ventilator weaning/ or (mechanical\$ adj5 ventilat\$).mp. or (ventilat\$ adj5 (wean* or liberat* or extubat*)).mp.

2. Clinical Protocols/ or guidelines as topic/ or practice guidelines as topic/ or (guideline or practice guideline).pt. or exp Patient Care Management/ or (protocol\$ or guideline\$).mp.

3. 1 and 2

4. Qualitative Research/ or interviews as topic/ or focus groups/ or narration/ or questionnaires/ or self report/ or exp attitudes/ or exp tape recording/ or Nursing Methodology Research/

5. (qualitative or ethno $\$$ or emic or etic or phenomenolog\$ or hermeneutic\$ or heidegger $\$$ or Husserl\$ or colaizzi\$ or giorgi or glaser\$ or strauss\$ or van kaam\$ or van manen\$).mp. 
6. (constant compar\$ or focus group\$ or grounded theory or narrative analysis or lived experience or life experience $\$$ or theoretical sampl \$ or purposive sampl\$ or ricoeur\$ or speigelberg\$ or merleau\$ or metasynthes\$ or meta-synthes\$ or metasummar\$ or meta-summar \$ or metastud\$ or meta-stud\$ or maximum variation or snowball\$ or field stud\$ or field note or fieldnote or field record $\$$ or content analy\$ or unstructured categor $\$$ or structured categor $\$$ or action research or audiorecord\$ or taperecord\$ or videorecord\$ or videotap \$ or digitalrecord\$ or digitaltap\$).mp.

7. (thematic\$ adj3 analy\$).mp.

8. ((participant\$ or nonparticipant\$ or non-participant\$ or non participant\$) adj3 observ\$).mp.

9. ((audio or tape or tapes or taping or video\$ or digital\$) adj5 (record\$ or interview\$)).mp.

10.(findings or interview).tw.

$11.0 \mathrm{r} / 4-10$

12.3 and 11

\section{Appendix 2. Embase (Ovid SP) search strategy}

1. artificial ventilation/ or ventilator/ or exp positive end expiratory pressure/ or (mechanical ${ }^{\star}$ adj5 ventilat*).mp. or (ventilat* adj5 (wean* or liberat* or extubat*)).mp.

2. clinical protocol/ or practice guideline/ or (guideline or practice guideline).pt. or patient care/ or (protocol ${ }^{\star}$ or guideline ${ }^{\star}$ ).mp.

3. 1 and 2

4. qualitative research/or interview/ or information processing/or verbal communication/ or questionnaire/ or self report/ or exp attitude/ or recording/ or nursing methodology research/ or (qualitative or ethno* or emic or etic or phenomenolog* or hermeneutic ${ }^{\star}$ or heidegger ${ }^{\star}$ or Husserl ${ }^{\star}$ or colaizzi ${ }^{\star}$ or giorgi* or glaser $^{\star}$ or strauss ${ }^{\star}$ or van kaam ${ }^{\star}$ or van manen ${ }^{\star}$ ).mp. or (constant compar ${ }^{\star}$ or focus group ${ }^{\star}$ or grounded theory or narrative analysis or lived experience* or life experience* or theoretical sampl* or purposive sampl* or ricoeur* or speigelberg ${ }^{\star}$

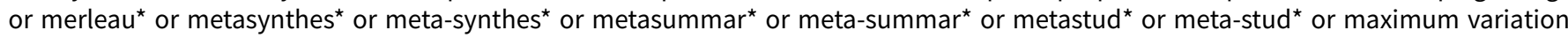
or snowball* or field stud ${ }^{\star}$ or field note ${ }^{\star}$ or fieldnote* or field record $^{\star}$ or content analy* or unstructured categor ${ }^{\star}$ or structured categor ${ }^{\star}$ or action research or audiorecord ${ }^{\star}$ or taperecord ${ }^{\star}$ or videorecord ${ }^{\star}$ or videotap ${ }^{\star}$ or digitalrecord ${ }^{\star}$ or digitaltap ${ }^{\star}$.. $\mathrm{mp}^{*}$ or (thematic* adj3 $^{*}$ analy $\left.^{\star}\right)$.mp. or ((participant ${ }^{\star}$ or nonparticipant ${ }^{\star}$ or non-participant ${ }^{\star}$ or non participant $\left.{ }^{\star}\right)$ adj3 observ $)^{\star}$.mp. or ((audio or tape or tapes or taping or video* or digital*) adj5 (record* or interview*)).mp. or (findings or interview).tw. (2333396)

5.3 and 4

\section{1 and 2 and 3}

\section{Appendix 3. CINAHL (EBSCO host) search strategy}

S1. ((MH "Ventilator Weaning") OR (MH "Ventilators, Mechanical") OR (MH "Ventilation, Negative Pressure") OR (MH "Respiration, Artificial") OR (MH "Positive Pressure Ventilation")) OR ((mechanical* and ventilat $\left.{ }^{\star}\right)$ or (ventilat* and (wean* or liberat* or extubat $\left.\left.\left.{ }^{\star}\right)\right)\right)$ S2. ((MH "Practice Guidelines") OR (MH "Patient Care Plans")) OR (guideline or practice guideline) OR (protocol` or guideline $^{\star}$ )

S3. S1 and S2

S4. ((MH "Qualitative Studies") OR (MH "Interviews") OR (MH "Focus Groups") OR (MH "Narratives") OR (MH "Questionnaires") OR (MH "Self Report") OR (MH "Audiorecording") OR (MH "Research, Nursing") ) OR (qualitative or ethno* or emic or etic or phenomenolog* or hermeneutic ${ }^{\star}$ or heidegger ${ }^{\star}$ or Husserl ${ }^{\star}$ or colaizzi* or giorgi* or glaser* or strauss* or van kaam* or van manen*) OR ( constant compar ${ }^{\star}$ or focus group ${ }^{\star}$ or grounded theory or narrative analysis or lived experience* or life experience* or theoretical sampl* or purposive sampl* or ricoeur ${ }^{\star}$ or speigelberg* or merleau* or metasynthes* or meta-synthes ${ }^{\star}$ or metasummar ${ }^{\star}$ or meta-summar ${ }^{\star}$ or metastud ${ }^{\star}$ or meta-stud ${ }^{\star}$ or maximum variation or snowball ${ }^{\star}$ or field stud ${ }^{\star}$ or field note* or fieldnote* or field record ${ }^{\star}$ or content analy* or unstructured categor ${ }^{*}$ or structured categor ${ }^{\star}$ or action research or audiorecord ${ }^{\star}$ or taperecord ${ }^{\star}$ or videorecord $^{\star}$ or videotap or digitalrecord $^{\star}$ or digitaltap $^{\star}$ ) OR ( (thematic ${ }^{\star}$ and analy $\left.{ }^{\star}\right)$ or ((participant* or nonparticipant ${ }^{\star}$ or non-participant* or non participant $\left.{ }^{\star}\right)$ and observ $\left.{ }^{\star}\right)$ or ((audio or tape or tapes or taping or video* or digital $\left.{ }^{\star}\right)$ and $\left(\right.$ record $^{\star}$ or interview $\left.\left.{ }^{\star}\right)\right)$ or (findings or interview))

S5. S3 and S4

\section{Appendix 4. PsycINFO (Ovid SP) search strategy}

1. exp Artificial Respiration/ or (mechanical ${ }^{\star}$ adj5 ventilat ${ }^{\star}$ ).mp. or (ventilat ${ }^{\star}$ adj5 (wean* or liberat* or extubat $\left.{ }^{\star}\right)$ ).mp.

2. exp Clinical Practice/ or exp Treatment Guidelines/ or exp Professional Standards/ or (guideline or practice guideline).mp. or (protocol* or guideline*).mp.

3. 1 and 2

4. exp Qualitative Research/ or exp Interviews/ or exp Group Discussion/ or exp Narratives/ or exp Questionnaires/ or exp Self Report/ or exp Attitudes/ or exp Tape Recorders/ or (qualitative or ethno* or emic or etic or phenomenolog* or hermeneutic* or heidegger* or Husserl ${ }^{\star}$ or colaizzi ${ }^{\star}$ or giorgi ${ }^{\star}$ or glaser ${ }^{\star}$ or strauss ${ }^{\star}$ or van kaam* or van manen ${ }^{\star}$ ).mp. or (constant compar ${ }^{\star}$ or focus group ${ }^{\star}$ or grounded theory or narrative analysis or lived experience* or life experience* or theoretical sampl ${ }^{\star}$ or purposive sampl* or ricoeur ${ }^{\star}$ or speigelberg* $^{\star}$ or merleau* ${ }^{\star}$ or metasynthes* or meta-synthes* or metasummar ${ }^{\star}$ or meta-summar ${ }^{\star}$ or metastud ${ }^{\star}$ or meta-stud ${ }^{\star}$ or maximum variation or snowball* or field stud ${ }^{\star}$ or field note* or fieldnote* or field record ${ }^{\star}$ or content analy* or unstructured categor* or structured categor ${ }^{\star}$ or action research or audiorecord ${ }^{\star}$ or taperecord ${ }^{\star}$ or videorecord ${ }^{\star}$ or videotap ${ }^{\star}$ or digitalrecord ${ }^{\star}$ or digitaltap $^{\star}$ ).mp. or (thematic adj3 $^{*}$ analy ${ }^{\star}$.mp. or ((participant ${ }^{\star}$ or nonparticipant ${ }^{\star}$ or non-participant ${ }^{\star}$ or non participant $\left.{ }^{\star}\right)$ adj3 observ*).mp. or ((audio or tape or tapes or taping or video* or digital ${ }^{\star}$ ) adj3 (record* or interview*)).mp. or (findings or interview).mp.

Factors that impact on the use of mechanical ventilation weaning protocols in critically ill adults and children: a qualitative evidence- 


\section{3 and 4}

\section{Appendix 5. ISI Web of Science search strategy}

\#1. TS=((mechanical ${ }^{\star}$ and ventilat $\left.{ }^{\star}\right)$ or (ventilat ${ }^{\star}$ SAME (wean* or liberat $^{\star}$ or extubat $\left.\left.\left.^{\star}\right)\right)\right)$

$\# 2$. TS=(guideline or practice guideline) or $\mathrm{TS}=\left(\right.$ protocol $^{\star}$ or guideline $\left.{ }^{\star}\right)$

\#3. \#2 AND \#1

\#4. TS=((qualitative or ethno* or emic or etic or phenomenolog* or hermeneutic* or heidegger ${ }^{\star}$ or Husserl* or colaizzi ${ }^{\star}$ or giorgi* or glaser* or strauss* or van kaam* or van manen ${ }^{\star}$ ) or (constant compar ${ }^{\star}$ or focus group* or grounded theory or narrative analysis or lived experience* or life experience ${ }^{\star}$ or theoretical sampl ${ }^{\star}$ or purposive sampl ${ }^{\star}$ or ricoeur ${ }^{\star}$ or speigelberg* or merleau* or metasynthes* or meta-synthes ${ }^{\star}$ or metasummar $^{\star}$ or meta-summar ${ }^{\star}$ or metastud ${ }^{\star}$ or meta-stud ${ }^{\star}$ or maximum variation or snowball* or field stud* or field note* or fieldnote* or field record ${ }^{\star}$ or content analy* or unstructured categor ${ }^{\star}$ or structured categor ${ }^{\star}$ or action research or audiorecord ${ }^{\star}$ or taperecord $^{\star}$ or videorecord ${ }^{\star}$ or videotap* or digitalrecord $^{\star}$ or digitaltap ${ }^{\star}$ ) or (thematic ${ }^{\star}$ and analy $\left.{ }^{\star}\right)$ or ((participant* or nonparticipant $^{\star}$ or non-participant $^{\star}$ or non participant $\left.t^{\star}\right)$ and observ $\left.{ }^{\star}\right)$ or ((audio or tape or tapes or taping or video* or digital $\left.{ }^{\star}\right)$ and (record ${ }^{\star}$ or interview $\left.\left.^{\star}\right)\right)$ or (findings or interview))

\#5. \#4 AND \#3

\section{Appendix 6. LILACS (BIREME) search strategy}

((mechanical\$ and ventilat\$) or (ventilat\$ and (wean\$ or liberat\$ or extubat\$))) [Palabras] and (guideline or practice guideline) or (protocol $\$$ or guideline\$) [Palabras] and ((qualitative or ethno\$ or emic or etic or phenomenolog\$ or hermeneutic\$ or heidegger\$ or Husserl\$ or colaizzi\$ or giorgi\$ or glaser\$ or strauss\$ or van kaam\$ or van manen\$) or (constant compar\$ or focus group\$ or grounded theory or narrative analysis or lived experience or life experience or theoretical sampl\$ or purposive sampl\$ or ricoeur\$ or speigelberg\$ or merleau or metasynthes $\$$ or meta-synthes $\$$ or metasummar\$ or meta-summar $\$$ or metastud\$ or meta-stud\$ or maximum variation or snowball\$ or field stud\$ or field note $\$$ or fieldnote $\$$ or field record\$ or content analy $\$$ or unstructured categor $\$$ or structured categor $\$$ or action research or audiorecord $\$$ or taperecord $\$$ or videorecord $\$$ or videotap $\$$ or digitalrecord $\$$ or digitaltap $\$$ ) or (thematic $\$$ and analy $\$$ ) or ((participant\$ or nonparticipant\$ or non-participant\$ or non participant\$) and observ\$) or ((audio or tape or tapes or taping or video\$ or digital\$) and (record\$ or interview\$)) or (findings or interview)) [Palabras]

\section{Appendix 7. Study eligibility form}

Date form completed:

Study ID.

Title

\section{Study ID for RevMan}

(Family name of first author and year of publication + letter if more than one per year, e.g. Smith 2001a)

\section{Are there other articles of the same study?}

Yes, No, Unclear

\section{Study eligibility.}

\section{A. Types of study}

Does the study incorporate qualitative methods and

fully report data collection and analysis methods

and findings?

Yes, No, Unclear

\section{B. Focus of study}

Does the study focus on the design, development, training, uptake, implementation and/or evaluation of weaning protocols?

\section{Yes, No, Unclear}

\section{Conclusion:}

If any of the answers to A. or B. are 'No', exclude.

Factors that impact on the use of mechanical ventilation weaning protocols in critically ill adults and children: a qualitative evidence- 
If any of the answers to A. or B. are 'Unclear', proce

of first author and year of publication + letter if more than one per year, e.g. Smith 2001a)

\section{Are there other articles of the same study?}

Yes, No, Unclear

Study eligibility.

\section{A. Types of study}

Does the study incorporate qualitative methods and

fully report data collection and analysis methods

and findings?

Yes, No, Unclear

B. Focus of study

Does the study focus on the design, development, training, uptake, implementation and/or evaluation of weaning protocols?

\section{Yes, No, Unclear}

\section{Conclusion:}

If any of the answers to A. or B. are 'No', exclude.

If any of the answers to A. or B. are 'Unclear', proceed to reading of full paper.

More information needed before inclusion decision (specify)

\section{Appendix 8. Data extraction form}

For all categories of data - where information is not provided or is unclear, please state.

Date form completed:

Study ID

Title

\section{Study ID for RevMan}

(Family name of first author and year of publication + letter if more than one per year, e.g. Smith 2001a)

\section{Electronic Database}

Which one?

\section{Unpublished Source}

Where?

\section{Personal Communication}

From whom?

\section{Study Design}

\section{Was the study conducted as ...}

Stand alone qualitative study

Part of larger qualitative study

Part of larger mixed methods study

Factors that impact on the use of mechanical ventilation weaning protocols in critically ill adults and children: a qualitative evidence- 
Focus of study

Development of protocol

Implementation of protocol

Evaluation of protocol

Mixed (specify)

Other (specify

Aims and Objectives

Phenomena of interest e.g. attitudes / perceptions / knowledge / understandings / behaviour

\section{Study population}

\section{Participants}

Numbers

Gender

Length of service

Grades

Method of selection e.g. purposive / convenience sampling

Inclusion / Exclusion criteria

\section{Theoretical/Conceptual framework}

\section{Stated framework / orientation}

e.g. phenomenology, feminist, grounded theory, critical inquiry, interpretivist, ethnography ${ }^{\star}$

\section{Detail provided regarding chosen framework}

e.g. rationale for choice / how framework relates to study aims and objectives

\section{Data collection}

Method(s) of data collection e.g.

unstructured / semi structured individual interviews / focus groups / participant observation / non-participant observation

Method(s) of data recording e.g. hand written notes / digital recording

Detail provided re chosen data collection methods

e.g. rationale for choice of methods/ how these methods relate to theoretical /conceptual framework

\section{Data analysis}

Method(s) of data analysis e.g. thematic content analysis, grounded theory, discourse analysis, narrative analysis

Procedures for data analysis e.g. use of computer software package, process(es) of coding

Detail provided re chosen data analysis methods

e.g. rationale for choice of methods / how these methods relate to theoretical / conceptual framework

\section{Research rigour}

Reliability e.g. transparency - making explicit e.g. interview guide, following conventions e.g. transcribing, shared analyses Validity e.g. search for disconfirming evidence, respondent validation, comprehensive data treatment, reflexivity

Factors that impact on the use of mechanical ventilation weaning protocols in critically ill adults and children: a qualitative evidencesynthesis (Review)

Copyright (C) 2018 The Cochrane Collaboration. Published by John Wiley \& Sons, Ltd. 
Detail provided re chosen methods of research rigour

e.g. how these methods / processes relate to theoretical / conceptual framework

\section{Stated study strengths and limitations}

\section{Reviewer rating of study}

'Fit' between stated aims/objectives and study design/process i.e. does the way the study went about collecting and analysing data make sense in terms of underlying aims and objectives

\section{Methodological quality}

High, Medium, Low, Unsure

\section{Quality of findings (i.e. 'richness' = detail provided in relation to outcome measures of interest}

High, Medium, Low, Unsure

\section{Study Setting}

\section{Country}

\section{Hospital setting}

\section{Type}

\section{Location(s)}

\section{Bed numbers}

\section{ICU setting}

Single ICU, >1 ICU (specify no.):

\section{Type of patient population}

Paediatric only patients

Mixed adult and paediatric patients

Adult medical only

Adult surgical only

Adult cardiac only

Adult mixed medical, surgical, trauma

Adult 'Other' (specify):

Type of ICU unit

Open, Closed, Not stated

Any other descriptor of unit e.g. average length of stay

\section{Organization of care}

ICU staffing (specify numbers)

Nurses

Medical personnel

Respiratory therapists

Other (specify):

Factors that impact on the use of mechanical ventilation weaning protocols in critically ill adults and children: a qualitative evidence- 


\section{ICU staff:patient ratio}

(specify staff i.e. nurse and/or doctor)

Any other descriptor of organization of care (e.g. nature of multi-disciplinary / team working / staff characteristics such as, ratio of specialist to non-specialist / years of ICU experience)

Intervention and delivery

Type of protocol

Written

Automated

Description of protocol e.g. SIMV, PS, Intermittent T-piece

Length of time protocol has been in use (specify or N/A)

Background - design and development e.g. why protocol introduced, whose decision,

how designed/developed (e.g. evidence-based) and by whom (e.g. presence of 'champion')?

\section{Delivered by}

Nurse

Respiratory therapist

Nurse \& Respiratory therapist

Doctors

All

Other

Not specified

Procedure(s) for delivery e.g. how protocol implemented / different roles and responsibilities etc.

Training required (specify)

(e.g. degree, respiratory module, ICU course, in-service)

Nurse; Doctor; Respitatory Therapist; Other

\section{Training received (specify)}

(e.g. degree, respiratory module, ICU course, in-service)

Nurse; Doctor; Respitatory Therapist; Other

Previous/other current weaning practice within ICU unit(s)?

\section{Study Findings}

'Process' outcomes e.g. perceptions, attitudes, views of healthcare professionals / behaviour of healthcare professionals / nature of multidisciplinary working / staff morale / hospital 'culture'

Author(s)' inferences / implications for practice, policy

Author(s)' conclusions

Any other issues / comments

\section{Appendix 9. Quality assessment of included studies}

Factors that impact on the use of mechanical ventilation weaning protocols in critically ill adults and children: a qualitative evidence- 


\begin{tabular}{|c|c|c|c|c|c|c|c|c|c|c|c|}
\hline Study ID & $\begin{array}{l}\text { Is } \\
\text { there a } \\
\text { logical } \\
\text { fit be- } \\
\text { tween } \\
\text { stat- } \\
\text { ed re- } \\
\text { search } \\
\text { aim(s) } \\
\text { and } \\
\text { method(s } \\
\text { used? }\end{array}$ & $\begin{array}{l}\text { Was the } \\
\text { recruit- } \\
\text { ment } \\
\text { strategy } \\
\text { appro- } \\
\text { priate } \\
\text { to the } \\
\text { aims of } \\
\text { the re- } \\
\text { search? } \\
\text { ) }\end{array}$ & $\begin{array}{l}\text { Is there a detailed } \\
\text { statement of steps } \\
\text { taken in data collec- } \\
\text { tion? }\end{array}$ & $\begin{array}{l}\text { Is } \\
\text { there } \\
\text { a } \\
\text { clear } \\
\text { and } \\
\text { de- } \\
\text { tailed } \\
\text { state- } \\
\text { ment } \\
\text { of } \\
\text { find- } \\
\text { ings? }\end{array}$ & $\begin{array}{l}\text { Were } \\
\text { the } \\
\text { data } \\
\text { au- } \\
\text { dio-reco } \\
\text { ed } \\
\text { and } \\
\text { tran- } \\
\text { scribed? }\end{array}$ & $\begin{array}{l}\text { Is there a detailed } \\
\text { statement of steps } \\
\text { taken in data analy- } \\
\text { sis? } \\
\text { ord- } \\
\text { I? }\end{array}$ & $\begin{array}{l}\text { Did data } \\
\text { analy- } \\
\text { sis in- } \\
\text { volve in- } \\
\text { ter-rater } \\
\text { discus- } \\
\text { sion? }\end{array}$ & $\begin{array}{l}\text { Was } \\
\text { there } \\
\text { con- } \\
\text { sid- } \\
\text { era- } \\
\text { tion } \\
\text { of } \\
\text { dis- } \\
\text { con- } \\
\text { firm- } \\
\text { ing } \\
\text { find- } \\
\text { ings? }\end{array}$ & $\begin{array}{l}\text { Is } \\
\text { there } \\
\text { evi- } \\
\text { dence } \\
\text { of a re- } \\
\text { flexive } \\
\text { con- } \\
\text { cern } \\
\text { with } \\
\text { the } \\
\text { con- } \\
\text { duct } \\
\text { of the } \\
\text { study? }\end{array}$ & $\begin{array}{l}\text { Is there evidence of } \\
\text { analysis and interpreta- } \\
\text { tion of the findings at a } \\
\text { conceptual and theoreti- } \\
\text { cal level? }\end{array}$ & $\begin{array}{l}\text { Sum- } \\
\text { mary } \\
\text { qual- } \\
\text { ity } \\
\text { as- } \\
\text { sess- } \\
\text { ment }\end{array}$ \\
\hline $\begin{array}{l}\text { Black- } \\
\text { wood } \\
2004\end{array}$ & Yes & Yes & Yes, minimal & Yes & Yes & Yes, minimal & Yes & Yes & No & No, not relevant & $\mathrm{HIGH}$ \\
\hline $\begin{array}{l}\text { Gelsthor- } \\
\text { pe } 2004\end{array}$ & No & Yes & Yes, minimal & No & Yes & Yes, minimal & Yes & Yes & Yes & No, relevant & $\begin{array}{l}\text { MOD- } \\
\text { ER- } \\
\text { ATE }\end{array}$ \\
\hline $\begin{array}{l}\text { Hansen } \\
2007\end{array}$ & Yes & No & Yes, full detail & Yes & Yes & Yes, full detail & $\begin{array}{l}\text { Not re- } \\
\text { ported }\end{array}$ & No & No & No, not relevant & $\begin{array}{l}\text { MOD- } \\
\text { ER- } \\
\text { ATE }\end{array}$ \\
\hline $\begin{array}{l}\text { Hansen } \\
\text { 2009a }\end{array}$ & Yes & No & Yes, minimal detail & Yes & Yes & Yes, minimal detail & No & Yes & No & No, not relevant & $\begin{array}{l}\text { MOD- } \\
\text { ER- } \\
\text { ATE }\end{array}$ \\
\hline $\begin{array}{l}\text { Hansen } \\
\text { 2009b }\end{array}$ & Yes & No & Yes, minimal detail & Yes & Yes & Yes, full detail & $\begin{array}{l}\text { Not re- } \\
\text { ported }\end{array}$ & No & No & No, not relevant & $\begin{array}{l}\text { MOD- } \\
\text { ER- } \\
\text { ATE }\end{array}$ \\
\hline $\begin{array}{l}\text { Keogh } \\
2009\end{array}$ & Yes & No & Yes, minimal detail & No & Yes & Yes, minimal detail & Yes & No & No & No, not relevant & LOW \\
\hline $\begin{array}{l}\text { Kydonaki } \\
2011\end{array}$ & Yes & Yes & Yes, full detail & Yes & Yes & Yes, full detail & Yes & Yes & Yes & Yes, relevant & $\mathrm{HIGH}$ \\
\hline $\begin{array}{l}\text { Lavelle } \\
2011\end{array}$ & Yes & Yes & Yes, minimal detail & Yes & Yes & Yes, minimal detail & Yes & No & Yes & No, not relevant & $\mathrm{HIGH}$ \\
\hline
\end{tabular}




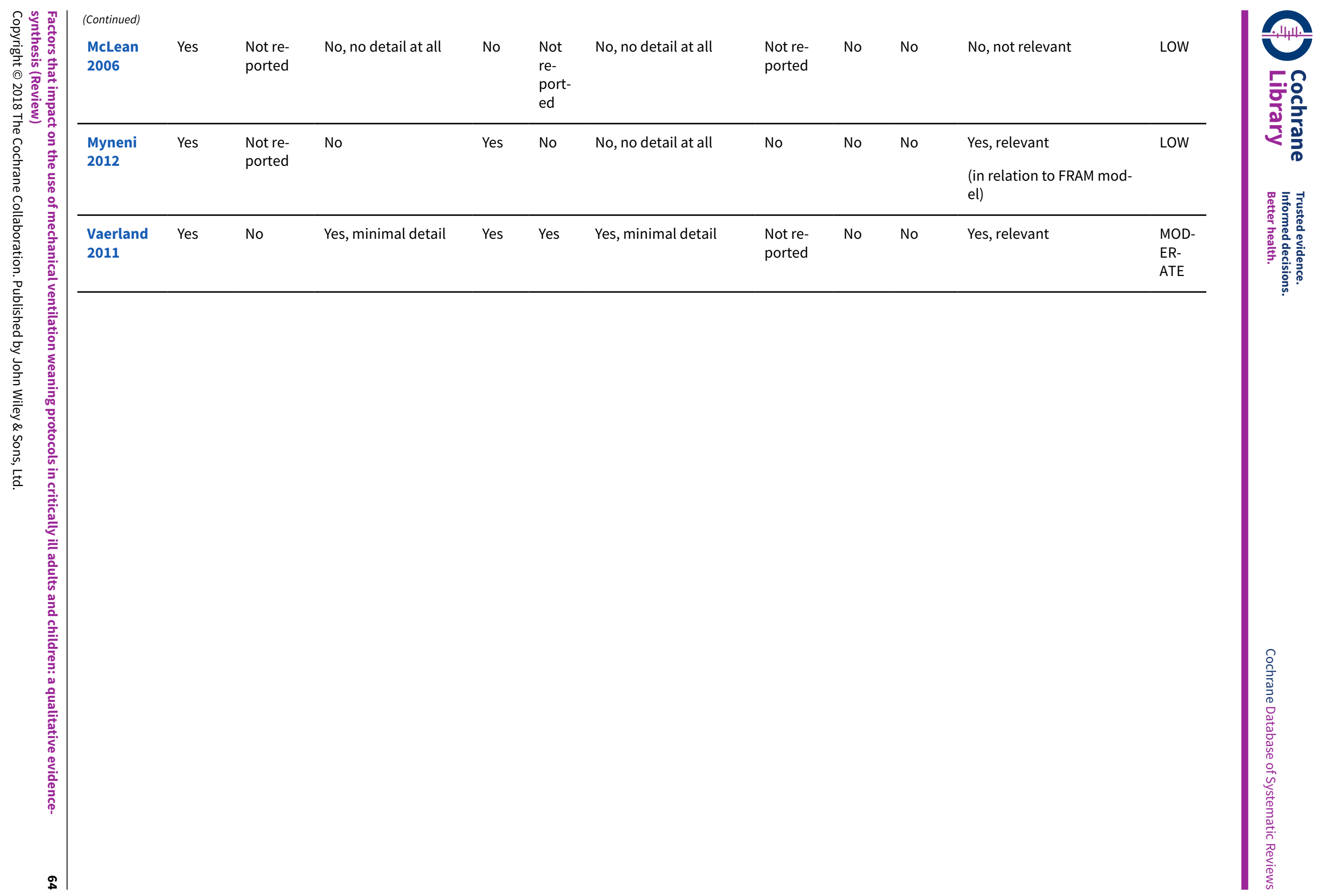


Appendix 10. Impact of removal of low-quality study evidence on summary statements

\begin{tabular}{|c|c|c|c|c|c|c|}
\hline $\begin{array}{l}\text { Summary state- } \\
\text { ment }\end{array}$ & $\begin{array}{l}\text { Origi- } \\
\text { nal con- } \\
\text { fidence } \\
\text { rating }\end{array}$ & $\begin{array}{l}\text { Ratioanle for origi- } \\
\text { nal confidence rat- } \\
\text { ing }\end{array}$ & $\begin{array}{l}\text { Relevant stud- } \\
\text { ies }^{\star}\end{array}$ & $\begin{array}{l}\text { Impact of re- } \\
\text { moval of low } \\
\text { quality studies } \\
\text { on evidence } \\
\text { synthesis }\end{array}$ & $\begin{array}{l}\text { New con- } \\
\text { fidence } \\
\text { rating }\end{array}$ & $\begin{array}{l}\text { Rationale for } \\
\text { new confidence } \\
\text { rating }\end{array}$ \\
\hline $\begin{array}{l}\text { Physicians and nurs- } \\
\text { es should receive } \\
\text { training on the prac- } \\
\text { ticalities of using a } \\
\text { protocol being intro- } \\
\text { duced into the inten- } \\
\text { sive care setting in } \\
\text { order to ensure prop- }\end{array}$ & Moderate & $\begin{array}{l}\text { The studies were of } \\
\text { mixed quality and } \\
\text { the finding was seen } \\
\text { in } 5 \text { settings. }\end{array}$ & $\begin{array}{l}\text { Blackwood } 2004 \\
\text { Hansen 2009b } \\
\text { Lavelle } 2011 \\
\text { McLean 2006* } \\
\text { Myneni 2012* }\end{array}$ & $\begin{array}{l}\text { Impact: con- } \\
\text { fidence rating } \\
\text { drops to 'Low' } \\
\text { because coher- } \\
\text { ence of finding } \\
\text { decreases }\end{array}$ & Low & $\begin{array}{l}\text { The studies were } \\
\text { of at least mod- } \\
\text { erate quality and } \\
\text { the finding was } \\
\text { seen in } 3 \text { settings }\end{array}$ \\
\hline
\end{tabular}

and implementation

\begin{tabular}{|c|c|c|c|c|c|c|}
\hline $\begin{array}{l}\text { The use of a protocol } \\
\text { increases felt confi- } \\
\text { dence and compe- } \\
\text { tence amongst nurs- } \\
\text { es and junior physi- } \\
\text { cians as it 'supports' } \\
\text { autonomous prac- } \\
\text { tice }\end{array}$ & Moderate & $\begin{array}{l}\text { The studies were of } \\
\text { mixed quality and } \\
\text { the finding was seen } \\
\text { in } 4 \text { settings }\end{array}$ & $\begin{array}{l}\text { Hansen 2009b } \\
\text { Keogh 2009* } \\
\text { Kydonaki } 2011 \\
\text { (Scotland) } \\
\text { Kydonaki } 2011 \\
\text { (Greece) }\end{array}$ & $\begin{array}{l}\text { Impact: con- } \\
\text { fidence rating } \\
\text { drops to 'Low' } \\
\text { because coher- } \\
\text { ence of finding } \\
\text { decreases }\end{array}$ & Low & $\begin{array}{l}\text { The studies were } \\
\text { of at least mod- } \\
\text { erate quality and } \\
\text { the finding was } \\
\text { seen in } 3 \text { settings }\end{array}$ \\
\hline $\begin{array}{l}\text { Nurses and respira- } \\
\text { tory therapists high- } \\
\text { lighted lack of inter- } \\
\text { est in the protocol } \\
\text { amongst physicians }\end{array}$ & Low & $\begin{array}{l}\text { The studies were of } \\
\text { low/moderate qual- } \\
\text { ity and the finding } \\
\text { was seen in } 2 \text { set- } \\
\text { tings }\end{array}$ & $\begin{array}{l}\text { Hansen } 2007 \\
\text { Myneni 2012* }\end{array}$ & No impact & Low & $\begin{array}{l}\text { The study was of } \\
\text { moderate quality } \\
\text { and the finding } \\
\text { was seen in } 1 \text { set- } \\
\text { ting }\end{array}$ \\
\hline
\end{tabular}

lack of reference to/ disregard of the protocol during interaction

\begin{tabular}{|c|c|c|c|c|c|c|}
\hline $\begin{array}{l}\text { The use of a proto- } \\
\text { col is associated with } \\
\text { abdication of profes- } \\
\text { sional responsibili- } \\
\text { ty and/or a clinically } \\
\text { uncritical/apathetic } \\
\text { approach to weaning }\end{array}$ & Moderate & $\begin{array}{l}\text { The studies were of } \\
\text { mixed quality and } \\
\text { the finding was seen } \\
\text { in } 6 \text { settings }\end{array}$ & $\begin{array}{l}\text { Blackwood } 2004 \\
\text { Gelsthorpe } 2004 \\
\text { Hansen 2009a } \\
\text { Keogh 2009* } \\
\text { McLean 2006* } \\
\text { Myneni 2012* }\end{array}$ & $\begin{array}{l}\text { Impact: con- } \\
\text { fidence rating } \\
\text { drops to 'Low' } \\
\text { because coher- } \\
\text { ence of finding } \\
\text { decreases }\end{array}$ & Low & $\begin{array}{l}\text { The studies were } \\
\text { of at least mod- } \\
\text { erate quality and } \\
\text { the finding was } \\
\text { seen in } 3 \text { settings }\end{array}$ \\
\hline $\begin{array}{l}\text { No one protocol is } \\
\text { able to address the } \\
\text { diversity of ICU pa- } \\
\text { tient conditions and } \\
\text { requirements }\end{array}$ & High & $\begin{array}{l}\text { The majority of stud- } \\
\text { ies were of at least } \\
\text { moderate quality } \\
\text { and the finding was } \\
\text { seen in } 8 \text { settings }\end{array}$ & $\begin{array}{l}\text { Blackwood 2004 } \\
\text { Hansen 2009a } \\
\text { Hansen 2009b } \\
\text { Kydonaki 2011 } \\
\text { (Scotland) } \\
\text { Kydonaki } \\
\text { 2011(Greece) }\end{array}$ & No impact & High & $\begin{array}{l}\text { The studies were } \\
\text { of at least mod- } \\
\text { erate quality and } \\
\text { the finding was } \\
\text { seen in } 6 \text { settings }\end{array}$ \\
\hline
\end{tabular}


Myneni 2012 *

Lavelle 2011

Vaerland 2011

\section{ICU working routines} impact adversely on weaning. Examples include: the limited availability of physicians outside of set times (such as morning clinical rounds); a more 'proactive' approach to weaning at the beginning of a working day; and the interruption to weaning caused by

patient visiting (hours)
Moderate The majority of stud- Blackwood 2004 ies were of at least moderate quality and the finding was seen in 4 settings
Blackwood 2004
Gelsthorpe 2004

Hansen 2007

Hansen 2009a

Hansen 2009b

Myneni 2012*

\section{Impact: con-} fidence rating drops to 'Low' because coherence of finding decreases
Low

The studies were of at least moderate quality and the finding was seen in 3 settings

\begin{tabular}{|c|c|c|c|c|c|c|}
\hline $\begin{array}{l}\text { Weaning is frequent- } \\
\text { ly subordinated to } \\
\text { other clinical prior- } \\
\text { ities, particularly in } \\
\text { the context of caring } \\
\text { for critically-ill pa- } \\
\text { tients }\end{array}$ & Low & $\begin{array}{l}\text { The studies were of } \\
\text { moderate/low qual- } \\
\text { ity and the finding } \\
\text { was seen in } 2 \text { set- } \\
\text { tings }\end{array}$ & $\begin{array}{l}\text { Hansen } 2007 \\
\text { Hansen 2009a } \\
\text { Hansen 2009b } \\
\text { Myneni 2012* }\end{array}$ & No impact & Low & $\begin{array}{l}\text { The studies were } \\
\text { of moderate } \\
\text { quality and the } \\
\text { findings were } \\
\text { seen in one set- } \\
\text { ting }\end{array}$ \\
\hline $\begin{array}{l}\text { Use of a protocol fa- } \\
\text { cilitates a shared un- } \\
\text { derstanding of the } \\
\text { weaning process, } \\
\text { thereby enhancing } \\
\text { interprofessional } \\
\text { collaboration and } \\
\text { through this greater } \\
\text { effectiveness in } \\
\text { weaning }\end{array}$ & Moderate & $\begin{array}{l}\text { The studies were of } \\
\text { mixed quality and } \\
\text { the finding was seen } \\
\text { in } 6 \text { settings }\end{array}$ & $\begin{array}{l}\text { Hansen 2007 } \\
\text { Hansen 2009a } \\
\text { Hansen 2009b } \\
\text { Keogh 2009* } \\
\text { Kydonaki 2011 } \\
\text { (Scotland) } \\
\text { Kydonaki } 2011 \\
\text { (Greece) } \\
\text { McLean 2006* } \\
\text { Vaerland 2011 }\end{array}$ & No impact & Moderate & $\begin{array}{l}\text { The studies were } \\
\text { of at least mod- } \\
\text { erate quality and } \\
\text { the finding was } \\
\text { seen in } 4 \text { settings }\end{array}$ \\
\hline $\begin{array}{l}\text { Nurses understand } \\
\text { the protocol as ad- } \\
\text { vancing professional } \\
\text { autonomy. As such, } \\
\text { it motivates clinical } \\
\text { practice }\end{array}$ & Moderate & $\begin{array}{l}\text { The studies were of } \\
\text { mixed quality and } \\
\text { the finding was seen } \\
\text { in5 settings }\end{array}$ & $\begin{array}{l}\text { Hansen } 2007 \\
\text { Kydonaki } 2011 \\
\text { (Scotland) } \\
\text { Kydonaki } 2011 \\
\text { (Greece) } \\
\text { McLean 2006* }\end{array}$ & No impact & Moderate & $\begin{array}{l}\text { The studies were } \\
\text { of at least mod- } \\
\text { erate quality and } \\
\text { the finding was } \\
\text { seen in } 4 \text { settings }\end{array}$ \\
\hline
\end{tabular}

Factors that impact on the use of mechanical ventilation weaning protocols in critically ill adults and children: a qualitative evidence- 
Vaerland 2011

A protocol con-
tributes positively to
weaning as it helps
raise the profile of
weaning generally,
prompting clinicians
to think about wean-
ing when they might
otherwise focus on
other clinical priori-
ties

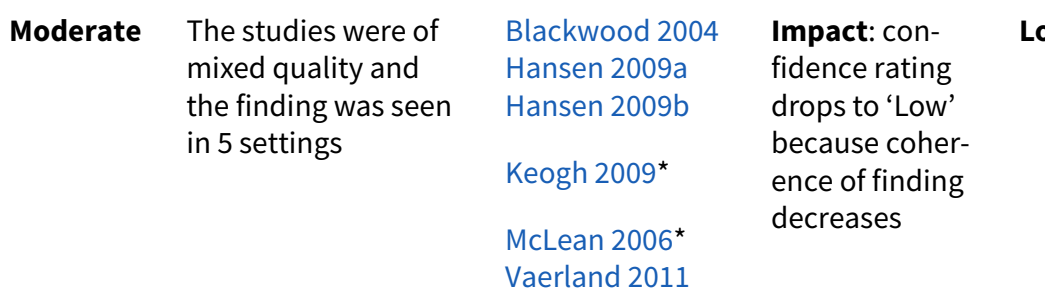

Low $\quad \begin{aligned} & \text { The studies were } \\ & \text { of at least mod- } \\ & \text { erate quality and } \\ & \text { the finding was } \\ & \text { seen in } 3 \text { settings }\end{aligned}$

\begin{tabular}{|c|c|c|c|c|c|}
\hline $\begin{array}{l}\text { Protocols should } \\
\text { have clarity in their } \\
\text { design and instruc- } \\
\text { tion, and be straight- } \\
\text { forward to use }\end{array}$ & Low & $\begin{array}{l}\text { All of the studies } \\
\text { were of low quality } \\
\text { and the finding was } \\
\text { seen in } 3 \text { settings }\end{array}$ & $\begin{array}{l}\text { Keogh 2009* } \\
\text { McLean 2006* } \\
\text { Myneni 2012* }\end{array}$ & $\begin{array}{l}\text { Impact: the } \\
\text { summary state- } \\
\text { ment and the } \\
\text { evidence on } \\
\text { which it is } \\
\text { based are lost } \\
\text { from the analy- } \\
\text { sis }\end{array}$ & N/A \\
\hline
\end{tabular}

\begin{tabular}{|c|c|c|}
\hline $\begin{array}{l}\text { Protocols should } \\
\text { be readily accessi- } \\
\text { ble/visible within an } \\
\text { ICU unit at all times }\end{array}$ & Low & $\begin{array}{l}\text { The study was of low } \\
\text { quality and the find- } \\
\text { ing was seen in } 1 \text { set- } \\
\text { ting }\end{array}$ \\
\hline
\end{tabular}

Impact: the N/A N/A
summary state-
ment and the
evidence on
which it is
based are lost
from the analy-
sis
Impact: the N/A
summary state-
ment and the
evidence on
which it is
based are lost
from the analy-
sis

\begin{tabular}{|c|c|c|c|c|c|c|}
\hline $\begin{array}{l}\text { Nurses understand } \\
\text { a protocol to be a } \\
\text { useful communica- } \\
\text { tion tool, providing a } \\
\text { framework through } \\
\text { which they can ex- } \\
\text { plain and otherwise } \\
\text { communicate about } \\
\text { the process of wean- } \\
\text { ing their child from } \\
\text { ventilation }\end{array}$ & Low & $\begin{array}{l}\text { The study was of low } \\
\text { quality and the find- } \\
\text { ing was seen in } 1 \text { set- } \\
\text { ting }\end{array}$ & Keogh 2009* & $\begin{array}{l}\text { Impact: the } \\
\text { summary state- } \\
\text { ment and the } \\
\text { evidence on } \\
\text { which it is } \\
\text { based are lost } \\
\text { from the analy- } \\
\text { sis }\end{array}$ & N/A & $\mathrm{N} / \mathrm{A}$ \\
\hline
\end{tabular}

`Studies assessed as ‘Low quality’ are marked with an asterisk

ICU: Intensive Care Unit

N/A: Not applicable

Appendix 11. Impact of removal of evidence from paediatric ICU study on summary statements

\begin{tabular}{lllllll}
\hline $\begin{array}{l}\text { Summary state- } \\
\text { ment }\end{array}$ & $\begin{array}{l}\text { Origi- } \\
\text { nal con- } \\
\text { fidence } \\
\text { rating }\end{array}$ & $\begin{array}{l}\text { Rationale for origi- } \\
\text { nal confidence rat- } \\
\text { ing }\end{array}$ & $\begin{array}{l}\text { Relevant stud- } \\
\text { ies }\end{array}$ & $\begin{array}{l}\text { Impact of re- } \\
\text { moval of evi- } \\
\text { dence from study } \\
\text { conducted in a } \\
\text { paediatric ICU }\end{array}$ & $\begin{array}{l}\text { New con- } \\
\text { fidence } \\
\text { rating }\end{array}$ & $\begin{array}{l}\text { Rationale for } \\
\text { new confi- } \\
\text { dence rating }\end{array}$ \\
\hline
\end{tabular}

Factors that impact on the use of mechanical ventilation weaning protocols in critically ill adults and children: a qualitative evidence- 
(Continued)

The use of a protocol increases felt confidence and competence amongst nurses and junior physicians as it 'supports' autonomous practice

Moderate

Impact: con-

fidence rating

drops to 'Low' be-

cause coherence

of finding decreases
Low

The studies were of at least moderate quality and the finding was seen in 3 settings

Kydonaki 2011

(Greece)

The use of a protocol is associated with abdication of professional responsibility and/or a clinically uncritical/apathetic approach to weaning

Moderate

\begin{tabular}{|c|c|c|c|c|}
\hline $\begin{array}{l}\text { The studies were } \\
\text { of mixed quality } \\
\text { and the finding was } \\
\text { seen in } 6 \text { settings }\end{array}$ & $\begin{array}{l}\text { Blackwood } 2004 \\
\text { Gelsthorpe } 2004 \\
\text { Hansen 2009a } \\
\text { Keogh 2009* }\end{array}$ & $\begin{array}{l}\text { Impact: con- } \\
\text { fidence rating } \\
\text { drops to 'Low' be- } \\
\text { cause coherence } \\
\text { of finding decreas- } \\
\text { es }\end{array}$ & Low & $\begin{array}{l}\text { The studies } \\
\text { were of at least } \\
\text { moderate qual- } \\
\text { ity and the find- } \\
\text { ing was seen in } \\
3 \text { settings }\end{array}$ \\
\hline
\end{tabular}

McLean 2006

Myneni 2012

Moderate

The studies were
of mixed quality
and the finding was
seen in 6 settings
thereby enhancing interprofessional collaboration and through this greater effectiveness in weaning

\begin{tabular}{|c|c|c|c|}
\hline $\begin{array}{l}\text { Hansen } 2007 \\
\text { Hansen 2009a } \\
\text { Hansen 2009b }\end{array}$ & No impact & Moderate & $\begin{array}{l}\text { The studies } \\
\text { were of at least } \\
\text { moderate qual- } \\
\text { ity and the find- } \\
\text { ing was seen in } \\
4 \text { settings }\end{array}$ \\
\hline Keogh 2009* & & & 4 settıngs \\
\hline
\end{tabular}

Kydonaki 2011

(Scotland)

Kydonaki 2011

(Greece)

McLean 2006

Vaerland 2011

A protocol con-
tributes positively to
weaning as it helps
raise the profile of
weaning generally,
prompting clinicians
to think about wean-
ing when they might
otherwise focus on
other clinical priori-
ties

Moderate The studies were of mixed quality and the finding was seen in 5 settings

Blackwood $2004 \quad$ No impact

Moderate

Hansen 2009a

Hansen 2009b

Keogh 2009*

McLean 2006

Vaerland 2011

Moderate

The studies were of at least moderate quality and the finding was seen in 4 settings

\begin{tabular}{|c|c|c|c|c|c|c|}
\hline $\begin{array}{l}\text { Protocols should } \\
\text { have clarity in their } \\
\text { design and instruc- } \\
\text { tion, and be straight- } \\
\text { forward to use }\end{array}$ & Low & $\begin{array}{l}\text { All of the studies } \\
\text { were of low quality } \\
\text { and the finding was } \\
\text { seen in } 3 \text { settings }\end{array}$ & $\begin{array}{l}\text { Keogh 2009* } \\
\text { McLean } 2006 \\
\text { Myneni } 2012\end{array}$ & $\begin{array}{l}\text { Impact: the sum- } \\
\text { mary statement } \\
\text { and the evidence } \\
\text { on which it is } \\
\text { based are lost } \\
\text { from the analysis }\end{array}$ & N/A & $\mathrm{N} / \mathrm{A}$ \\
\hline $\begin{array}{l}\text { Nurses understand } \\
\text { a protocol to be a } \\
\text { useful communica- } \\
\text { tion tool, providing a } \\
\text { framework through }\end{array}$ & Low & $\begin{array}{l}\text { The study was of } \\
\text { low quality and the } \\
\text { finding was seen in } \\
1 \text { setting }\end{array}$ & Keogh 2009* & $\begin{array}{l}\text { Impact: the sum- } \\
\text { mary statement } \\
\text { and the evidence } \\
\text { on which it is }\end{array}$ & N/A & $\mathrm{N} / \mathrm{A}$ \\
\hline
\end{tabular}

Factors that impact on the use of mechanical ventilation weaning protocols in critically ill adults and children: a qualitative evidence- 
(Continued)

which they can ex-

plain and otherwise

communicate about

the process of wean-

ing their child from

ventilation based are lost

from the analysis

*Study conducted in a paediatric ICU is marked with an asterisk

N/A: Not applicable

Appendix 12. Impact of the removal of evidence from two studies not involving use of a protocol on summary statements

\begin{tabular}{|c|c|c|c|c|c|c|}
\hline Summary statement & $\begin{array}{l}\text { Origi- } \\
\text { nal con- } \\
\text { fidence } \\
\text { rating }\end{array}$ & $\begin{array}{l}\text { Rationale for original } \\
\text { confidence rating }\end{array}$ & Relevant studies* & $\begin{array}{l}\text { Impact of } \\
\text { removal } \\
\text { of evi- } \\
\text { dence } \\
\text { from } \\
\text { studies } \\
\text { not in- } \\
\text { volving } \\
\text { the use of } \\
\text { a proto- } \\
\text { col }\end{array}$ & $\begin{array}{l}\text { New con- } \\
\text { fidence } \\
\text { rating }\end{array}$ & $\begin{array}{l}\text { Rationale for new } \\
\text { confidence rating }\end{array}$ \\
\hline $\begin{array}{l}\text { Physicians and nurses } \\
\text { should possess a com- } \\
\text { prehensive (patho) } \\
\text { physiological knowl- } \\
\text { edge base }\end{array}$ & Moderate & $\begin{array}{l}\text { The studies were of at } \\
\text { least moderate quali- } \\
\text { ty and the finding was } \\
\text { seen in } 3 \text { settings }\end{array}$ & $\begin{array}{l}\text { Blackwood 2004* } \\
\text { Hansen } 2007 \\
\text { Vaerland } 2011\end{array}$ & $\begin{array}{l}\text { Impact: } \\
\text { confi- } \\
\text { dence rat- } \\
\text { ing drops } \\
\text { to 'Low' } \\
\text { because } \\
\text { coherence } \\
\text { of finding } \\
\text { decreases }\end{array}$ & Low & $\begin{array}{l}\text { The studies were } \\
\text { of at least mod- } \\
\text { erate quality and } \\
\text { the finding was } \\
\text { seen in } 2 \text { settings }\end{array}$ \\
\hline $\begin{array}{l}\text { Physicians and nurs- } \\
\text { es delivering protocol- } \\
\text { ized weaning should } \\
\text { receive ongoing dis- } \\
\text { cipline-relevant clini- } \\
\text { cal training to increase } \\
\text { clinical competence } \\
\text { and confidence }\end{array}$ & Moderate & $\begin{array}{l}\text { The majority of stud- } \\
\text { ies were of high quali- } \\
\text { ty and the finding was } \\
\text { seen in } 3 \text { settings }\end{array}$ & $\begin{array}{l}\text { Blackwood 2004* } \\
\text { Hansen } 2009 b^{\star} \\
\text { Lavelle } 2011\end{array}$ & $\begin{array}{l}\text { Impact: } \\
\text { confi- } \\
\text { dence rat- } \\
\text { ing drops } \\
\text { to 'Low' } \\
\text { because } \\
\text { coherence } \\
\text { of finding } \\
\text { decreases }\end{array}$ & Low & $\begin{array}{l}\text { The study was of } \\
\text { high quality and } \\
\text { the finding was } \\
\text { seen in } 1 \text { setting }\end{array}$ \\
\hline $\begin{array}{l}\text { Physicians and nurses } \\
\text { should receive train- } \\
\text { ing on the practicali- } \\
\text { ties of using a protocol } \\
\text { being introduced into } \\
\text { the intensive care set- } \\
\text { ting to ensure prop- } \\
\text { er understanding and } \\
\text { implementation }\end{array}$ & Moderate & $\begin{array}{l}\text { The studies were of } \\
\text { mixed quality and the } \\
\text { finding was seen in } 5 \\
\text { settings }\end{array}$ & $\begin{array}{l}\text { Blackwood 2004* } \\
\text { Hansen 2009b* } \\
\text { Lavelle } 2011 \\
\text { McLean } 2006 \\
\text { Myneni } 2012\end{array}$ & $\begin{array}{l}\text { No im- } \\
\text { pact }\end{array}$ & Moderate & $\begin{array}{l}\text { The studies were } \\
\text { of mixed quality } \\
\text { and the finding } \\
\text { was seen in } 3 \text { set- } \\
\text { tings }\end{array}$ \\
\hline
\end{tabular}

Factors that impact on the use of mechanical ventilation weaning protocols in critically ill adults and children: a qualitative evidence- 
(Continued)

The cautious approach to (protocolized) weaning by inexperienced nurses is mediated by felt lack of clinical competence and confidence
High

The studies were of at least moderate quality and the finding was seen in 7 settings

\begin{tabular}{|c|c|}
\hline Blackwood 2004* & $\begin{array}{l}\text { No im- } \\
\text { pact }\end{array}$ \\
\hline
\end{tabular}

Hansen 2007

Hansen 2009b*

Kydonaki 2011

(Scotland)

Kydonaki 2011

(Greece)

Lavelle 2011

Vaerland 2011

High

High ty

\section{The studies were of at} least moderate quality and the finding was seen in 7 settings

\section{Gelsthorpe 2004}

Hansen 2007

Hansen 2009b*

Kydonaki 2011

(Scotland)

Kydonaki 2011

(Greece)

Lavelle 2011

Vaerland 2011

\begin{tabular}{|c|c|c|}
\hline $\begin{array}{l}\text { No im- } \\
\text { pact }\end{array}$ & High & $\begin{array}{l}\text { The studies were } \\
\text { of at least mod- } \\
\text { erate quality and } \\
\text { the finding was } \\
\text { seen in } 6 \text { settings }\end{array}$ \\
\hline
\end{tabular}

The studies were of at least moderate quality and the finding was seen in 6 settings

\begin{abstract}
Lack of clinical comdence is understood contribute effectively
\end{abstract}

\section{Nurses understand} personal weaning competence and confidence to be based on the day-to-day routine of work, and the experience consequently gained

$\begin{array}{lllll}\text { Moderate } & \begin{array}{l}\text { The studies were of at } \\ \text { least moderate quali- } \\ \text { ty and the finding was } \\ \text { seen in 4 settings }\end{array} & \begin{array}{l}\text { Gelsthorpe 2004 } \\ \text { Hansen 2007 }\end{array} & \begin{array}{l}\text { No im- } \\ \text { pact }\end{array} & \text { Moderate } \\ & \text { Lavelle 2011 } & \\ & \text { Vaerland 2011 } & \\ & & \end{array}$

The studies were of at least moderate quality and the finding was seen in 4 settings
Following the protocol provides security for inexperienced physicians and nurses in that it ensured they are adhering to 'safe'/ accepted practice
Moderate The majority of studies were of high quality and the finding was seen in 4 settings

\begin{tabular}{|c|c|c|c|}
\hline $\begin{array}{l}\text { Hansen 2009b* } \\
\text { Kydonaki } 2011 \\
\text { (Scotland) } \\
\text { Kydonaki } 2011\end{array}$ & $\begin{array}{l}\text { No im- } \\
\text { pact }\end{array}$ & Moderate & $\begin{array}{l}\text { All of the studies } \\
\text { were of high quali- } \\
\text { ty and the finding } \\
\text { was seen in } 3 \text { set- } \\
\text { tings }\end{array}$ \\
\hline
\end{tabular}

(Greece)

Lavelle 2011

\begin{tabular}{|c|c|c|c|c|c|c|}
\hline $\begin{array}{l}\text { The use of a proto- } \\
\text { col increases felt con- } \\
\text { fidence and compe- } \\
\text { tence amongst nurs- } \\
\text { es and junior physi- } \\
\text { cians as it 'supports' }\end{array}$ & Moderate & $\begin{array}{l}\text { The studies were of } \\
\text { mixed quality and the } \\
\text { finding was seen in } 4 \\
\text { settings }\end{array}$ & $\begin{array}{l}\text { Hansen } 2009 b^{\star} \\
\text { Keogh } 2009 \\
\text { Kydonaki } 2011 \\
\text { (Scotland) }\end{array}$ & $\begin{array}{l}\text { No im- } \\
\text { pact }\end{array}$ & Moderate & $\begin{array}{l}\text { The studies were } \\
\text { of mixed quality } \\
\text { and the finding } \\
\text { was seen in } 3 \text { set- } \\
\text { tings }\end{array}$ \\
\hline
\end{tabular}


(Continued)

Kydonaki 2011

(Greece)

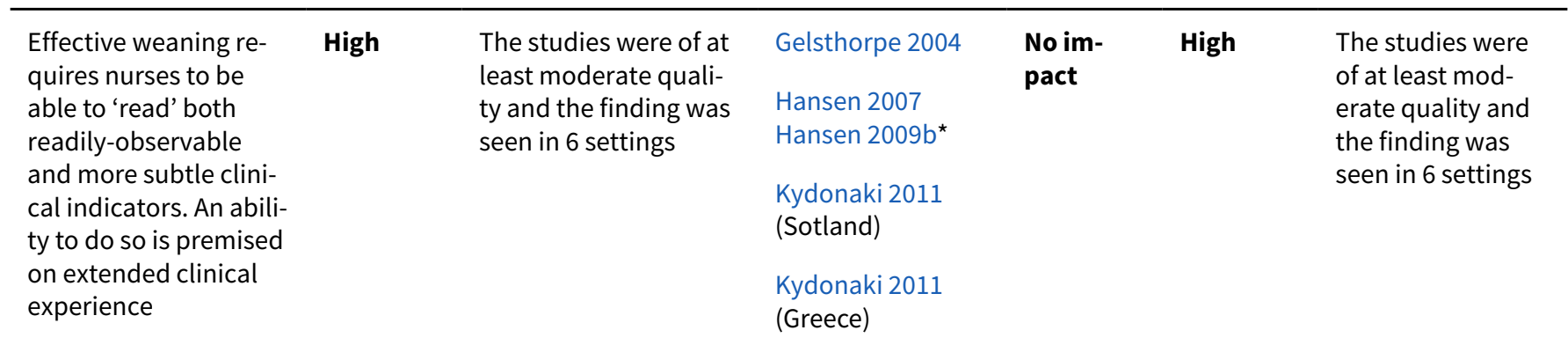

Lavelle 2011

Vaerland 2011

\begin{tabular}{l}
\hline Due to perceived lim- \\
itations in clinical \\
knowledge and exper- \\
tise, physicians con- \\
sider nursing staff as \\
most suitable for a \\
support role in wean- \\
ing, in which they op- \\
erate with limited au- \\
tonomy only
\end{tabular}

Low The study was of high $\quad$ Blackwood 2004*
quality and the finding
was seen in 1 setting

Impact: N/A N/A
the sum-
mary
statement
and the
evidence
on which
it is based
are lost
from the
analysis

Physicians are wary
of involving any but
the most experienced
nurses in weaning be-
cause it requires ad-
vanced clinical insight
and judgement

\section{Low} The study was of high
quality and the finding
was seen in 1 setting

Blackwood 2004*

Impact:

N/A

the sum-

mary

statement

and the

evidence

on which

it is based

are lost

from the

analysis

\begin{tabular}{|c|c|c|c|c|c|c|}
\hline $\begin{array}{l}\text { Nurses' role in wean- } \\
\text { ing is characterized } \\
\text { by them as that 'per- } \\
\text { mitted' by physicians. } \\
\text { Based on felt inequal- } \\
\text { ities in professional } \\
\text { status and consequent } \\
\text { authority, nurses do } \\
\text { not feel able to chal- } \\
\text { lenge physicians con- } \\
\text { cerning this limitation } \\
\text { placed on their wean- } \\
\text { ing role }\end{array}$ & Moderate & $\begin{array}{l}\text { The studies were of at } \\
\text { least moderate quali- } \\
\text { ty and the finding was } \\
\text { seen in } 3 \text { settings }\end{array}$ & $\begin{array}{l}\text { Hansen } 2007 \\
\text { Hansen } 2009 b^{\star} \\
\text { Kydonaki } 2011 \\
\text { (Sotland) } \\
\text { Kydonaki } 2011 \\
\text { (Greece) }\end{array}$ & $\begin{array}{l}\text { No im- } \\
\text { pact }\end{array}$ & Moderate & $\begin{array}{l}\text { The studies were } \\
\text { of at least mod- } \\
\text { erate quality and } \\
\text { the finding was } \\
\text { seen in } 3 \text { settings }\end{array}$ \\
\hline $\begin{array}{l}\text { The availability of rou- } \\
\text { tine (formal and in- } \\
\text { formal) opportunities } \\
\text { for interprofessional } \\
\text { discussion and learn- }\end{array}$ & Low & $\begin{array}{l}\text { The studies were of } \\
\text { moderate quality and } \\
\text { the finding was seen in } \\
2 \text { settings }\end{array}$ & $\begin{array}{l}\text { Gelsthorpe } 2004 \\
\text { Hansen 2009b* }\end{array}$ & $\begin{array}{l}\text { No im- } \\
\text { pact }\end{array}$ & Low & $\begin{array}{l}\text { The study was of } \\
\text { moderate quali- } \\
\text { ty and the finding } \\
\text { was seen in } 1 \text { set- } \\
\text { ting }\end{array}$ \\
\hline
\end{tabular}

Factors that impact on the use of mechanical ventilation weaning protocols in critically ill adults and children: a qualitative evidence- 
(Continued)

ing is considered by

nurses to be a crucial

bedrock of collabo-

rative and effective

weaning. Lack of time

is one factor militating

against such opportu-

nities

\begin{tabular}{|c|c|c|c|c|c|c|}
\hline $\begin{array}{l}\text { Nurses associate } \\
\text { physician reluctance } \\
\text { to involve nurses } \\
\text { in weaning deci- } \\
\text { sion-making with an } \\
\text { individualization of } \\
\text { nursing competence }\end{array}$ & Low & $\begin{array}{l}\text { The study was of mod- } \\
\text { erate quality and the } \\
\text { finding was seen in } 1 \\
\text { setting }\end{array}$ & Hansen 2009b* & $\begin{array}{l}\text { Impact: } \\
\text { the sum- } \\
\text { mary } \\
\text { statement } \\
\text { and the } \\
\text { evidence } \\
\text { on which } \\
\text { it is based } \\
\text { are lost } \\
\text { from the } \\
\text { analysis }\end{array}$ & N/A & $\mathrm{N} / \mathrm{A}$ \\
\hline
\end{tabular}

\begin{tabular}{|c|c|c|c|c|c|c|}
\hline $\begin{array}{l}\text { Nurses consider } \\
\text { physicians as able to } \\
\text { choose whether or not } \\
\text { to use the protocol }\end{array}$ & Low & $\begin{array}{l}\text { The studies were of } \\
\text { moderate quality and } \\
\text { the finding was seen in } \\
1 \text { setting }\end{array}$ & $\begin{array}{l}\text { Hansen } 2007 \\
\text { Hansen } 2009 b^{*}\end{array}$ & $\begin{array}{l}\text { No im- } \\
\text { pact }\end{array}$ & Low & $\begin{array}{l}\text { The study was of } \\
\text { moderate quali- } \\
\text { ty and the finding } \\
\text { was seen in } 1 \text { set- } \\
\text { ting }\end{array}$ \\
\hline
\end{tabular}

\begin{tabular}{|c|c|c|c|c|c|c|}
\hline $\begin{array}{l}\text { The use of a protocol } \\
\text { is associated with ab- } \\
\text { dication of profession- } \\
\text { al responsibility or a } \\
\text { clinically 'apathetic' }\end{array}$ & Moderate & $\begin{array}{l}\text { The studies were of } \\
\text { mixed quality and the } \\
\text { finding was seen in } 6 \\
\text { settings }\end{array}$ & $\begin{array}{l}\text { Blackwood 2004* } \\
\text { Gelsthorpe } 2004 \\
\text { Hansen } 2007\end{array}$ & $\begin{array}{l}\text { No im- } \\
\text { pact }\end{array}$ & Moderate & $\begin{array}{l}\text { The studies were } \\
\text { of mixed quality } \\
\text { and the finding } \\
\text { was seen in } 5 \text { set- } \\
\text { tings }\end{array}$ \\
\hline
\end{tabular}

approach to weaning, or both

Hansen 2009a

Keogh 2009

McLean 2006

Myneni 2012

\begin{tabular}{|c|c|c|c|c|c|c|}
\hline $\begin{array}{l}\text { No one protocol is } \\
\text { able to address the } \\
\text { diversity of ICU pa- } \\
\text { tient conditions and } \\
\text { requirements }\end{array}$ & High & $\begin{array}{l}\text { The majority of stud- } \\
\text { ies were of at least } \\
\text { moderate quality and } \\
\text { the finding was seen in } \\
8 \text { settings }\end{array}$ & $\begin{array}{l}\text { Blackwood 2004* } \\
\text { Hansen 2009a } \\
\text { Hansen 2009b* } \\
\text { Kydonaki } 2011 \\
\text { (Scotland) } \\
\text { Kydonaki } 2011 \\
\text { (Greece) } \\
\text { Lavelle } 2011 \\
\text { McLean } 2006 \\
\text { Myneni } 2012 \\
\text { Vaerland } 2011\end{array}$ & $\begin{array}{l}\text { No im- } \\
\text { pact }\end{array}$ & High & $\begin{array}{l}\text { The majority of } \\
\text { studies were of } \\
\text { at least moderate } \\
\text { quality and the } \\
\text { finding was seen } \\
\text { in } 7 \text { settings }\end{array}$ \\
\hline $\begin{array}{l}\text { ICU routines impact } \\
\text { adversely on wean- } \\
\text { ing. Examples includ- }\end{array}$ & Moderate & $\begin{array}{l}\text { The majority of stud- } \\
\text { ies were of at least } \\
\text { moderate quality and }\end{array}$ & $\begin{array}{l}\text { Blackwood 2004* } \\
\text { Gelsthorpe } 2004\end{array}$ & $\begin{array}{l}\text { No im- } \\
\text { pact }\end{array}$ & Moderate & $\begin{array}{l}\text { The majority of } \\
\text { studies were of } \\
\text { moderate quali- }\end{array}$ \\
\hline
\end{tabular}

Factors that impact on the use of mechanical ventilation weaning protocols in critically ill adults and children: a qualitative evidence- 
(Continued)

ed: the limited availability of physicians outside of set times (such as morning clinical rounds); a more 'proactive' approach to weaning at the beginning of a working day; and the interruption to weaning caused by patient visiting (hours) the finding was seen in Hansen 2007 4 settings

Hansen 2009a

Hansen 2009b*

Myneni 2012 ty and the finding was seen in 3 settings

\section{Nurses prioritize con- tinuity of care as nec- essary for patient-spe- cific clinical insight and effective weaning. Staffing pressures can encourage the rotat- ing of nurses between patients, which mili- tates against this con- tinuity}

Weaning is frequent-
ly subordinated to im-
mediate clinical priori-
ties, particularly in the
context of caring for
acutely ill/deteriorat-
ing patients

\begin{tabular}{|c|c|c|c|c|c|}
\hline Low & $\begin{array}{l}\text { The studies were of } \\
\text { moderate quality and } \\
\text { the finding was seen in } \\
\text { one setting }\end{array}$ & $\begin{array}{l}\text { Hansen } 2007 \\
\text { Hansen 2009b* }\end{array}$ & $\begin{array}{l}\text { No im- } \\
\text { pact }\end{array}$ & Low & $\begin{array}{l}\text { The study was of } \\
\text { moderate quali- } \\
\text { ty and the finding } \\
\text { was seen in one } \\
\text { setting }\end{array}$ \\
\hline
\end{tabular}

\begin{tabular}{|c|c|c|c|c|c|}
\hline $\begin{array}{l}\text { Physicians consider } \\
\text { that a protocol will } \\
\text { have little or no mate- } \\
\text { rial impact on wean- } \\
\text { ing because the ICU } \\
\text { practice already en- } \\
\text { courages clinicians to } \\
\text { wean proactively }\end{array}$ & Low & $\begin{array}{l}\text { The study was of high } \\
\text { quality and the finding } \\
\text { was seen in } 1 \text { setting }\end{array}$ & Blackwood 2004* & $\begin{array}{l}\text { Impact: } \\
\text { the sum- } \\
\text { mary } \\
\text { statement } \\
\text { and the } \\
\text { evidence } \\
\text { on which } \\
\text { it is based } \\
\text { are lost } \\
\text { from the } \\
\text { analysis }\end{array}$ & N/A \\
\hline
\end{tabular}

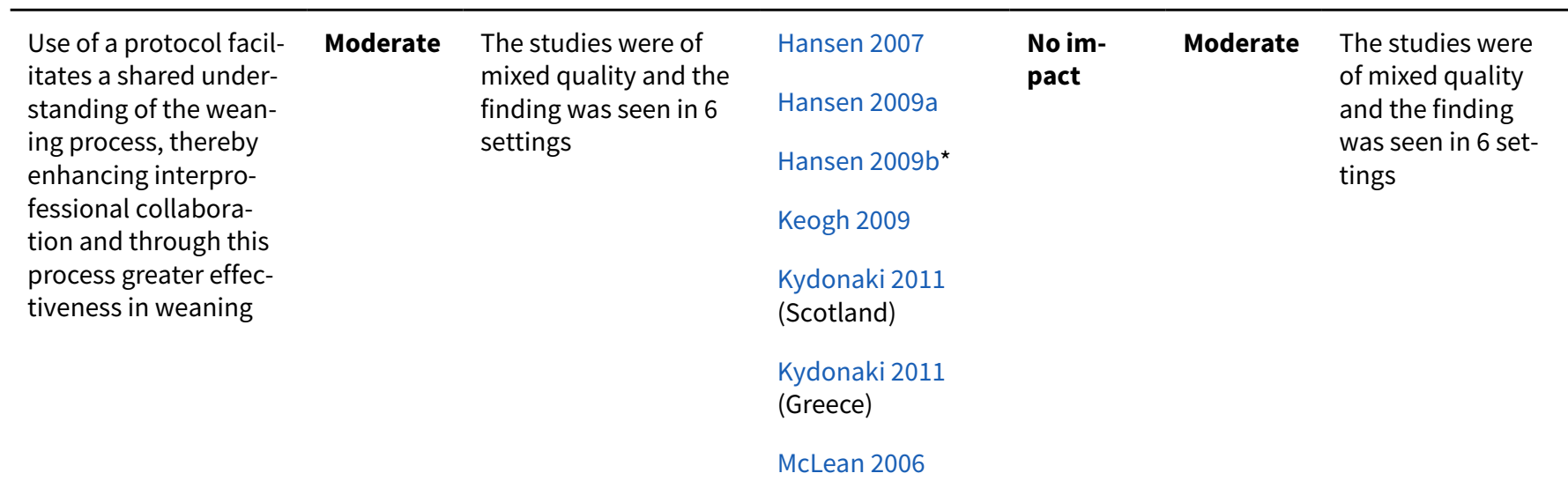


Vaerland 2011

\begin{tabular}{|c|c|c|c|c|c|c|}
\hline $\begin{array}{l}\text { A protocol contributes } \\
\text { positively to wean- } \\
\text { ing as it helps raise } \\
\text { the profile of wean- } \\
\text { ing generally, prompt- } \\
\text { ing clinicians to think } \\
\text { about weaning when } \\
\text { they might otherwise } \\
\text { focus on other clinical } \\
\text { priorities }\end{array}$ & Moderate & $\begin{array}{l}\text { The studies were of } \\
\text { mixed quality and the } \\
\text { finding was seen in } 5 \\
\text { settings }\end{array}$ & $\begin{array}{l}\text { Blackwood 2004* } \\
\text { Hansen 2009a } \\
\text { Hansen 2009b* } \\
\text { Keogh } 2009 \\
\text { McLean } 2006 \\
\text { Vaerland } 2011\end{array}$ & $\begin{array}{l}\text { No im- } \\
\text { pact }\end{array}$ & Moderate & $\begin{array}{l}\text { The studies were } \\
\text { of mixed quality } \\
\text { and the finding } \\
\text { was seen in } 4 \text { set- } \\
\text { tings }\end{array}$ \\
\hline
\end{tabular}

${ }^{*}$ Studies not involving the use of a protocol are marked with an asterisk

N/A: Not applicable

WHAT'S NEW

\begin{tabular}{lll}
\hline Date & Event & Description \\
\hline 17 December 2018 & Amended & Editorial team changed to Cochrane Emergency and Critical Care \\
\hline
\end{tabular}

\section{H I S T O R Y}

Protocol first published: Issue 7, 2015

Review first published: Issue 10, 2016

\begin{tabular}{lll}
\hline Date & Event & Description \\
\hline 1 November 2016 & Amended & Acknowledgement section updated \\
\hline 12 October 2015 & New search has been performed & $\begin{array}{l}\text { The heading structure used in this review may not reflect } \\
\text { Cochrane Qualitative and Implementation Methods (CQIMG) rec- } \\
\text { ommendations which are forthcoming. }\end{array}$ \\
\hline
\end{tabular}

\section{CONTRIBUTIONS OF AUTHORS}

Conceiving the review: Bronagh Blackwood (BB)

Co-ordinating the review: Joanne Jordan (JJ), BB

Undertaking manual searches: JJ

Screening search results: JJ, Louise Rose (LR)

Organizing retrieval of papers: JJ, LR

Screening retrieved papers against inclusion criteria: JJ, LR

Appraising quality of papers: JJ, BB, Katy Dainty (KD)

Abstracting data from papers: JJ, BB, KD

Writing to authors of papers for additional information: JJ

Providing additional data about papers: JJ

Obtaining and screening data on unpublished studies: JJ

Data management for the review: JJ, KD

Entering data into Review Manager 5 (RevMan 2014): JJ

Synthesis and interpretation of data: JJ, KD, Jane Noyes (JN)

Factors that impact on the use of mechanical ventilation weaning protocols in critically ill adults and children: a qualitative evidence- 
Writing the review: All authors

Securing funding for the review: LR

Performing previous work that was the foundation of the present study: BB

Guarantor for the review (one author): JJ

Person responsible for reading and checking review before submission: JJ

\section{DECLARATIONS OF INTEREST}

Joanne Jordan: none known.

Louise Rose: none known.

Katie N Dainty: none known.

Jane Noyes: none known.

Bronagh Blackwood was involved in the design, conduct and publication of a study included in the review (Blackwood 2004).

\section{SOURCES OF SUPPORT}

\section{Internal sources}

- Canadian Institutes of Health Research Knowledge Synthesis grant, Canada.

Part funding of review

\section{External sources}

- No sources of support supplied

\section{DIFFERENCES BETWEEN PROTOCOLANDREVIEW}

Objectives: in the review we expand on the objectives outlined in the protocol. In doing so, we use the body of evidence derived from integrating the qualitative synthesis with the effectiveness review to suggest the circumstances in which weaning protocols are most likely to be used.

Criteria for considering studies for this review: in the review we include more detail than outlined in the protocol.

Data extraction and management: two rather than three authors undertook data extraction. A specifically-designed data extraction form was used rather than the anticipated standardized form.

Assessment of risk of bias: in the review this section has been renamed Assessment of confidence in the extracted evidence; this change reflects methodological developments occurring in the three years since the protocol was published.

Data Synthesis: in the review this section has been renamed Thematic synthesis of qualitative evidence; we provide a detailed explanation of the process of synthesizing the qualitative evidence, in relation to the type and quality of data available.

\section{NOTES}

2015: The heading structure used in the review may not reflect Cochrane Qualitative and Implementation Methods (CQIMG) recommendations which are forthcoming.

\section{N DEX TERMS}

\section{Medical Subject Headings (MeSH)}

${ }^{\star}$ Critical Care; Clinical Protocols; Critical Illness; Evidence-Based Practice; Health Knowledge, Attitudes, Practice; Qualitative Research; Respiration, Artificial [adverse effects]; Staff Development; Ventilator Weaning [ ${ }^{\star}$ ethods]

\section{MeSH check words}

Adult; Child; Humans 